Running head: USE-OF-FORCE SIMULATION TRAINING

Examining the Influence of Practice, Feedback and Fidelity on the Effectiveness of Use-of-Force Simulation Training in the Military Domain: A Meta-Analytic Review

\title{
Shevaun Corey
}

A thesis submitted to the faculty of Graduate Studies and Research in partial fulfillment of the requirements of the Masters of Arts degree.

\author{
Department of Psychology \\ Carleton University \\ Ottawa, ON
}

September 2006

Copyright $(\mathbb{C} 2006$, Shevaun Corey 


$\begin{array}{ll}\begin{array}{l}\text { Library and } \\ \text { Archives Canada }\end{array} & \begin{array}{l}\text { Bibliothèque et } \\ \text { Archives Canada }\end{array} \\ \begin{array}{l}\text { Published Heritage } \\ \text { Branch }\end{array} & \begin{array}{l}\text { Direction du } \\ \text { Patrimoine de l'édition }\end{array} \\ \begin{array}{l}\text { 395 Wellington Street } \\ \text { Ottawa ON K1A 0N4 }\end{array} & \begin{array}{l}\text { 395, rue Wellington } \\ \text { Ottana ON K1A ON4 } \\ \text { Canada Oa }\end{array}\end{array}$

Your file Votre référence ISBN: 978-0-494-18255-0 Ourfile Notre référence ISBN: 978-0-494-18255-0

NOTICE:

The author has granted a nonexclusive license allowing Library and Archives Canada to reproduce, publish, archive, preserve, conserve, communicate to the public by telecommunication or on the Internet, loan, distribute and sell theses worldwide, for commercial or noncommercial purposes, in microform, paper, electronic and/or any other formats.

The author retains copyright ownership and moral rights in this thesis. Neither the thesis nor substantial extracts from it may be printed or otherwise reproduced without the author's permission.
AVIS:

L'auteur a accordé une licence non exclusive permettant à la Bibliothèque et Archives Canada de reproduire, publier, archiver, sauvegarder, conserver, transmettre au public par télécommunication ou par l'Internet, prêter, distribuer et vendre des thèses partout dans le monde, à des fins commerciales ou autres, sur support microforme, papier, électronique et/ou autres formats.

L'auteur conserve la propriété du droit d'auteur et des droits moraux qui protège cette thèse. $\mathrm{Ni}$ la thèse ni des extraits substantiels de celle-ci ne doivent être imprimés ou autrement reproduits sans son autorisation.
In compliance with the Canadian

Privacy Act some supporting forms may have been removed from this thesis.

While these forms may be included in the document page count, their removal does not represent any loss of content from the thesis.
Conformément à la loi canadienne sur la protection de la vie privée, quelques formulaires secondaires ont été enlevés de cette thèse.

Bien que ces formulaires aient inclus dans la pagination, il n'y aura aucun contenu manquant. 


\begin{abstract}
The majority of the world's military agencies rely heavily on use-of-force simulators to train their soldiers, despite the fact that we still know very little about the effectiveness of this training approach. Drawing on Cognitive Load Theory and the statistical technique of metaanalysis, the current study examines the relationship between several training factors (related to practice, feedback, and fidelity) and various performance measures (related to accuracy, judgment, maneuvering, and communication) in the context of use-of-force training in the military domain. Results indicate that simulation training in this area results in better training outcomes than non-simulation training, and by increasing practice times, incorporating instructor feedback, and using high fidelity simulators, simulation training can be improved. However, several variables appear to moderate the relationship between these training factors and training performance (e.g., the experience level of the learner). These results suggest that Cognitive Load Theory is a useful theory for understanding how learning occurs in simulated training contexts and they also provide the basis for making practical recommendations to agencies that incorporate use-of-force simulation training into their instructional regime.
\end{abstract}




\section{Acknowledgements}

First and foremost I would like to extend my deepest gratitude to my supervisor Craig Bennell. Your endless time, guidance, and support are the key components that have enabled me to complete this thesis. Your enthusiasm for sound research and your academic integrity has inspired me to continue my graduate studies. For all of this I thank you.

My warmest appreciation goes to my parents who have always supported my endeavors in more ways than one, and who have always believed in me. Your endless encouragement has helped me to visualize and actively meet my goals. My mom has taught me to always strive for perfection and my father has taught me to work hard for what you want, and for this I thank you both.

My biggest thanks goes to Joshua, who has been the chief source of support throughout my degree. Your love, encouragement, understanding, and assistance have not gone unnoticed. I am so grateful to have you in my life, and I do not know what I would do without you. I love you.

I would also like to thank my grandparents, Nan and Papa. You have always stood by me and encouraged me to further my education. For your support and love, I thank you both.

Last, but definitely not least I would like to thank my committee, for their time and feedback. Thanks to my lab mates, Sarah, Natalie, and Alyssa, for their unwavering support and assistance. Thank you to Natalie, Etelle, and June, for your assistance throughout my degree. Finally, thanks to Jax and Loki, who have given up lots of playtime during the completion of this thesis. 
Table of Contents

Examining the Influence of Practice, Feedback and Fidelity on the Effectiveness of Use-ofForce Simulation Training in the Military Domain: A Meta-Analytic Review ................1

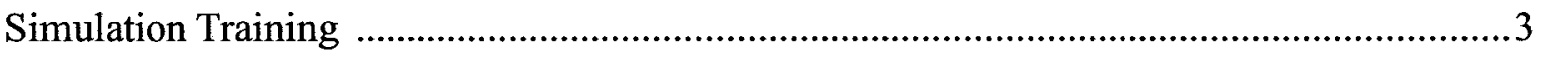

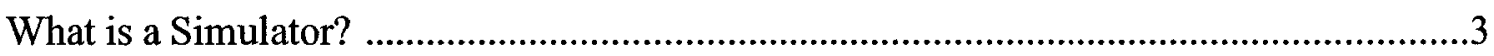

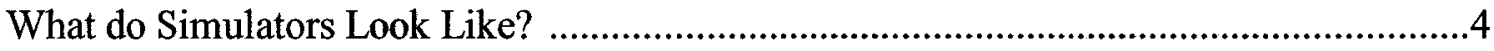

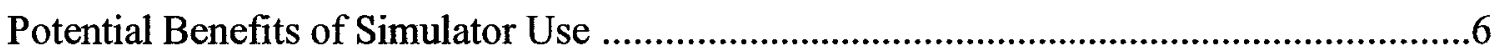

Previous Research on Simulation training in the Military Domain ..................................

Cognitive Load Theory: A Theory of Learning in Training Environments .........................11

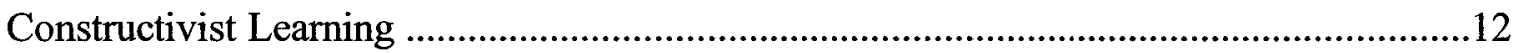

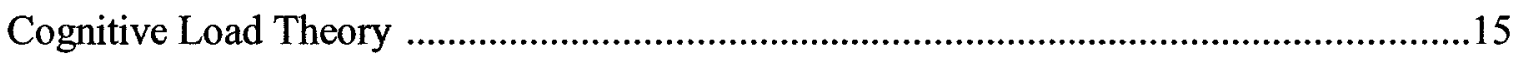

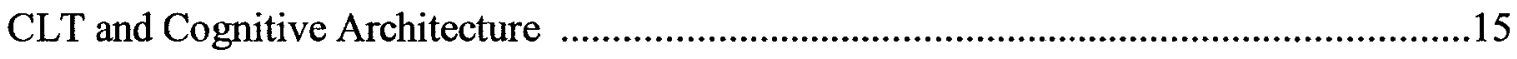

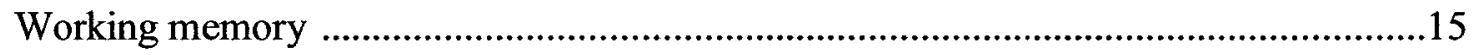

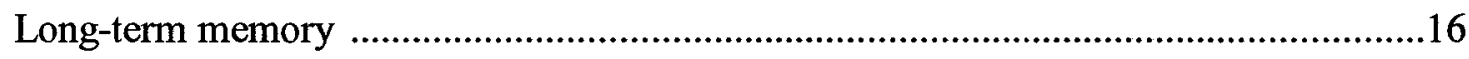

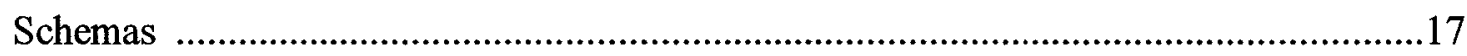

Types of Cognitive Load and Element Interactivity ...............................................19

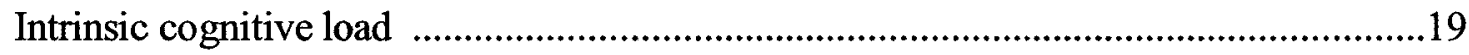

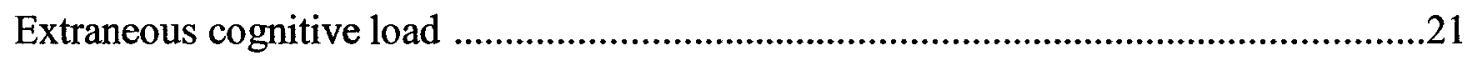

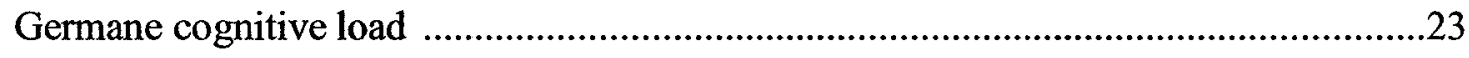

Difference Between Novices and Experts: The Effects of Cognitive Load ....................25

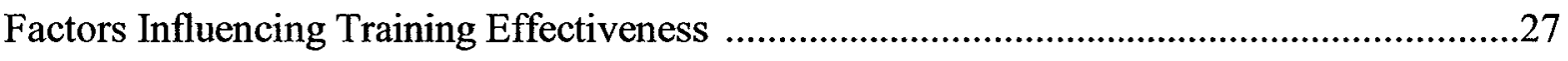

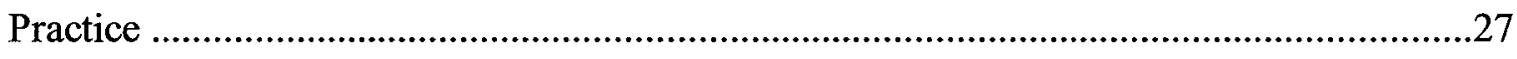

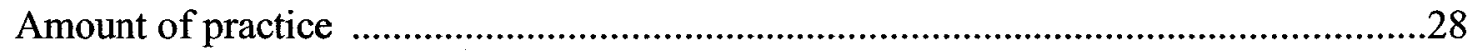




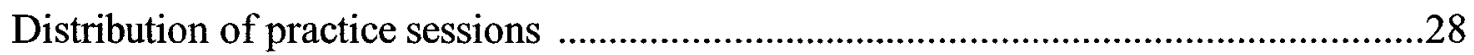

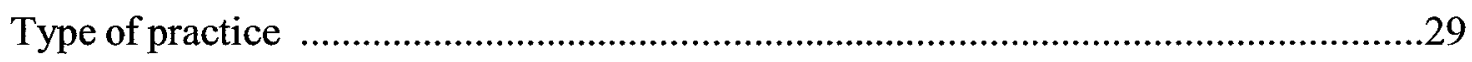

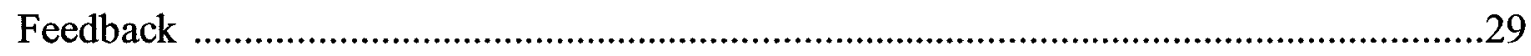

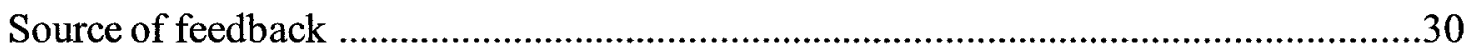

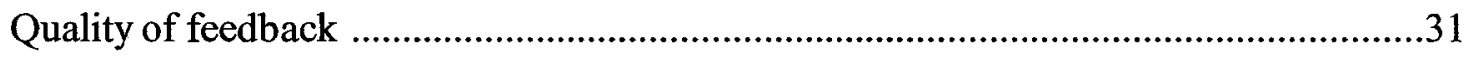

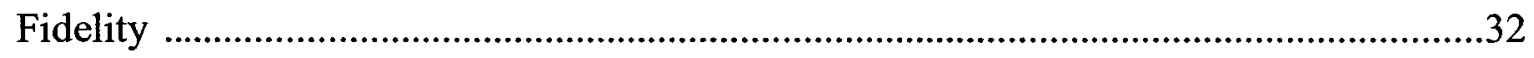

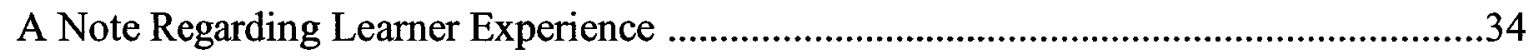

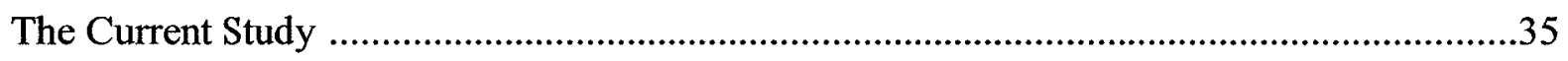

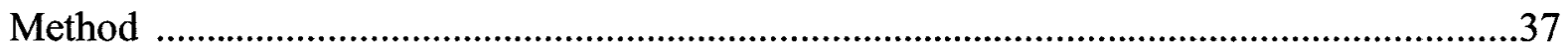

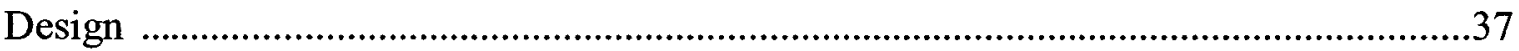

Advantages and Disadvantages of Meta-Analysis ....................................................39

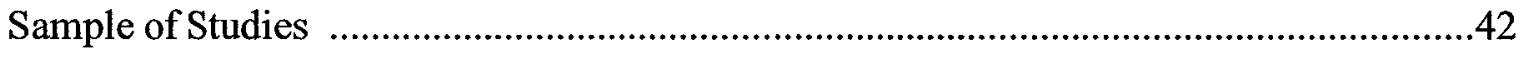

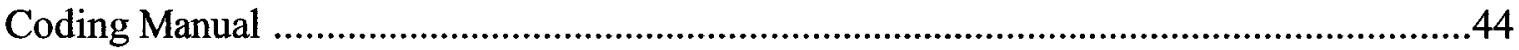

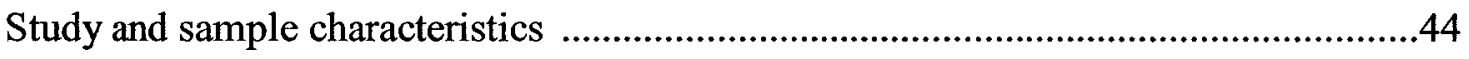

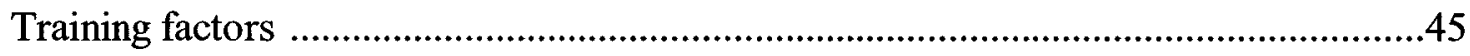

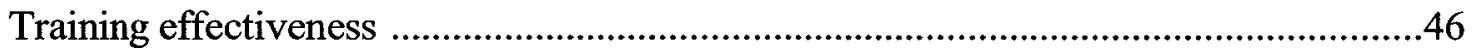

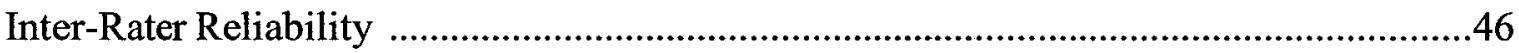

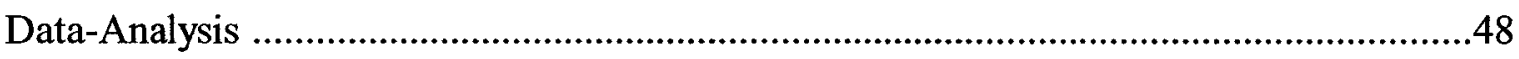

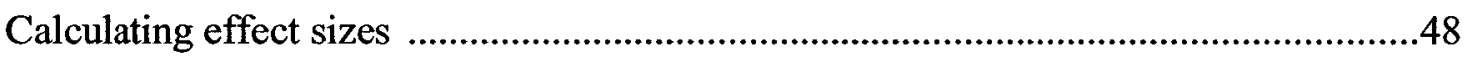

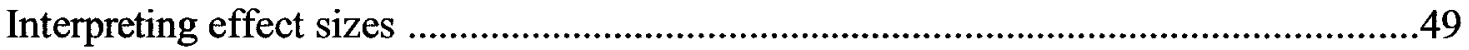

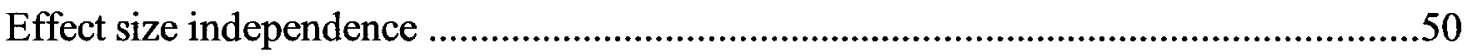

Examining the impact of potential moderator variables .........................................50

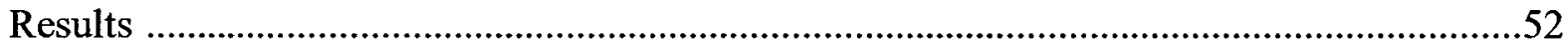




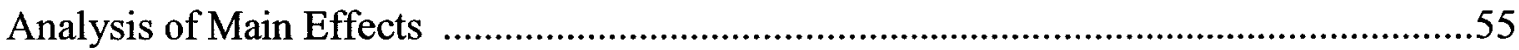

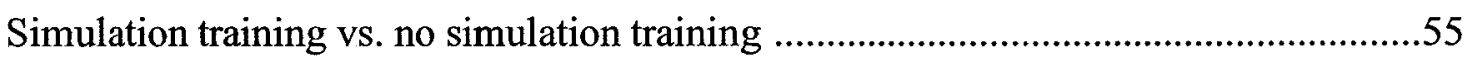

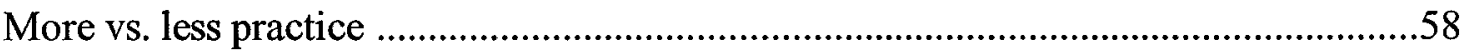

Part-to-whole-task practice vs. whole-task practice .................................................58

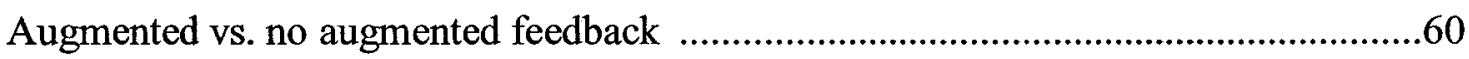

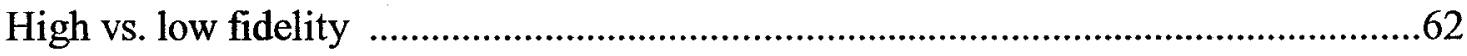

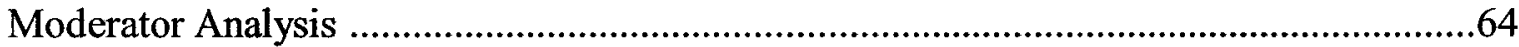

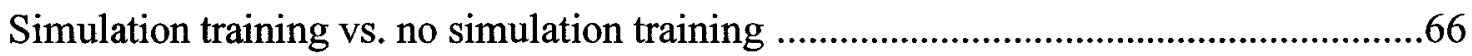

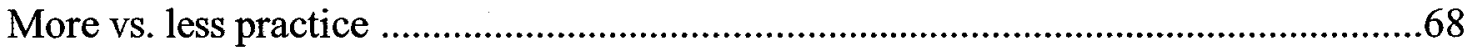

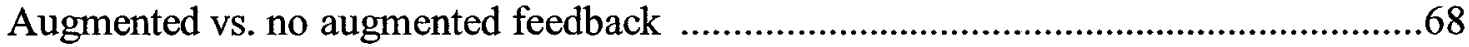

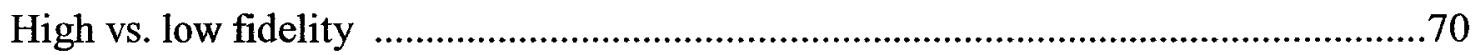

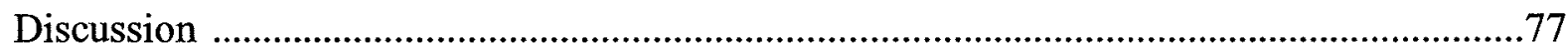

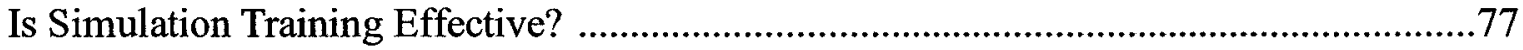

The Significance of Practice, Feedback, and Fidelity in Simulation Training Contexts ....78

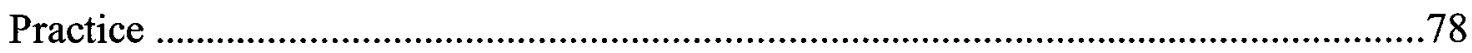

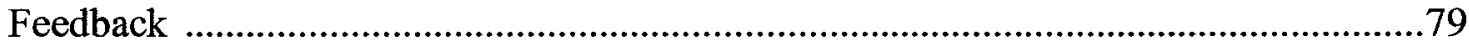

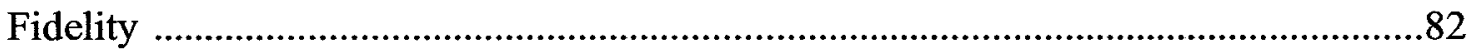

Recommendations for Improving Use-of-Force Simulation Training ..............................85

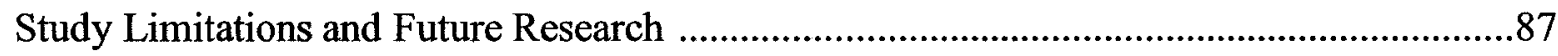

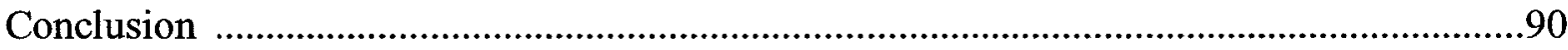

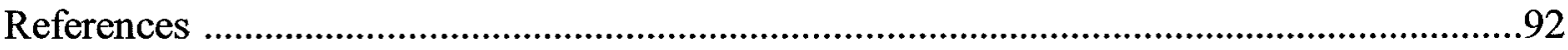




\section{List of Tables}

Table 1. List of variables coded for and examined in the present meta-analysis .45

Table 2. Moderator variables examined in the current study .51

Table 3. Studies included in the present meta-analysis 53

Table 4. Percentage of studies examining various training factors (i.e., contrasts) of interest in the present meta-analysis

Table 5. Mean effect of simulation training versus no simulation training on aggregated outcome measures of training effectiveness

Table 6. Mean corrected $d$ and mean weighted $d$ for the influence of practice on aggregated outcome measures of training effectiveness .59

Table 7. Mean corrected $d$ and mean weighted $d$ for the influence of feedback on aggregated outcome measures of training effectiveness .61

Table 8. Mean corrected $d$ and mean weighted $d$ for the influence of fidelity on aggregated outcome measures of training effectiveness

Table 9. Reported $Q$ statistics for the homogeneity analysis of the training factors overall and according to the aggregate categories of performance measures

Table 10. Mean weighted $d, Q$ statistics, and significance levels of significant moderating variables for simulation vs. no simulation training

Table 11. Mean weighted $d, Q$ statistics, and significance levels of significant moderating variables for augmented vs. no augmented feedback

Table 12. Mean weighted $d, Q$ statistics, and significance levels of significant moderating variables for high vs. low fidelity 


\section{List of Figures}

Figure 1. A hypothetical illustration of an individual schema and the collective network of schemas associated with an M-16 rifle

Figure 2. The additive effects of intrinsic and extraneous cognitive load when intrinsic cognitive load is (a) low and (b) high

Figure 3. An illustration of the additive components of total cognitive load: intrinsic, extraneous, and germane load .25

Figure 4. A simple feedback-response chain (Bennell \& Jones, 2004) 30 
List of Appendices

Appendix A. List of Researchers Contacted for Studies or Data for Inclusion in the Present

Meta-Analysis 110

Appendix B. Coding Manual 111

Appendix C. List of Individual Performance Measures by Aggregate Categories 128

Appendix D. Statistical Conversions to $d$ 132

Appendix E. Complete Tables of Effect Sizes for the Training Effectiveness of each Training Factor 133 
Examining the Influence of Practice, Feedback and Fidelity on the Effectiveness of Useof-Force Simulation Training in the Military Domain: A Meta-Analytic Review

This thesis examines the impact that factors such as practice, feedback, and fidelity have on simulator training effectiveness in the military domain. ${ }^{1}$ In the present study, the specific focus will be on use-of-force simulation training, where trainees are taught specific skills that are utilized during use-of-force encounters (e.g., de-escalation skills, gunnery skills, tactical skills, etc.) (Firearms Training Systems, Inc.; FATS, 2005a). From a practical perspective, this is an important area of research because the majority of the world's military agencies (including the US and Canadian Army, Navy, and Air Force) rely heavily on use-of-force simulators to train their soldiers (FATS, 2005a, 2005b). Indeed, FATS, which is one of the worlds leading simulator suppliers, regularly reports annual earnings in excess of $\$ 50$ million dollars from military contracts (FATS, 2005b). This research also has real theoretical importance, in that it will provide information about how people learn in simulated training environments, if in fact they do, and how this learning experience can be enhanced.

Despite the fact that simulation training has become widespread (Alessi, 2000), we still know very little about its effectiveness (Bennell \& Jones, 2004). Instead of concentrating on this issue, the majority of literature found in the military domain simply describes existing simulation training systems or focuses on the development of new simulators (e.g., Burnside, 1990; Pleban \& Salvetti, 2003; Salter, Eakin, \& Knerr, 1999,

\footnotetext{
${ }^{1}$ The original focus of the current thesis was on the effectiveness of use-of-force simulation training in the law enforcement domain. However, only four studies (two of which are published) currently exist that deal with this issue and none of them met the inclusion criteria set out for the present meta-analysis. The logical alternative was to examine the effectiveness of use-of-force simulation training in the military domain. While not the original intent of the author, conducting such a study will likely provide insight into the potential value of use-of-force simulation training in the law enforcement domain, as the delivery of the training and the tasks learned by the trainees in the two domains is fundamentally the same.
} 
etc.). In these studies, the emphasis is typically on reducing training costs, enhancing learner safety, and/or influencing user acceptance (Alessi, 2000). This is not to say that studies of training effectiveness do not exist within this context. They do. Some of these studies even focus on improving training by identifying core training principles (typically related to fidelity issues) (e.g., Alluisi, 1978; Matheny, 1978; Pleban \& Salvetti, 2003; Sterling, 1996). However, these types of studies are in the minority and they are typically conducted in a haphazard fashion. That is, researchers examine the impact of one training factor or another, and there is little agreement between researchers in terms of what training outcomes should be measured (e.g., in two studies examining practice time, one gathered performance measures related to shooting accuracy only, the other looked at the overall target hit rate, the number of times a weapon was fired, the miss distance (i.e., where a shot actually hit versus where it should have hit).

The end result of this state of affairs is a high level of confusion - confusion about whether simulation training works and to what degree, and confusion about what factors influence simulation training effectiveness and why. A meta-analytic review of all military studies that have looked at the effectiveness of simulation training for use-offorce encounters will help eliminate some of the existing confusion. In addition, it will provide a foundation for more productive research in the future. However, before proceeding with this meta-analysis, it is first necessary to describe in more detail what simulation training is and how it is implemented. Following this, a brief review of some of the previous research on simulation training programs in the military will be provided to give an indication of the types of studies that have been conducted to date. Then, a theoretical framework will be proposed that will assist in understanding how simulation 
training can indeed be effective. Lastly, a number of training principles that emerge from this theoretical perspective will be presented, which, if incorporated into the training of military personnel should maximize training gains. It is this hypothesis that will be tested in the meta-analysis.

\section{Simulation Training}

What Is a Simulator?

A simulator is a "training device that artificially duplicates the conditions that would be encountered in an actual operation or situation" (Wehrenberg, 1986, p. 102). Simulators are used for training purposes in a wide variety of contexts (e.g., medicine, science, policing, etc.) all over the world (Canadian Police College, 2003; Gordon, Wilkerson, Shaffer, \& Armstrong, 2001; Lavoie \& Good, 1988). They are typically used to teach people how to make appropriate decisions in various situations under fieldcompatible conditions (Gordon, et al., 2001; Lane \& Tang, 2000; Stock, Borum, \& Baltzley, 1998; Wehrenberg, 1986). For example, various military branches use simulators in order to facilitate use-of-force mission rehearsals, where a soldier might have to provide suppressive fire while other members of his team search for and recover equipment in a combat area (Nullmeyer \& Spiker, 2000).

Simulation training is generally incorporated within the context of an overall training program, much like any other training device or technique, with the purpose of enhancing learning in a given area. To illustrate, a typical study by White, Carson, and Wilbourn (1991a) involved 166 trainees (both male and female) in a US Air Force Security Police course. The participants were randomly assigned to either a control group, receiving 30 minutes of hands-on marksmanship training, or a trained group 
(consisting of 6 sub-groups), receiving one of several simulation conditions. The type of simulation training received by participants in the trained group differed in one of three ways: (1) with respect to practice time (participants received either 10 or 20 minutes), (2) weapon recoil (their weapons simulated realistic recoil action or did not), and (3) weapon noise (the simulator provided the report of gunfire or did not). After each of these groups completed their training, they all fired their weapons at silhouette targets on a firing range, as they would be expected to during their qualification course. Participants were assessed in terms of their number of hits on target and the results suggested that those participants in the trained group had greater performance gains compared to the control group; especially those participants who received (or did not receive) both weapon recoil and weapon noise.

\section{What Do Simulators Look Like?}

The technologically advanced simulators currently used within military institutions come equipped with a number of features. These features include life-size screens that permit the projection of high quality images from a ceiling-mounted video projector (FATS, 2005a; Federal Law Enforcement Training Centre; FLECT, 1986). A wide variety of scenarios currently exist, or can be authored to the meet the specific requirements of the agency, each relating to a realistic use-of-force situation that may be encountered by the trainee. In addition, simulators come outfitted with a wide range of realistic, infrared-light emitting weapons. Firearms can be connected to carbon dioxide containers to provide realistic recoil action and all weapons are weighted and balanced to feel like the real thing (there is also an option in many simulators for instructor controlled weapon malfunctions). In addition, trainees are required to treat the scenarios as veritable 
use-of-force situations, using verbal commands and taking cover as appropriate. Artificial trees and other aspects of the terrain encountered in combat environments are often placed in the simulation training room to enhance authenticity (Burnside, 1990; Winn, 2002).

Most simulators now come equipped with seamless branching technology, which can be either computer or instructor controlled (FATS, 2005a). Computer controlled branching responds to the trainee's infrared-light emitting weapons. Essentially, the trainee's action or lack thereof in a given scenario automatically lowers or raises the level of threat presented on the video without interrupting the motion picture. Hence, the onscreen consequences of a trainee's decision provide immediate feedback. Instructor controlled branching can override the pre-set computer programmed branching alternatives in order to modify the outcome of a scenario based on the trainee's actions. It also allows the instructor to control other factors, such as the lighting and weather conditions in a given scenario.

For feedback purposes, most simulators have the capability of replaying the actions of the trainee (FATS, 2005a). In this way, the trainee and the instructor can both watch the trainee's performance to see where things went wrong and discuss alternative responses that would have been more likely to result in the desired outcome. In addition, after the training session is complete, simulators can provide a printed summary of the trainee's performance (FATS, 2005a). For example, if the trainee fired his weapon during the scenario, the output will specify the number of shots fired, the accuracy of the shots, and whether any innocent people were harmed. These hard-copy summaries of evaluation 
scores also provide an opportunity for the instructor and trainee to discuss various performance issues.

Potential Benefits of Simulator Use

Military operations consistently require that a soldier problem solve and strategize in conflict-ridden scenarios (Pleban, Matthews, Salter, \& Eakin, 2002). These complex cognitive tasks must necessarily be integrated with motor skills such as weapon manipulation. Simulation training is frequently used within the military domain because it allows trainees to practice, acquire, and enhance both decision-making and motor skills under reasonably realistic situations (Endsley et al., 2000; Pleban et al., 2002). According to many researchers, training with simulators provides many advantages over other pedagogical options (such as classroom instruction, role-playing, training with real machinery and ammunition in the field, etc.). These include:

- The opportunity to expose trainees to an increased number of practice trials, with the possibility of varying the scenarios and conditions presented to the learner (Means, Salas, Crandall, \& Jacobs, 1993; Wehrenberg, 1986; van Berkum \& de Jong, 1991).

- The opportunity to practice maneuvers/skills in "dangerous" situations without undue risk (i.e., errors can be committed that, in the real world, would result in fatal consequences) (Geber, 1990).

- Reduced training costs (i.e., in terms of manpower, ammunition, lives, etc.) (Dennis \& Harris, 1998; Sterling, 1996).

- More reliable training environments (Fink \& Shriver, 1978; Geber, 1990). 
- Training can be tailored to meet a range of instructional purposes and the ability of the learners themselves (Dennis \& Harris, 1998).

- The opportunity to introduce conflicts into the training context and the ability to increase the number of conflicts that can ordinarily be covered during training (FATS, 2005a; Fink \& Shriver, 1978).

- Enhanced opportunities to provide augmented feedback (e.g., from an instructor) given the on-screen performance summary and the hard copy evaluation provided by the simulator (FATS, 2005a).

- The opportunity to control extraneous factors during training such as lighting, weather conditions, and weapon malfunctions (Burnside, 1990; Magee, 1987).

\section{Previous Research on Simulation Training in the Military Domain}

The benefits associated with simulation training should not be confused with the effectiveness of simulation training, if effectiveness (e.g., enhanced learning, sustained learning, transfer of learning, etc.) has not actually been measured. Such confusion is apparent throughout the literature (Goodyear, Njoo, Hijne, \& van Berkum, 1991). In fact, as mentioned above, military research has rarely examined training effectiveness directly, but has instead focused on issues such as reducing training costs, enhancing learner safety, and influencing user acceptance (Alessi, 2000). As indicated previously, the research that has examined training effectiveness to date is largely atheoretical in nature and has been conducted in a haphazard fashion (Alessi, 2000). For example, in the studies that have examined factors that may influence the effectiveness of simulation training, rarely is a reason given as to why specific factors have been focused on (e.g., Campshure, Witmer, \& Drucker, 1990; Shlechter, Bessemer, \& Kolosh, 1992; White et 
al., 1991a, 1991b, etc.). In addition, any attempt to integrate the findings from the research into actual simulation training programs (in an effort to enhance the impact of the training) is very uncommon (Alessi, 2000; Andrews, Carroll, \& Bell, 1995).

The research by Salter and colleagues (1999) is a case in point. They conducted a study in which soldiers from the Mechanized Infantry Training Division at Fort Benning, Georgia, rated various Virtual Individual Combatant (VIC) simulations on several dimensions related to fidelity (including realism, difficulty, and speed). Why fidelity was focused on in this study (versus, say, feedback, or practice times) was never made clear, nor has any attempt been made since this study was conducted to determine whether the realism, difficulty, or speed associated with VIC training scenarios actually influences this form of training.

Likewise, White et al. (1991b) examined the influence of practice time on training effectiveness when participants used an M-16 rifle simulator (as measured by shooting accuracy during a re-test phase). More specifically, they examined the impact of increasing practice time by 10 -minutes (from 10-minutes to 20 -minutes). No mention was made about why increasing practice time should increase shooting accuracy, particularly an additional 10-minutes of practice time, and, perhaps unsurprisingly, no significant difference in shooting accuracy was found across the two practice conditions.

In a similar way to how training factors (e.g., fidelity, practice, feedback, etc.) are selected in an apparently random fashion, outcome measures also seem to be chosen with little regard as to their importance or relevance. For example, some researchers focus solely on subjective measures when evaluating simulation training. The study by Pleban et al. (2002) provides a representative example of this situation. They examined the 
effectiveness of individual combat simulators for enhancing decision-making skills in mission planning scenarios. After taking part in four 25-minute scenarios, participants completed a subjective self-report evaluating training effectiveness. Eighty-six percent of participants reported that they believed their decision-making skills improved as a result of the simulation training. Whether the participants' skills had actually improved was never reported.

Objective measures of training effectiveness have also been considered and range from study to study, often including measures such as shooting accuracy, target acquisition, errors of omission, etc. (Krebs, McCarley, \& Bryant, 1999; Pleban et al., 2002; Sterling, 1996; White et al., 1991a, 1991b). Sterling (1996), for example, assessed the effectiveness of platoon gunnery training simulations using objective measures such as the percentage of vehicles and soldiers killed during battle scenarios. In a study by Pleban and Salvetti (2003), where soldiers underwent simulation training to learn how to clear opposing forces from two-story buildings, training effectiveness was measured by recording the frequency with which a number of predetermined training outcomes were accomplished (such as number of casualties, number of rooms properly cleared, inaccurate reporting of the location of opposing forces, incorrect holding of a weapon, failure to yell "clear" once a room was cleared, etc).

To add to the confusion generated by the apparently random selection of training factors and outcome measures by researchers in this area, inconsistent results are also reported across studies in terms of actual training effectiveness. That is, while some studies produce results that strongly support simulation training, others report far weaker findings. For example, a study conducted by McAnulty (1992), in which he evaluated the 
effectiveness of the AH-1 Flight and Weapons Simulator (FWS) in enhancing gunnery skills in the AH-1F helicopter, produced strong, positive results. Compared to participants that took part in actual live-fire training, participants taking part in monthly or quarterly simulation training sessions exhibited greater gains in gunnery skills (i.e., shooting accuracy) between pre- and post-tests (participants in the live-fire control group actually exhibited a decline in performance from pre- to post-test).

On the other hand, a study by Shlechter, Bessemer, Nesselroade, Jr., and Anthony (1995) produced weak results. In their study, nine armored units completed various training scenarios involving basic skills (e.g., shooting), tactical movements, and defensive techniques using the SIMulation NETworking training system. Their results indicated that the time it took to complete the scenarios, the number of errors made, and the amount of coaching needed, improved as the training progressed. However, the decrease in errors and coaching time was not significant. In addition, further examination of the data by the researchers revealed that the improvements made by the participants terminated after the third training phase (there were five in all).

This brief review highlights several key problems with the existing use-of-force simulation training research in the military domain. First, the research is generally atheoretical in nature (i.e., lacking a theoretical basis for the examination of certain training factors). Second, and related, there are major differences across studies, both in terms of what training factors have been examined and what outcome measures have been considered, making it difficult to establish whether it is more productive to focus on certain factors/measures over others (i.e., are stronger results more likely under certain conditions?). Third, the results relating to training effectiveness are inconsistent across 
studies, with some studies showing strong results and some showing weak results, making it difficult to reach a firm conclusion about the usefulness of simulation technology as a training device.

The next section of this thesis will attempt to resolve some of these issues (particularly the first issue) by presenting a theory about how people learn in training environments. Not only does this theory suggest that simulation training can be effective, it also points to factors that will enhance training effectiveness. Thus, a theoretical rationale will be provided for the examination of specific training factors in this and future research (these factors are discussed in an upcoming section). The meta-analysis that forms the core of this thesis effectively resolves the second issue by examining the impact that all of the training factors and outcome measures (in isolation and in combination) examined to date have on simulation training effectiveness. This metaanalysis will also clarify the final issue of whether simulation training is effective, since average effect sizes across studies can be calculated.

Cognitive Load Theory: A Theory of Learning in Training Environments

Instructional design is the "field of study concerned with improving student learning" (Tennyson \& Schott, 1997, p. 1). Currently, there are two dominant instructional design theories dealing with how learning takes place in training contexts. The first is referred to as Constructivism, and the second, Cognitive Load Theory (CLT). This thesis will argue that CLT is the more useful theory of the two for understanding the learning process in simulated training environments. Not only is CLT more intuitively appealing, as its principles can be applied to learning in simulated environments, and easier to comprehend, but, compared to Constructivism, it will be shown that CLT is also 
supported to a larger extent by empirical research findings. However, before proceeding to discuss CLT, a brief review of the main concepts underlying constructivist learning will be provided.

\section{Constructivist Learning}

Constructivist theories of learning are referred to by a variety of names including discovery learning, problem-based learning, the minimally guided approach to learning, experiential learning, and inquiry learning (Kirschner, Sweller, \& Clark, 2006). As indicated by these names, the essence of Constructivism is that, "instruction is more a matter of nurturing the ongoing processes whereby learners ordinarily and naturally come to understand the world in which they live... [and where] knowledge is an active process of construction, not the receipt of information from external sources" (Knuth \& Cunningham, 1993, p. 164). In other words, learners are expected to acquire knowledge and solve problems by actively constructing their own solutions in a self-directed manner within an environment with an abundant amount of information and stimuli (Kirschner et al., 2006; Tennyson \& Schott, 1997). These environments can include any relevant materials that may aid the learner in coming up with their own solutions to a problem, such as books, computers, building materials, etc. (Roblyer, 1996).

Another aspect of this theory is that learning is thought to take place most efficiently through experience within the context in which the skills will be used (much like an apprenticeship, where learning takes place by observing an expert in a particular domain) (Honebein, Duffy, \& Fishman, 1993; Kirschner et al., 2006). However, from a constructivist perspective, the role of the trainer in these environments is to facilitate discovery-based learning by providing the learner with information relevant to the task, 
only if it is needed (Kirschner et al., 2006). According to Kirschner and his colleagues, advocates for Constructivism feel that providing learners with explicit instruction on the types of learning techniques they should be using actually deters from knowledge acquisition. Such instructions are thought to interfere with one's ability to use previous experience and knowledge to incorporate and construct one's own way of learning in a particular situation. By impeding this type of knowledge acquisition, the learner would be unable to access the information when faced with similar problems in the future because meaningful "construction" has not occurred (Wickens, 1992).

While various researchers claim that constructivist theories provide an adequate explanation of how learning takes place, many others refute these claims, citing empirical evidence that instruction involving some type of guidance is beneficial in promoting effective learning. For example, Klahr and Nigam (2004) conducted a study comparing direct instruction and discovery learning using children in the third and fourth grades. The children had to determine how different characteristics of wooden ramps (e.g., length and steepness) affected the distance that two types of balls (e.g., rubber balls and golf balls) rolled. Results showed that the children who received direct instruction about how the different ramp characteristics would affect their balls learned much more than the children who were left to discover the effects on their own. For example, when the researchers asked the children questions about a third ramp characteristic, surface (e.g., rough or smooth), which was not part of the direct instruction, the direct instruction group was better able to make inferential judgments from what they had previously learned. In addition, Mayer (2004) reviewed studies examining constructivist and guided learning (i.e., where learners were given explicit instructions or information) using word 
and math problems and found that guided learners performed significantly better than those receiving no guidance. Similar results have been found in other studies examining conservation strategies (Beilin, 1965; Brainerd, 1972; Gelman, 1969; Inhelder, Sinclair \& Bovet, 1974; May \& Tisshaw, 1975; Wallach \& Sprott, 1964), computer programming (Clements \& Merriman, 1988; Dalbey \& Linn, 1985; Fay \& Mayer, 1994; Kurland \& Pea, 1985; Lee \&Thompson, 1997; Littlefield et al., 1988) and general problem solving (Craig, 1956; Gagné \& Brown, 1961; Kittel, 1957; Shulman \& Keisler, 1966).

The studies above illustrate that one of the major problems with Constructivism is that it does not take into account one's cognitive architecture (Kirschner et al., 2006). For example, the theory fails to acknowledge the limited capacity of our working memory (WM), and thus the amount of information that one can consider in the environment at any one time. Instead, this theory assumes that learners have an unlimited capacity with which to absorb and process information, and to identify the information that is most important when learning a particular task (Tennyson \& Schott, 1997). Given the structures making up our cognitive system, this is an unrealistic assumption, especially in complex environments (Kirschner et al., 2006). In fact, many researchers are now beginning to realize that, "any instructional procedure that ignores the[se] structures...is not likely to be effective" (Kirschner et al., 2006, p. 5). More recent theories of instructional design that acknowledge this fact are typically considered more viable than Constructivism. The theory that is receiving the most widespread support at the moment, and the one focused on in the present research, is Cognitive Load Theory (CLT). ${ }^{2}$

\footnotetext{
${ }^{2}$ Beyond the fact that Constructivism has received little empirical support as a theory of learning in training environments, an additional reason for why it is not examined within the context of this thesis is because it cannot be examined using the available research in the area of use-of-force simulation training. Indeed, no research in this area has tested (or even mentioned) the Constructivist approach. Given what a
} 


\section{Cognitive Load Theory}

Proposed in the late $1980 \mathrm{~s}, \mathrm{CLT}$ is an instructional theory with its roots in cognitive theories of learning. It was further developed throughout the 1990s and research on its effectiveness continues today (Bannert, 2002; Kirschner et al., 2006; Paas, Renk1, \& Sweller, 2003; Sweller, 1999). In essence, CLT proposes ways in which instructional material can be presented to trainees in order to promote learning, explicitly taking into consideration the restrictive capacity of a trainee's WM (Kirschner, 2002; Paas et al., 2003). In other words, CLT works not only by considering the structure of the information presented to a learner but also by taking into account a learner's cognitive architecture, which allows for the adequate processing of that information (Paas et al., 2003). The result is a "variety of new and sometimes counterintuitive instructional designs and procedures" (Paas et al., 2003, p. 1), which serves to enhance learning.

\section{CLT and Cognitive Architecture}

Cognitive architecture encompasses various systems of human memory, including WM and long-term memory (LTM), which aid in the processing of information (Paas et al., 2003). The ability of our cognitive architecture to process complex information is aided by the acquisition and automation of cognitive structures referred to as schemas (Paas et al., 2003). The process by which WM, LTM, and schemas aid in the processing and understanding of learned information is discussed below.

Working memory. Working memory is defined by Baddeley (1992) as "a brain system that provides temporary storage and manipulation of the information necessary for such complex cognitive tasks as...learning and reasoning" (p. 556). Working memory

Constructivist would recommend in this setting (i.e., encouraging trainers to stand back so that trainees can practice what they like) this is not all that surprising. 
is utilized during any conscious cognitive activity to organize, compare, or manipulate information (Narayanan, 2005). However, it is limited to the processing of approximately seven single elements, or two or three interacting elements, at any given time (Groeger, 1997; Kirschner, 2002; Paas et al., 2003). An element is defined as any piece of information that needs to be learned, such as a word, a letter, a number, etc. (Sweller, 1994).

In order to test the assumption that WM is limited in its capacity to process information, Baddeley and his colleagues conducted several well-known experiments, using dual-task techniques. Baddeley and Hitch (1974), for example, conducted a study whereby participants were required to continually repeat sequences of six digits aloud while simultaneously completing difficult or easy reasoning problems. This resulted in participants completing difficult reasoning problems at a much slower rate than simpler ones, clearly indicating that, when a learner is required to process increasingly complex amounts of information (e.g., six digits plus the elements contained in the reasoning problem) WM capacity can be exceeded. In contrast, the simpler problem coupled with six digits was not sufficiently complex to cause WM capacity to become overwhelmed.

Long-term memory. Long-term memory is the system used to store knowledge or skills that are not currently being processed in WM, but are needed for intellectual understanding (Bower, 1972). Unlike WM, LTM is not limited and it stores information so that it can be retrieved when needed (Bower, 1972). The way in which LTM stores information is in the form of schemas, which are developed after repeated exposure to information or by the deliberate rehearsal of a task (Groeger, 1997). Proficiency in any domain is due to knowledge accumulation and storage in LTM and the ability of our WM 
to efficiently retrieve that knowledge (i.e., by recalling or recognizing it) (Kirschner, 2002). Therefore, if an instructional format requires that a learner process many new elements of information that have not previously been encountered, it is likely that effective learning will not occur (Kirschner, 2002).

Schemas. If a learner adequately processes incoming information, that information can form schemas, or meaningful associations, which are stored in LTM. Schemas are "cognitive structures that serve to organize information into meaningful concepts" (Tennyson \& Elmore, 1997, p. 58) by incorporating "multiple elements of information into a single element with a specific function" (Paas et al., 2003, p. 2). In the use-of-force training context, a schema can represent anything from a type of weapon (e.g., an M-16 rifle) to the various behaviours an individual typically engages in when using a firearm (e.g., the weapon is loaded, aimed, and fired, etc.). ${ }^{3}$ A learner's memory can be influenced when schemas interact with incoming information as a way of making it meaningful (i.e., by assimilating new information with existing concepts) (Chi, Glaser, \& Rees, 1982; Sweller, 1994; Tennyson \& Elmore, 1997). For example, an army cadet learning to operate an M-16 rifle will encounter new and differing types of targets (e.g., standing, sitting, moving, etc.) and, as he learns how to accurately fire at them, this new information will be incorporated into his existing 'M-16' or 'firearm' schema (see Figure 1).

\footnotetext{
${ }^{3}$ A sequence of behaviours that one typically engages in within a certain context is often referred to as a script (Groeger, 1997). Historically, schemas and scripts were treated as separate cognitive structures by cognitive psychologists (Abelson, 1981), but this is no longer the case. For example, according to Groeger (1997) a "script is a specific type of schema which is an amalgamation of knowledge of particular types of frequently encountered events" (p. 81).
} 


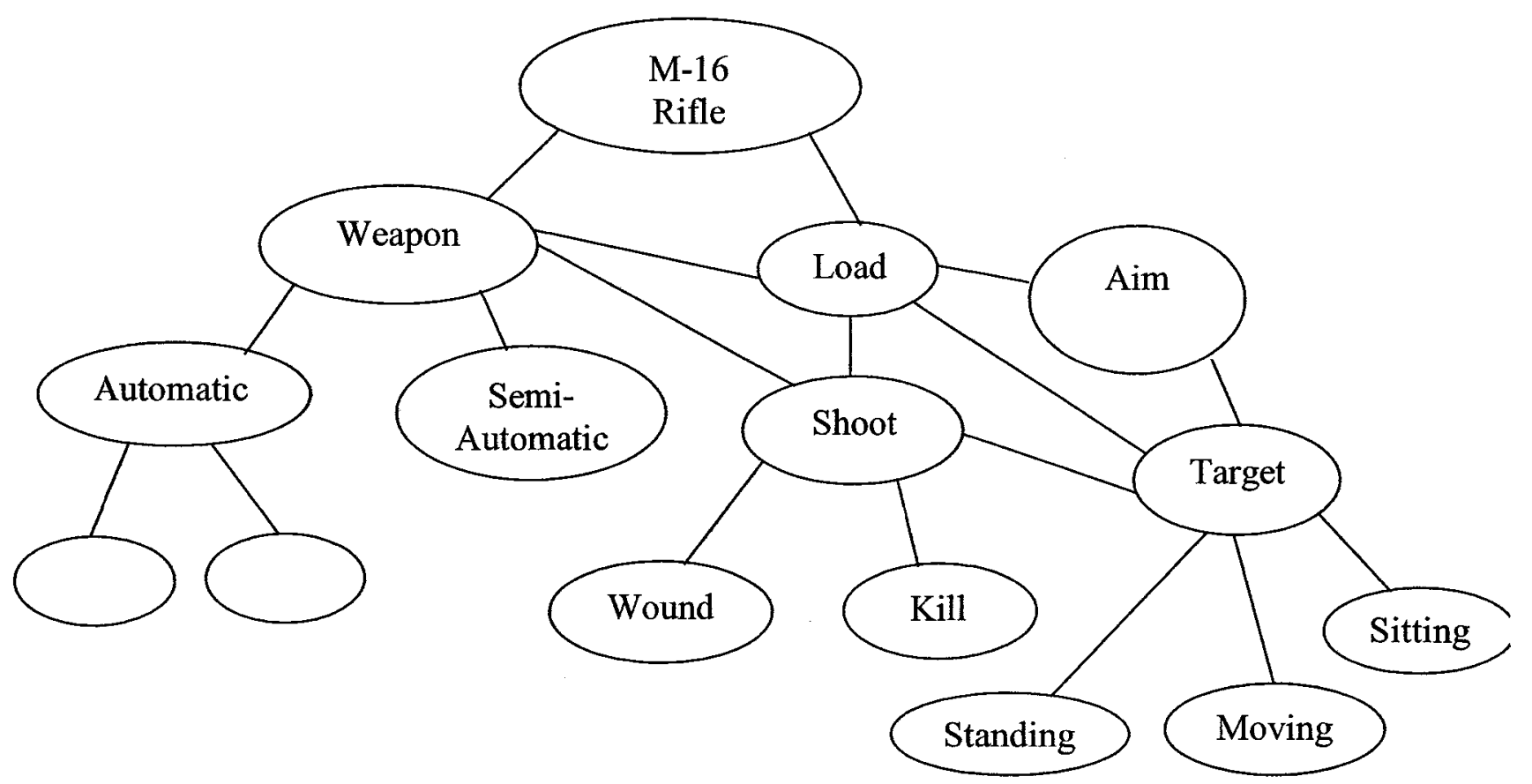

Figure 1. A hypothetical illustration of an individual schema and the collective network of schemas associated with an M-16 rifle.

Schemas typically serve two functions (Sweller, van Merriënboer, \& Paas, 1998). First, acquired schemas assist with the storage and organization of large amounts of information in LTM. Due to their network structure (i.e., a composition of overlapping and embedded schemata), schemas serve as efficient storage mechanisms (i.e., a massive amount of information can be stored in a small space) (Kirschner, 2002). Second, once schemas are automated, ultimately through experience, they help to reduce WM load by allowing learners to quickly access information from LTM (Marshall, 1995). According to proponents of CLT, training contexts that foster schema acquisition and automation are likely to be more effective than those that do not allow meaningful associations to develop (Kirschner, 2002). 
Types of Cognitive Load and Element Interactivity

Of fundamental importance to CLT is the cognitive load experienced by the trainee when learning a new task. According to CLT, several types of cognitive load exist, including intrinsic, extraneous, and germane load (Sweller, 1999). Each type of load affects WM, in terms of the load placed on it. For example, "WM load is affected by the inherent nature of the [to-be-learned] material" (i.e., intrinsic cognitive load) (Kirschner, 2002, p. 4), as well as by the ways in which the to-be-learned material is presented to the learner (i.e., extraneous and germane cognitive load). Each type of load will be discussed individually in terms of what it is, how it affects one's ability to learn, and how it can be manipulated to enhance learning.

Intrinsic cognitive load. Intrinsic cognitive load is generated by the intrinsic complexity of the information being conveyed to the learner. The more complex the information is that must be learned, the higher the intrinsic cognitive load. In some cases, the inherent characteristics of "some information is such that if understanding is to occur it will impose a heavy working memory load" (Pollack, Chandler, \& Sweller, 2002, p. 62 ), regardless of the manner in which it is presented to the learner.

Intrinsic cognitive load is determined largely by the amount of interactivity that exists between the elements of the to-be-learned information (Paas et al., 2003; Pollack et al., 2002). Element interactivity can range from low to high. Information that is low in element interactivity can be learned on its own regardless of any other elements (Paas et al., 2003). For example, when being instructed on how to shoot an M-16 rifle, one only needs to learn how to aim and pull the trigger (each one of these elements can be learned independent of the other). Information that is low in element interactivity generates a low 
level of intrinsic cognitive load because to learn it, only a limited number of elements need to be processed by WM at any one time (Chandler \& Sweller, 1996).

Information that is high in element interactivity can also be taught element by element. However, the information cannot truly be learned until one fully understands how the elements interact with one another (Paas et al., 2003). For example, a soldier entering a combat zone with his M-16 rifle will not only need to consider those elements that are required to fire his weapon (aiming and pulling the trigger), but also a range of elements that determine whether a shot should be fired (e.g., the location of targets, opportunities for cover, whether civilians are present, etc.). In order to learn how to fire an M-16 rifle in naturalistic settings all of these elements must be attended to and processed collectively and, therefore, the material will impose a high intrinsic cognitive load.

Different types of information vary inherently in their level of element interactivity and associated intrinsic load. Consequently, this is a feature of the information that cannot be altered by changing the format of the instruction (Paas et al., 2003). Indeed, the only way to reduce intrinsic cognitive load in a situation where the trainee must learn a complex task would be to initially give the trainees a simpler task that omits some interacting elements. With very complex, highly interactive tasks, this may be the only way to facilitate learning. Eventually, however, simultaneous processing of all essential elements must occur, because it is only then that a real understanding of the to-be-learned information can be facilitated (Paas et al., 2003).

This recommendation, of slowly introducing elements of complex information to facilitate learning, is supported by empirical research. For example, Pollack and 
colleagues (2002) examined a sample of first year industrial trade students who were learning electrical safety tests. These researchers found that students who studied instructions with isolated elements at phase one, followed by instructions with interacting elements at phase two, learned more effectively than those students who received the instructions with interacting elements at both phases. This study supports the notion that, initially, complex information should be presented in a simplified fashion, followed by the simultaneous presentation of all the necessary information (at least until appropriate schemas have been acquired).

Extraneous cognitive load. Extraneous cognitive load consists of extra and unnecessary demands placed on WM, which are produced by the learning materials and methods of instruction used in the training context (Clark, Nguyen, \& Sweller, 2006). Extraneous load directly interferes with learning because already limited WM resources are expended upon irrelevant activities (i.e., activities that are unrelated to schema acquisition and automation) (Paas et al., 2003). Given its source, extraneous load can be reduced or eliminated by manipulating the manner in which information is presented to the learner.

Consider a situation in which a soldier is required to learn marksmanship skills. Typically, this task is accomplished by initially presenting the soldier with stationary silhouette type targets before eventually moving towards the presentation of mobile targets (i.e., an enemy target or member of an opposing force) within interactive training scenarios. Given the ultimate goal of teaching soldiers to respond effectively to real world events, the use of stationary targets in such training is most likely unnecessary and potentially counter-productive (Morgan, 1991). More specifically, stationary practice 
may foster schematic representations that are in fact inappropriate to the target task of responding effectively to enemy targets that are in motion. As a result, the trainee may experience high levels of extraneous load when attempting to mentally integrate what was learned in stationary target practice with what is presented in interactive training, thus preventing the acquisition of appropriate schemas. Proponents of CLT would argue that the appropriate instructional strategy in this case is the removal of unnecessary training components (i.e., stationary target practice) in order to decrease the extraneous load experienced by the learner (Cooper, 1998).

Extraneous cognitive load becomes a particularly important consideration in instructional settings when intrinsic cognitive load is high because these two types of load are presumed to be additive (Paas et al., 2003). Accordingly, if intrinsic load is low, the level of extraneous load becomes less important because the total load experienced by the trainee may still be below the threshold of processing capacity afforded by WM (Paas et al., 2003) (see Figure 2a). Therefore, instructional formats designed with the intention to reduce extraneous cognitive load are thought to be most beneficial when element interactivity is high (Paas et al., 2003) (see Figure $2 b$ ), as is typically the case in use-offorce training. 
(a)

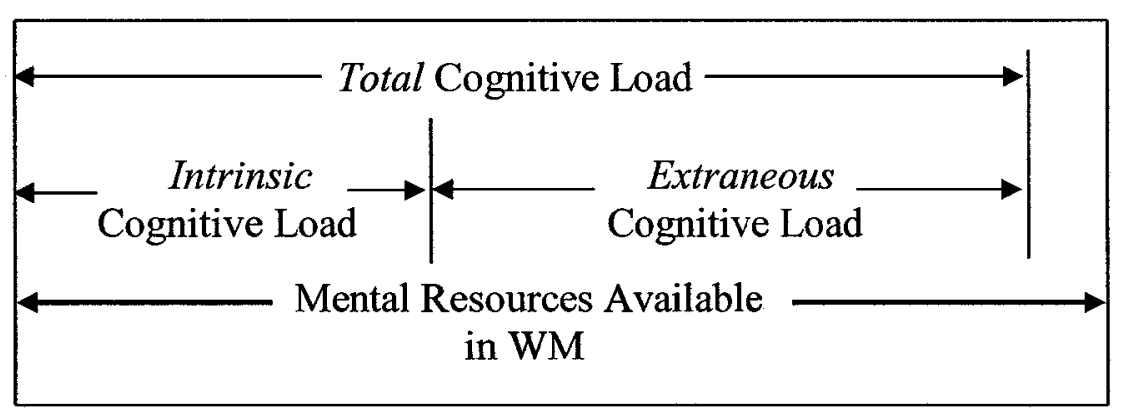

(b)

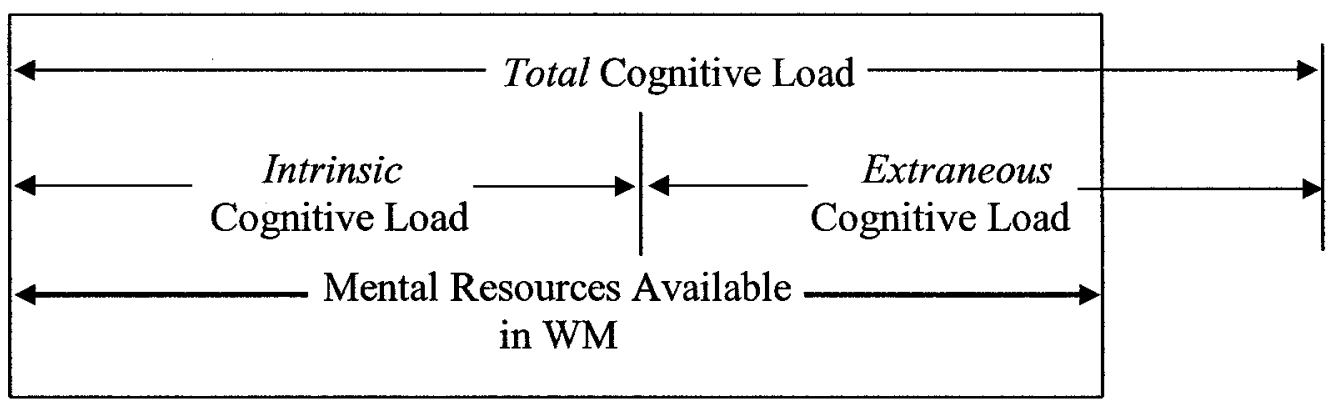

Figure 2. The additive effects of intrinsic and extraneous cognitive load when intrinsic cognitive load is (a) low and (b) high.

Germane cognitive load. In contrast to extraneous load, germane cognitive load promotes learning through direct efforts to enhance schema acquisition (Moreno, 2004). However, both germane and extraneous load are generated from the method of instruction. Essentially, the goal from a CLT perspective is to increase germane load whenever possible within the bounds of WM capacity (Paas et al., 2003). This can be accomplished in a variety of ways. For example, while learning may occur more easily if simple scenarios are provided to trainees, the skills that emerge from such training will be more limited than skills built from more realistic (i.e., complex) training examples (e.g., 
such as when an instructor introduces weapon malfunctions, variations in lighting, or high levels of background noise into the training scenario) (Clark et al., 2006). Under these circumstances, a higher cognitive load is imposed on the learner. However, this load is considered germane load because the learner will ultimately develop a broader schematic framework, allowing him or her to perform more effectively in a wider range of use-of-force situations.

As mentioned earlier, the various types of cognitive load are additive. Therefore, as illustrated in Figure 3, the total cognitive load experienced by a trainee during training is equal to intrinsic plus extraneous plus germane load (Kirschner, 2002). It is assumed that if a trainee experiences low intrinsic load due to the information being learned and/or low extraneous load due to the use of appropriate instructional procedures, the result will be unused WM capacity. This situation may be further enhanced by structuring the training in such a way as to promote schema acquisition (i.e., increasing germane load) (Kirschner, 2002; Sweller et al., 1998). However, increasing germane load will only be successful if the total cognitive load experienced by the trainee is within the limitations dictated by WM (Kirschner, 2002). In other words, intrinsic and extraneous load must be low enough to ensure that adding germane load will not overburden the trainee. 


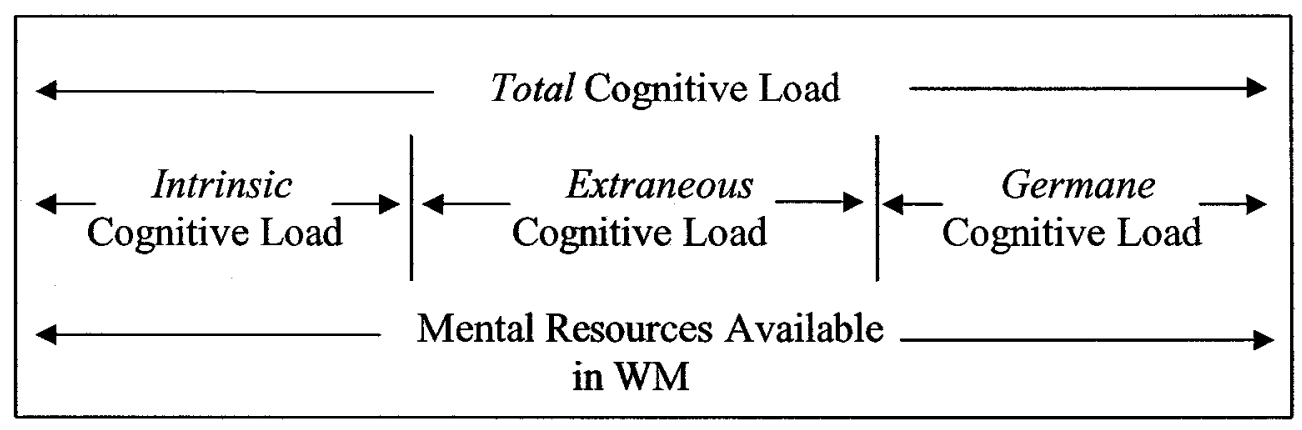

Figure 3. An illustration of the additive components of total cognitive load: intrinsic, extraneous, and germane load.

Differences Between Novices and Experts: The Effects on Cognitive Load

A primary component of CLT, and a factor that will be focused on in the current investigation, relates to the effect that learner experience (referred to as expertise in the CLT literature) has on cognitive load (and, thus, one's ability to learn). Learner experience was briefly mentioned in terms of schema acquisition and automation (see p. 17) and will now be discussed in terms of its effects on cognitive load.

When a learner has low prior knowledge in a domain, schema acquisition has not yet occurred and, therefore, cognitive load during training will necessarily be high (Moreno, 2004; Sweller, 1988). As a result, novice learners may experience extreme levels of cognitive overload when processing complex information if they are not provided with training that is appropriately structured (e.g., low extraneous load) (Mayer \& Moreno, 2003). Once a learner becomes proficient in a particular domain, cognitive load will diminish when the same type of complex information is encountered, and training will need to be revised to reflect this fact. In fact, a phenomenon known as the expertise reversal effect can occur, whereby "instructional techniques that [were] 
effective with novices can lose their effectiveness and even become ineffective when used with more experienced learners" (Paas et al., 2003, p. 3).

For example, Kalyuga, Chandler, and Sweller (1998) examined the impact that a learner's level of expertise and the format of instruction had on learning efficiency. The participants included novices and experts who were taught about electrical circuitry in various formats. These formats included a redundant format with text and diagrams presented separately (i.e., the text and diagrams contained essentially the same information), an integrated format with text and diagrams combined, and a diagram only format. The results indicated that novices learned most efficiently (i.e., schema acquisition occurred most readily) from the integrated format because the extraneous cognitive load associated with searching for information across two different sources of information (i.e., text and diagram) was reduced. In contrast, the experts learned most efficiently when presented with the diagram only format. This finding suggests that, because experts have already developed task-relevant schemas, they can learn from less detailed information compared to novices. However, if presented with unnecessary (i.e., redundant) information, the expert will still process it in WM and, as a result, experience unnecessary cognitive load. Similar findings have been reported by others (e.g., Clark et al., 2006; Kalyuga, Ayres, Chandler, \& Sweller, 2003; Kalyuga, Chandler, \& Sweller, 2000; McNamara, Kintsch, Songer, \& Kintsch, 1996, etc.).

Unfortunately, the study of expertise, and how it relates to the effectiveness of training strategies, is plagued by definitional problems. Indeed, there is currently no consensus in the research literature about how to quantify a learner's expertise (Ericsson \& Lehman, 1996). It has been suggested by some researchers that expertise be assessed 
using achievement tests that are appropriate to the task that the trainee is learning (learners that score higher on the test would be said to possess a higher level of expertise) (Clark et al., 2006). However, such tests do not exist for all tasks and are impractical to administer in many training contexts (Clark et al., 2006). Other researchers have preferred to simply equate expertise with experience and, as a result, use proxy measures such as years of experience within a particular domain to define expertise (e.g., Dochy, Segers, Van den Bossche, \& Gijbels, 2003; Ericsson \& Lehman, 1996). Given that the current study relies exclusively on existing studies, such definitional issues will not be resolved here.

\section{Factors Influencing Training Effectiveness}

A number of potential factors that affect training outcomes emerge from CLT. Although these factors have been shown to impact training in other domains, they have not yet been examined in a detailed or systematic fashion within a simulation training context. These factors relate to the domains of practice, feedback, and fidelity. The following section discusses ways in which these factors can be incorporated into use-offorce simulation training contexts and demonstrates how they can potentially enhance learning, based on an understanding of CLT.

\section{Practice}

Practice is the deliberate, repeated rehearsal of a task in order to improve one's skill level (Webster, 2005). Previous research has demonstrated that learning in general is more effective in contexts where the student is an active participant rather than a passive observer (James et al., 2002; Tailby \& Haslam, 2003). For example, military research has found that, while students typically retain only $50 \%$ of instructional content based on 
simple handouts and visual aids, engaging trainees in realistic practice of required skills has the potential to increase retention rates to $90 \%$ (California Assembly Concurrent Resolution 58 Study Committee, 1991). Furthermore, by increasing the amount of practice in the original learning environment, the long-term retention of tasks is improved (Bjork, 1994; Hurlock \& Montague, 1982; Tremblay, Welsh \& Elliott, 2001).

How does CLT suggest that practice be incorporated into the training context? Although never made explicit, CLT bears directly on three important practice-related issues: amount, distribution, and type.

Amount of practice. The overall amount of practice is positively correlated with the level of learning and performance (Hauptmann \& Karni, 2002). According to CLT, this would be because sufficient practice time must be given to the learner to ensure that they acquire meaningful schemas that allow them to automate the procedural tasks they are practicing (Clark et al., 2006). This automation then allows the learner to focus cognitive resources on the processing of complex aspects arising in any given situation (Clark et al., 2006).

Distribution of practice sessions. The distribution of a fixed amount of practice time is also a significant consideration in training effectiveness (Dempster \& Farris, 1990). Compared to spaced practice, massed practice (e.g., practicing for several hours straight) has been shown to lead to superior performance on both motor and cognitive skills, but only within the training context itself (Corrington, 1997; Druckman \& Bjork, 1991; Moss, 1996). Distributing practice sessions over time (e.g., over the span of several days) aids in the long-term retention of such skills, which is ultimately the goal of any use-of-force training (Baddeley \& Longman, 1978; Cahill \& Toppino, 1993). According 
to CLT, distributing practice sessions over time will generally be more effective than massed practice, even when the total amount of practice received by the trainees is the same (Clark et al., 2006). This is because distributed practice decreases cognitive load by frequently freeing up resources in WM for schema acquisition. Massed practice sessions, on the other hand, cause WM capacity to be overloaded because large amounts of information are presented to the learner in a single session (Clark et al., 2006). With no available WM space, the transfer and retention of schemas in LTM will be prevented.

Type of practice. When several tasks must be performed simultaneously (e.g., procedural and decision-making tasks), as is the case with most use-of-force situations, it is recommended that part-task training (i.e., the practice of individual skills) be alternated with whole-task training (i.e., the practice of multiple skills concurrently) (Means et al., 1993). While both forms of rehearsal are integral to one's ultimate performance, it has been demonstrated that incorporating whole-task training into training programs allows the learner to form stronger relationships between what is being taught during training and what will be encountered in the real world (where tasks must be performed simultaneously) (Detweiler \& Lundy, 1995; Lim \& Reiser, 2006). From a CLT perspective, this makes sense, because whole-task training is necessary to ensure proper schema acquisition and generalization. However, in order to achieve effective wholetask training without overloading the learner, the material may have to initially be simplified in early practice sessions (van Merriënboer, Kirschner, \& Kester, 2003). Feedback

Feedback is regarded as an essential factor in the acquisition and retention of desired response patterns (Rushall \& Siedentop, 1972; Schroth, 1995). Information 
feedback is broadly defined as information about the discrepancy between a given response and a prescribed standard of performance. Feedback resulting from an initial response provides: (1) a frame of reference for the quality of one's current performance, (2) a drive for the modification of one's current performance, and (3) a stimulus prompting a subsequent response that is expected to be a closer approximation of the desired behaviour (see Figure 4).

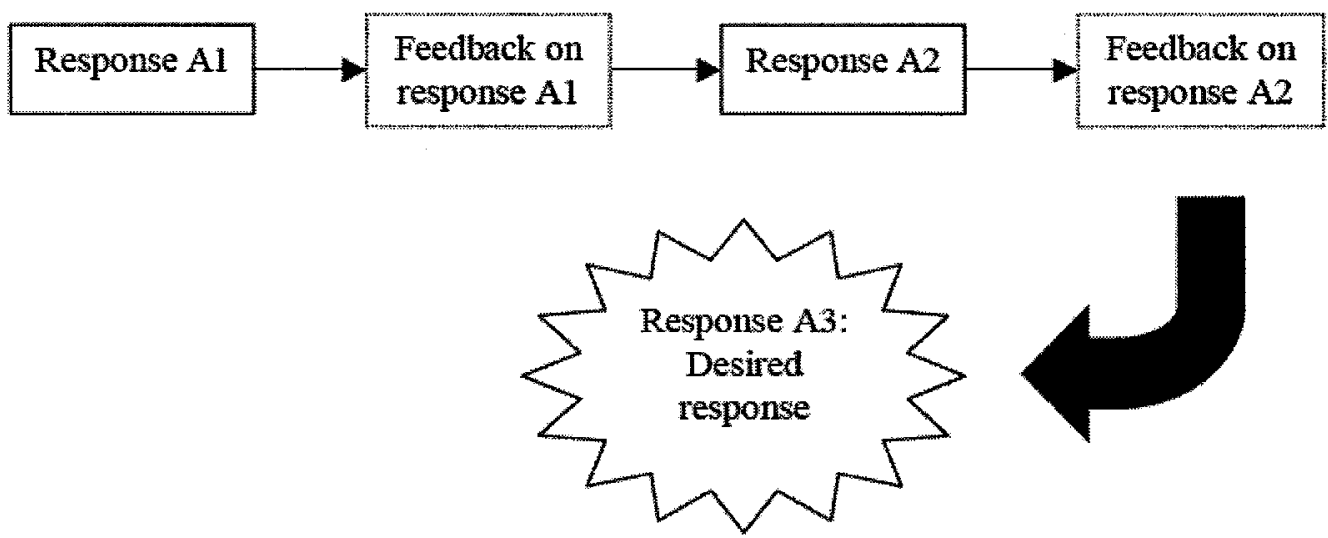

Figure 4. A simple feedback-response chain (Bennell \& Jones, 2004).

How does CLT suggest that feedback be incorporated into the training context? Again, CLT bears directly on two important issues related to feedback. These include the source and quality of feedback given to the learner.

Source of feedback. According to Holding (1965), there are two primary types of information feedback, categorized on the basis of the source of the feedback. The first is intrinsic and refers to the feedback inherent in the task itself (e.g., feedback from a training scenario). This form of feedback is supplied to the learner via a change in the environment following a given response. For example, when a platoon leader is 
commanding his unit during combat, the responses from the soldiers provide information to the platoon leader that he can use to modify his subsequent behaviour. The second form of feedback is termed augmented and refers to information that is not inherent in a given task. Primarily used as a learning tool, augmented feedback is typically provided by an instructor in a training context, though it can be provided by other sources (e.g., a peer group) (Druckman \& Bjork, 1991). As an example, when a platoon leader is learning to communicate properly to his unit during combat, the trainer can provide the individual with tips on how to improve their performance.

While the role of intrinsic feedback in training is indispensable to performance proficiency, the application of augmented feedback is not as clearly outlined (Rushall \& Siedentop, 1972). According to CLT, the difficulty in supplying the learner with artificial performance knowledge is that the beneficial effects of this feedback on training performance may not translate to naturalistic settings in which the individual must rely solely on intrinsic feedback cues (Bennell \& Jones, 2004). In addition, the learner may become overly dependent upon instructor feedback and fail to establish the cognitive links (i.e., schemas) required for consolidating proper stimulus-response patterns (Frank, 2002; Holding, 1965; Nullmeyer \& Spiker, 2000). Thus, effective augmented feedback must have the ability to signal one's attention to relevant intrinsic cues in order to maintain high performance levels once the training program is terminated and the augmented feedback is removed.

Quality of feedback. According to CLT, feedback, especially that which is explanatory in nature (i.e., not simply telling a learner whether they are correct or not, but providing reasons why), helps to facilitate schema acquisition by focusing the learner's 
attention on relevant information in the training environment (Clark et al., 2006).

Providing explanatory feedback to the trainee increases the likelihood that important relationships between particular stimuli and appropriate responses are established without overloading the learner's WM in the process (by focusing on irrelevant information) (Moreno, 2004). This is especially important when the information or task to be learned is complex. Cognitive Load Theory stresses the importance of fostering an understanding of these stimulus-response patterns to promote the long-term retention of schemata relevant to the learning context (Clark et al., 2006). Feedback also allows the learner to further strengthen and develop schemas that have previously been acquired (Clark et al., 2006). For example, when the learner receives feedback, he or she evaluates it against schemas already stored in LTM. If it fits, then the schema may be added to or modified to increase its strength. If the information is not compatible with the schemas already held in LTM, than a new schema or schemas may be developed (Clark et al., 2006). With adequate amounts of practice, coupled with adequate explanatory feedback, meaningful schema development can only be enhanced.

\section{Fidelity}

Fidelity refers to the degree of realism possessed by a particular training context (Matheny, 1978; Winn, 2002). In terms of simulation training, it refers to "how closely a simulation imitates reality" (Alessi, 1988, p. 40). Several types of fidelity exist, including physical, psychological, and physiological fidelity. Physical fidelity refers primarily to the degree of realism associated with the equipment or aids used in the training context (e.g., realistic props, replicated weapon recoil, shoot-back effects, etc.) (Winn, 2002). When a training context has high physical fidelity, the simulator and/or other training 
materials "duplicate the appearance and feel of their real equipment counterparts" (Fink \& Shriver, 1978, p. 25). In contrast, psychological fidelity refers specifically to the degree of perceived equivalence between the training scenario and the target situation, from the trainee's perspective (Fink \& Shriver, 1978; Matheny, 1978). Finally, physiological fidelity refers to the capacity of the training situation to produce somatic reactions (e.g., stress) in the trainee reflecting those produced in target situations (i.e., the natural environment). All of these principles are interrelated in the sense that greater physical fidelity typically results in heightened psychological and physiological fidelity (Erwin, 1978).

How does CLT suggest that fidelity be incorporated into the training context? It is typically assumed that procedural and decision-making skills are most effectively transferred to real-world settings when training contexts conform to the environments in which these responses naturally occur (Christina, 1996; Helsen \& Starkes, 1999). However, despite the promising results of some high-fidelity simulators (e.g., Bernstein \& Gonzales, 1971; Boyd, 1992; Dobson et al., 2001), it should be noted that a number of studies have also demonstrated that rigid adherence to realism in training contexts is often unnecessary and sometimes even counterproductive (Alessi, 1988; Alessi, 2000; Hays \& Singer, 1989; Moreno \& Mayer, 2004). For instance, in a military study pertaining to the fidelity of flight simulators, it was found that, while visual displays benefited performance, increasing simulation fidelity through the inclusion of platform motion had no impact upon training effectiveness with novice pilots (Eddowes, 1978).

Cognitive Load Theory would dictate that fidelity is important in the training context because it serves to lessen the degree to which the learner would have to use WM 
capacity to process what they are learning (Clark et al., 2006; J. Sweller, personal communication, October 3,2005$)$. For example, more WM capacity will be used if a learner is sitting at a desk imagining that they are in the middle of a combat scenario versus being present in a simulated combat scenario. However, the degree of fidelity incorporated into the training context must be tailored to the learner, as described below.

\section{A Note Regarding Learner Experience}

As indicated previously, CLT emphasizes the importance of considering the experience of the learner when designing training programs (Kalyuga et al., 1998) and it may be the case that each of the factors just discussed needs to be considered in this light. For example, while distributing practice sessions over time may be the optimal schedule for maximizing skill retention over the long-term (on average), it may be beneficial for novice learners who have yet to acquire task relevant schemas to be exposed to massed practice for a short period of time at the outset of a training program. Likewise, although explanatory feedback may be necessary for novice learners at the outset of training (e.g., after each scenario) in order to facilitate schema acquisition, corrective feedback, or a total absence of feedback, may be more beneficial for the experienced learner who has already acquired the necessary schemas. Cognitive load theorists have yet to address the issue of expertise reversal as it relates to practice and feedback issues and, therefore, this aspect of the thesis will be exploratory in nature.

In contrast to practice and feedback, CLT has addressed the issue of expertise reversal when it comes to training fidelity. It is acknowledged by cognitive load theorists that the amount of fidelity incorporated into a training context should be tailored to suit the learner (Clark et al., 2006; J. Sweller, personal communication, October 3, 2005). For 
example, in line with the earlier results of Eddowes (1978), where increased fidelity impaired the performance of inexperienced pilots, recent research suggests that, for novice learners, a reduction of realism in training is often required to enable the learner to build up appropriate schemas and prevent excess cognitive load (Alessi, 2000; Alluisi, 1978; Winn, 2000). Although realism is important to the novice learner, extreme realism can be detrimental, especially when the complexity of the learning task is high (thus already taking up a lot of processing capacity) (Alessi, 1988). Experts, on the other hand, are better able to process scenarios with full fidelity because they have already acquired appropriate schemas and automated the necessary procedural skills (Alessi, 1988).

\section{The Current Study}

The previous section highlighted the importance of practice, feedback, and fidelity-related issues with regard to training in general, and the relationship between these training factors and CLT was established. However, the role of each of the factors mentioned has not been investigated in a systematic and comprehensive fashion in simulation training contexts, despite the fact that they all have the potential to enhance learning by decreasing WM load, enhancing schema acquisition and automation, promoting the long-term retention of these schemas, or automating procedural skills.

Unfortunately, based on the limited information contained in the studies that will be analyzed in the current meta-analysis, it will not be possible to examine the aforementioned training factors in absolute terms (e.g., comparing the effect of practice times that exceed 10 hours to practice times that do not exceed 10 hours). Specific information (relating to practice times, or any of the other training issues that have been discussed) is rarely, if ever, given in the studies, making it impossible to conduct such 
analyses. Instead, the studies provide information that allows for relative comparisons (e.g., the effect of more versus less practice) and, therefore, the current analysis will be restricted to these types of comparisons. Although this is not the ideal situation, especially for making recommendations that are of value in practical settings, valuable information can still be obtained by such analyses and CLT, as a potential theory of learning in simulated training environments, can certainly still be evaluated.

Thus, the present investigation will examine the above-mentioned training factors in order to determine if and how they influence simulation training effectiveness. This is accomplished by coding for their presence or absence in use-of-force simulation studies found within the military domain and seeing how they relate to a range of training outcome measures (a more in-depth discussion of these measures is provided below in the method section). For example, in relation to practice, the amount, type, and distribution of practice will be coded. In relation to feedback, the source and quality of feedback will be coded. Lastly, in relation to fidelity, the degree of fidelity will be coded. The following is a list of the hypotheses that will be examined in the present study. They are stated in relative terms in accordance with the degree of information provided in the sample of studies.

1a) Larger amounts of practice will be more beneficial in terms of training effectiveness, than smaller amounts of practice.

1b) Practice involving the sequencing of part-to-whole-task training will be more beneficial in terms of training effectiveness, than practice that solely involves part-task or whole-task training. 
1c) Spaced practice sessions will be more beneficial in terms of training effectiveness, than massed practice.

2a) Incorporating both intrinsic and augmented feedback into training will be more beneficial in terms of training effectiveness, than training that involves intrinsic feedback alone, or augmented feedback alone.

2b) Explanatory feedback will be more beneficial in terms of training effectiveness, than corrective feedback in isolation, or no feedback.

3) Incorporating high levels of fidelity into the training context will be more beneficial in terms of training effectiveness, than incorporating low levels of fidelity.

In addition, several other variables will be coded and analyzed in order to determine their influence, if any, on the effectiveness of use-of-force simulation training (these variables are discussed in detail in the following section). Most importantly, exploratory analyses will be conducted to determine how the above training factors interact with learner experience to influence training effectiveness. ${ }^{4}$

Method

Design

Meta-analysis was used to determine the influence of practice, feedback, and fidelity-related issues on the effectiveness of use-of-force simulation training. A metaanalysis is defined as the statistical analysis of "quantitative summaries of [empirical studies] that describe the typical strength of the effect or phenomenon, its variability, its

\footnotetext{
${ }^{4}$ Due to the lack of measurement options with regard to expertise, years of experience and previous taskrelated training are used as proxy measures in the present analysis. It is acknowledged that this is not ideal, however no other options were available and previous research has relied on variables such as these (e.g., Dochy et al., 2003; Ericsson \& Lehman, 1996).
} 
statistical significance, and the nature of the moderator variables from which one can predict the relative strength of the effect or phenomenon" (Rosenthal, 1995, p. 183). The goal of a meta-analysis is to generalize research findings and to identify the practicality of those results. It conforms to the same structure as most empirical studies by defining a problem, outlining the hypotheses, defining variables of interest, measuring those variables, sampling a population, and analyzing the data (Rosenthal, 1984).

In order to measure the impact of these training related issues on the effectiveness of use-of-force simulation training, reported and estimated effect sizes were used. An effect size in this case provides a quantified measure of the degree to which the experimental group (e.g., those receiving simulation training) and the control group (e.g., those receiving no simulation training, or a variation of the simulation training received by the experimental group) differ on a particular outcome measure (e.g., hits on target). Thus, an effect size provides a means by which to compare all of the study findings in the sample (Rosenthal, 1984).

The specific meta-analytic approach taken in the current meta-analysis follows the fixed (versus random) effects model, a common approach taken in many recent metaanalytic studies that are conceptually similar to the one undertaken here (e.g., Andrews \& Dowden, 2005; Arthur Jr., Bennett Jr., Edens, \& Bell, 2003; Gendreau, Goggin, Cullen, \& Andrews, 2001; Sharpe \& Rossiter, 2002). In contrast to the random effects model, a fixed effects model asserts that each effect size obtained from a study in a sample estimate[s] the corresponding population effect with random error that stems only from the chance factors associated with subject-level sampling error in that study, 
i.e., the 'luck of the draw' associated with sampling the subjects in each study from the population of potential subjects. (Lipsey \& Wilson, 2001, p. 117) Thus, under this model it is assumed that the sample of effect sizes under study should be relatively homogeneous and that any variation in effect sizes across studies does not exceed that which is due purely to sampling error (Lipsey \& Wilson, 2001).

If this is not found to be the case (i.e., studies included in the sample are found to be relatively heterogeneous), a fixed effects model can still be assumed. In this case, the researcher simply needs to make a further assumption that any variability beyond subjectlevel sampling error is systematic (i.e., derived from identifiable, non-random differences between studies) (Lipsey \& Wilson, 2001). The most common way of attempting to explain this excess variability is to examine potential moderator variables that systematically differentiate between research studies with larger or smaller effect sizes (more on what these potential moderators might be below). This was the approach adopted in the present study.

Advantages and Disadvantages of Meta-Analysis

A meta-analysis is considered a literature review, one, however, that differs from most traditional literature reviews that follow a narrative style (Rosenthal, 1984). In contrast to narrative literature reviews, meta-analytic reviews are "more systematic, more explicit, more exhaustive, and more quantitative" (Rosenthal, 1984, p. 17). A metaanalysis affords many other advantages over the traditional narrative review. These include the following:

- Instead of focusing solely on statistical significance, a meta-analysis uses all of the information available regarding outcome measures (Rosenthal, 1984). The use of 
effect sizes enables a comparison both within and across studies of the distribution, magnitude, and direction of those effects (Dowden, 1998).

- Because of the in-depth and thorough coding procedures used in meta-analyses, a large number of variables and their corresponding relationships can be investigated. This includes a statistical examination of the possible effects that methodological variables (e.g., gender of instructors, etc.) may have on the results (Glass, McGaw, \& Smith, 1981).

- A meta-analysis allows for the identification of any moderating variables, which can be statistically tested to determine the effects, if any, on the results (Glass et al., 1981; Rosenthal, 1984).

- A meta-analysis allows for the production of more reliable and valid conclusions because the results are quantified and the analysis is conducted statistically. Bias within the results due to subjective assessment is reduced (Rosenthal, 1984).

- Due to the rigorous coding methods and the inclusion of the source of the studies, replication of such studies can be accomplished easily. This allows a determination to be made as to whether the conclusions are empirically based or the product of bias (Dowden, 1998).

However, just as there are advantages, meta-analysis is not without its problems. These include the following:

- It is felt by some that adequate conclusions cannot be obtained from a sample of studies that differ in terms of their methodology (Glass et al., 1981). This is referred to as the apples to oranges debate and it posits that meta-analyses combine findings from studies that are not the same. However, Glass and his 
colleagues (1981) have addressed this concern by stating that, if generalizations across subjects occur in a study, generalizations across studies should not be looked at any differently. As was illustrated above, variables relating to methodology are coded for and statistically analyzed to determine whether they affect the results.

- The sample of studies includes designs both of weak and high quality and this may affect the obtained results (Glass et al., 1981; Rosenthal, 1984). However, this can also be coded for and empirically tested to determine the impact, if any, on the results (e.g., blind assignment vs. unblind assignment, random assignment vs. non-random assignment, baseline measures of performance vs. no baseline measures, etc.). According to Wolf (1986), reviews conducted in the past have failed to find this result. As a further precaution, if it is found that the quality of studies affects the results, than a weighting system can be used to de-emphasize studies of poor quality (Rosenthal, 1984).

- There is also a potential problem with results being affected by publication bias, meaning that if the studies in the sample are mainly articles from refereed journals, they will be more likely to favour significant results (Rosenthal, 1984). The concern is that the effect size estimates will be inflated. Although this criticism is warranted, meta-analyses can include studies from other sources (e.g., books, theses, dissertations, technical reports, unpublished manuscripts, etc.). Therefore, a study's level of publication can be coded for and statistically tested to determine whether the source of the study affects the results. 
- There is also concern that multiple results from the same study are incorporated into a meta-analysis (Glass et al., 1981). This would result in biased results, as the data would no longer be independent. To combat this issue, only a single outcome measure from each study should be included in the meta-analysis. In cases where there are several of the same outcome measures, the researcher should randomly choose one of them or take the average (Glass et al., 1981; Lipsey \& Wilson, 2001; Rosenthal, 1984).

\section{Sample of Studies}

The sample of studies collected by the present investigator focused on any and all studies dealing with use-of-force simulation training in the military domain. Computer searches of PsycINFO, Web of Science, ERIC, Dissertation Abstracts International, the US Army Research Institute, Google, the Defense Technical Information Center (DTIC), among other databases encountered, were conducted using the following key words: force; military; military simulations; military simulators; principles of training; simulation; simulation training; simulators; simulator training; training; training effectiveness; use-of-force; use-of-force simulation; use-of-force simulation training; useof-force simulation training effectiveness; use-of-force simulators; and weapon simulators. The reference sections of all articles and reports found with this search were also examined for other potential studies. In addition, several researchers (within North America and internationally) have been contacted in order to obtain any other relevant unpublished articles, reports, or data that may be included..$^{5}$

Articles selected for inclusion in the present study had to possess the following characteristics: 
- Only those studies focusing on use-of-force training using a simulator in the military domain are included. Any branch of the military is acceptable as long as use-of-force decision-making is the basis of the training and the training is conducted using a simulator.

- The study must include an experimental group of participants receiving some form of use-of-force simulation training compared to a control group not receiving the same training (including no training). It is acceptable for the control group to receive an alternate form of training as long as it is clear that the two groups received different forms of training. Training of the experimental group can be in any form as long as it involves the use of a simulator.

- The study should include a description of the training received by the participants. If insufficient information is included, such that it is unclear what the training involved, the study was excluded.

- An outcome measure of training effectiveness must be included. This measure can either be subjective (i.e., qualitative) or objective (i.e., quantitative) in nature. However, enough information must be present to allow the calculation of an effect size (i.e., sample size, $p$ values, etc.).

- Information relating to at least one of the three factors of practice, feedback, and/or fidelity must be included. Any mention of any factor is acceptable provided that enough information is included so it can be coded and analyzed. Otherwise, the study was excluded.

\footnotetext{
${ }^{5}$ For a list of all researchers contacted please see Appendix A.
} 


\section{Coding Manual}

A coding manual was designed by the primary author to be used for the metaanalytic review (see Appendix B). This manual focuses on several key areas: (1) study characteristics (e.g., year of publication, participant assignment, etc.), (2) sample characteristics (e.g., experience level, previous training, etc.), (3) factors related to training (i.e., practice, feedback, and fidelity), (4) outcome variables (e.g., performance measures that were considered), and (5) reported statistics (to calculate effect sizes). ${ }^{6}$ See Table 1 for a partial list of the coded variables.

Study and sample characteristics. Several study and sample characteristics were coded. The majority of these variables (e.g., year of publication, publication source, participant assignment, etc.) were coded because they are frequently examined in metaanalytic research and provide typical sources of variability in effect size distributions (Glass et al. 1981; Rosenthal, 1984). The remaining variables (experience level and previous training) were coded because of theoretical rationale provided in the introduction. 
Table 1

A partial list of the variables coded for and examined in the present meta-analysis.

$\begin{array}{ccc}\begin{array}{c}\text { Study and Sample } \\ \text { Characteristics }\end{array} & \text { Training Factors } & \text { Training Effectiveness }\end{array}$

1) Year of publication

2) Publication source

3) Selection bias

4) Participant assignment

5) Experience level

6) Previous task-related training
1) Practice

a) Amount

b) Type of tasks (part, whole)

c) Distribution (massed, spaced)

2) Feedback

a) Source (intrinsic, augmented)

b) Quality (corrective, explanatory, none)

3) Fidelity

a) Degree (high, low)
1) Accuracy

a) Number of hits on target

b) $\%$ of enemy targets killed

2) Judgment/Problem Solving

a) Time to acquire targets

b) Time to plan mission

3) Maneuvering

a) Distance traveled

b) Distance from targets

4) Communication

a) Time to report battle location to base

b) Number of combat reports sent to base with correct information

Training factors. The various training factors discussed above represent the independent variables in the current analysis. Initially, the studies were coded as to whether or not they compared groups receiving simulation training to groups not receiving simulation training. This was done to determine whether greater effects are observed within training contexts that incorporate simulations. In addition, issues related to each of the other training factors, including the amount of practice (more vs. less), the

\footnotetext{
${ }^{6}$ The coding manual in Appendix B is quite extensive. However, for the purpose of the current study not all of the variables coded for will be analyzed. Large portions of the variables in the manual are included for future research. The variables focused on in this thesis are marked with an asterisk.
} 
source of feedback (augmented vs. no augmented), and the degree of fidelity (high vs. low), among others, were coded.

Training effectiveness. The dependent variable in the current study is training effectiveness. In a military context, this construct refers to the ability of soldiers to meet various learning objectives and training standards (Army Research Institute, 1996). Thus, in the current study, training effectiveness is operationalized as the performance measures adopted in the current sample of studies (e.g., number of hits on target, the time it takes to acquire an enemy target, number of reports sent back to base, etc.). Due to the wide range of measures reported, several aggregate categories of performance measures were constructed. These include accuracy-, judgment/problem solving-, maneuvering-, and communication-based measures (see Appendix $\mathrm{C}$ for a comprehensive list of the performance measures included in each aggregate category). These categories selected because they are the ones that are focused on by the military in North America (US Army Field Manual, 1992).

The reasons for aggregating the performance measures was two-fold: (1) to ensure that an appropriate number of effect sizes were available for analysis (in some cases, only one or two effect sizes could be calculated for some performance measures) and (2) to provide some indication as to what types of skills are learned more effectively in a simulation training context (e.g., are larger effect sizes observed for accuracy-based performance measures compared to communication-based performance measures, etc.). Inter-Rater Reliability

Once all of the studies were collected and assessed according to the inclusion criteria they were coded using the manual described above and provided in Appendix B. 
A research assistant, blind to the purpose of the review, was trained in the scoring of the manual and was given a preliminary sample of two studies to code. Once these studies were coded, the student and the present investigator discussed any discrepancies in scoring to ensure that the coding manual was free from problems (the manual was revised when necessary). After the present investigator finished the coding of all the articles, the research assistant was provided with a random sample of articles ( $25 \%$ were coded). The rater was required to code this portion of studies independently without any input from the present investigator.

Inter-rater reliability was assessed by calculating the percent agreement between the two coders on the $25 \%$ of studies. Percent agreement is determined by dividing the number of correct coding classifications (i.e., where there was agreement between the coders) by the total number of coding classifications. Inter-rater reliability was determined for two sets of variables: (1) for all of the variables contained in the coding manual (minus any open-ended questions) ${ }^{7}$ and (2) for those variables of interest in the current study (e.g., all variables pertaining to the training factors of interest, the sample characteristics, and any other moderating variables). The percent agreement was $68 \%$ for the entire manual and $65 \%$ for the specific variables under study. ${ }^{8}$ Any discrepancies found between the researcher and the coder were discussed, and all subsequent analyses are based on $100 \%$ agreement.

\footnotetext{
${ }^{7}$ The open-ended questions contained in the coding manual were not analyzed in the present study and were obtained for future research only.

${ }^{8}$ Although the levels of inter-rater reliability that were obtained are considered acceptable, significantly larger values were obtained when a single study, which was the source of most of the discrepancies between the coder and researcher, was removed. The values that were obtained when this single study was omitted from the calculation was $74 \%$ for the entire manual and $73 \%$ for the variables of interest.
} 


\section{Data Analysis}

Calculating effect sizes. Effect sizes were calculated for each study in the sample to determine the impact that the specific training factors, outlined in the literature review, have on training effectiveness. The effect size adopted was the commonly used Cohen's $d$, where $d=\left(M_{1}-M_{2}\right) / s d$ (Wolf, 1986). In this case, $M_{1}$ is the mean training effectiveness for group 1 (experimental), $M_{2}$ is the mean training effectiveness for group 2 (control), and $s d$ is the pooled standard deviation. In the context of this thesis, $d$ refers to the standardized difference between the means (for a specific training outcome measure) obtained from trainees taking part in the experimental and control conditions (see Appendix D for a listing of the statistical conversions and their formulae). It should be noted that Cohen's $d$ suffers from a slight upward bias when based on small samples (Lipsey \& Wilson, 2001). Thus, all of the effect sizes were corrected using the following formula: corrected $d=1-(3 /[4 N-9])(d)$ (Lipsey \& Wilson, 2001), where $N$ is equal to sample size. Applying this correction provides a more appropriate (i.e., less inflated) set of effect sizes for analysis.

To estimate the effect size across all studies (indicating whether, on average, simulation training that incorporates a particular training factor results in greater training gains), average effect sizes must be calculated. Average effect sizes are calculated as $d_{c o r r}$ $=\Sigma d / n$, where $d$ is the corrected effect size for each study, and $n$ is the total number of studies (Wolf, 1986). In addition to these average corrected effect sizes (henceforth referred to as un-weighted effect sizes), mean weighted effect sizes $\left(d_{w}\right)$ will also be calculated. A mean weighted effect size is calculated by summing each effect size for a particular contrast (e.g., more versus less practice), multiplying that sum by its inverse 
variance $(w)$, and then dividing by the sum of the weights (i.e., inverse variances). This weighting procedure gives more weight to those effect sizes calculated from studies with larger sample sizes since they have less sampling error than the statistics calculated from smaller samples (Glass et al., 1981; Lipsey \& Wilson, 2001; Rosenthal, 1984). ${ }^{9}$ For this reason, the mean weighted effect sizes are focused on in this study when results are reported and interpreted. The statistical significance of the mean weighted effect sizes was determined by calculating $95 \%$ confidence intervals, with the assumption that, "if the confidence interval does not include zero, then the mean effect size is statistically significant" (Lipsey \& Wilson, 2001, p. 114).

Interpreting effect sizes. Once average weighted effect sizes are calculated there is a need to interpret them. Cohen (1988) provides rough guidelines for this purpose. He suggests that effect sizes ranging from .20 to .50 represent small effects, .50 to .80 represent moderate effects, and .80 or greater represent large effects. In addition to interpreting the effect sizes in this way, Cohen's (1988) $U_{3}$ will be calculated for each weighted effect size to indicate the degree of overlap between the control and experimental groups. As an example, if $d_{w}=.32$ for the contrast, more versus less practice, then Cohen's $U_{3}=.63$ (values of $U_{3}$ are obtained from a table provided by Cohen, 1988). This means that the average trainee, exposed to a simulation training program consisting of more practice, would have an outcome (e.g., a shooting accuracy score) greater than $63 \%$ of the trainees receiving less practice.

\footnotetext{
${ }^{9}$ The weighting procedure should not be confused with the procedure used to initially correct the effect sizes, although both are related to sample size. The correction is done to prevent the use of inflated effect sizes, and the weighting procedure ensures that those effect sizes obtained from larger sample studies are given more weight in the analysis.
} 
Effect size independence. Two effect sizes from the same study are considered to lack independence (Glass et al., 1981; Lipsey \& Wilson, 2001; Rosenthal, 1984). Thus, in the present meta-analysis, if a study provided multiple effect sizes for the same performance measure (e.g., hits on target), the separate effects were averaged to provide a single statistic. However, in cases where different sub-samples of participants contributed multiple effect sizes for the same performance measure in the same study, these effect sizes were treated independently. This procedure is consistent with the procedures followed in other meta-analyses (e.g., Arthur Jr. et al., 2003; Burke et al., 2006; Glass et al., 1981; Rosenthal, 1984; Wolf, 1986).

Examining the impact of potential moderator variables. As indicated above, it is possible that instead of having a homogeneous distribution of effect sizes across studies (as assumed with the fixed effects model), the distribution is heterogeneous (i.e., the variation in effect sizes around the mean exceeds that due to sampling error) (Lipsey \& Wilson, 2001). Under these conditions, various moderator variables are expected to account for this variation. In general, a moderator variable "is a qualitative (e.g., sex, race, class) or quantitative (e.g., level of reward) variable that affects the direction and/or strength of the relation between an independent or predictor variable and a dependent or criterion variable" (Baron \& Kenny, 1986, p. 1174). The moderator variables included in this study consist of study and sample characteristics as well as some training factors. A listing is provided in Table 2 . 


\section{Table 2}

Moderator variables examined in the current study.

\begin{tabular}{ll}
\hline \multicolumn{1}{c}{ Study and Sample Characteristics } & \multicolumn{1}{c}{ Training Factors } \\
\hline Year of publication & Type of tasks practiced \\
Publication source & Distribution of practice sessions \\
Selection bias & Source of feedback \\
Participant assignment & Quality of feedback \\
Experience level & \\
Previous task-related training & \\
\hline
\end{tabular}

Conducting moderator analyses will illuminate any variability beyond subjectlevel sampling error. Initially, overall tests of heterogeneity will be conducted on the training factors of interest based on the inclusion of unaggregated performance measures and all aggregate categories. This will be done using the $Q$ statistic, which follows a chisquare distribution (Wolf, 1986). A significant $Q$ indicates a heterogeneous subset of effect sizes. For example, if a significant $Q$ statistic is found for the subset of effect sizes obtained from studies examining more versus less practice, there is significant variability among these studies. Moderator variables may account for this variability.

The method used to analyze the variability found in the effect sizes (indicated by a significant $Q$ ) is referred to as 'analog to the ANOVA' (Lipsey \& Wilson, 2001). This method essentially tests the ability of a categorical variable (e.g., published or unpublished), to explain the excess effect size variability. The procedure involves partitioning the total variability into the portion explained by the categorical variable $\left(Q_{b}\right)$ and the residual or remaining portion $\left(Q_{w}\right)$ (Lipsey \& Wilson, 2001). More specifically, $Q_{b}$ is equal to the variation between the means of each category of the moderator variable (e.g., published versus unpublished), and $Q_{w}$ is equal to the variation within the categories of a moderator variable. According to Lipsey and Wilson, 
If significant variability is explained by the [moderator] variable (a significant $Q_{b}$ ) then the mean effect sizes across categories differ by more than sampling error, that is, show a statistically significant difference. If $Q_{w}$ is not statistically significant, the [moderator] variable represented in $Q_{b}$ is sufficient to account for the excess variability in the effect size distribution. ( p. 136)

In addition to calculating these statistics, average weighted effect sizes were calculated for each of the moderator variables as well as $95 \%$ CIs. For example, average effect sizes for published versus unpublished studies were calculated separately for those studies examining a specific training factor (e.g., more versus less practice). The $C I s$ are interpreted in the same manner as described above.

\section{Results}

Thirty-two independent research studies were originally obtained, however, 17 studies either did not include the necessary information needed to calculate effect sizes or did not meet all of the inclusion criteria outlined for the present study. Thus, these studies were excluded from all subsequent analyses. The final number of studies included in the present analysis is 15, of which three are published and 12 are unpublished (see Table 3 for a list of all 15 studies, year of publication, simulator used, and the variables and performance measures of interest). The studies yielded a total of 144 individual effect sizes based on the training factors outlined above for both aggregated and unaggregated performance measures. See Table 4 for a breakdown of how many of the 15 studies incorporate the training factors (i.e., contrasts) of interest in the present meta-analysis. 
Table 3

Studies included in the present meta-analysis.

\begin{tabular}{|c|c|c|c|c|}
\hline Author(s) & $\begin{array}{l}\text { Year of } \\
\text { Study }\end{array}$ & Simulator Used & $\begin{array}{c}\text { Variable(s) Under } \\
\text { Study }\end{array}$ & Outcome Variable(s) \\
\hline $\begin{array}{l}\text { Campshure, Witmer, and } \\
\text { Drucker }\end{array}$ & 1990 & $\begin{array}{l}\text { M1 Unit Conduct-of-Fire Trainer (U- } \\
\text { COFT) }\end{array}$ & $\begin{array}{l}\text { More vs. Less } \\
\text { Practice }\end{array}$ & $\begin{array}{l}\text { Accuracy } \\
\text { Judgment/Problem Solving }\end{array}$ \\
\hline DuBois and Smith & 1991 & $\begin{array}{l}\text { SIMulation NETwork-D M1 Tank } \\
\text { Simulator }\end{array}$ & High vs. Low Fidelity & $\begin{array}{l}\text { Accuracy } \\
\text { Judgment/Problem Solving } \\
\text { Maneuvering } \\
\text { Communication }\end{array}$ \\
\hline $\begin{array}{l}\text { Elliot, Wong, Dreby, and } \\
\text { Jarboe }\end{array}$ & 1995 & $\begin{array}{l}\text { Vehicle Integrated Defense System } \\
\text { (VIDS) }\end{array}$ & High vs. Low Fidelity & $\begin{array}{l}\text { Accuracy } \\
\text { Judgment/Problem Solving } \\
\text { Maneuvering }\end{array}$ \\
\hline Gray and Fuller & 1977 & $\begin{array}{l}\text { Advanced Simulator for Pilot } \\
\text { Training (ASPT) }\end{array}$ & High vs. Low Fidelity & Accuracy \\
\hline $\begin{array}{l}\text { Hughes, Paulsen Jr., } \\
\text { Brooks, and Jones }\end{array}$ & 1978 & $\begin{array}{l}\text { Advanced Simulator for Pilot } \\
\text { Training (ASPT) }\end{array}$ & $\begin{array}{l}\text { Augmented vs. No } \\
\text { Augmented Feedback } \\
\text { Part-to-Whole vs. } \\
\text { Whole Task Practice }\end{array}$ & Accuracy \\
\hline Lampton et al. & 2001 & $\begin{array}{l}\text { Fully Immersive Team Training } \\
\text { (FITT) System }\end{array}$ & $\begin{array}{l}\text { Augmented vs. No } \\
\text { Augmented Feedback }\end{array}$ & Judgment/Problem Solving \\
\hline $\begin{array}{l}\text { Leibrecht, Meade, } \\
\text { Schmidt, Doherty, and } \\
\text { Lickteig }\end{array}$ & 1994 & Mounted Warfare Test Bed (MWTB) & $\begin{array}{l}\text { High vs. Low Fidelity } \\
\text { Simulation vs. No } \\
\text { Simulation Training }\end{array}$ & $\begin{array}{l}\text { Accuracy } \\
\text { Judgment/Problem Solving } \\
\text { Maneuvering } \\
\text { Communication }\end{array}$ \\
\hline $\begin{array}{l}\text { Lintern, Thomley, Nelson, } \\
\text { and Roscoe }\end{array}$ & 1984 & $\begin{array}{l}\text { Visual Technology Research } \\
\text { Simulator (VTRS) }\end{array}$ & $\begin{array}{l}\text { High vs. Low Fidelity } \\
\text { Augmented vs. No } \\
\text { Augmented Feedback }\end{array}$ & Accuracy \\
\hline McAnulty & 1992 & $\begin{array}{l}\text { AH-1 Flight and Weapons Simulator } \\
\text { (FWS) }\end{array}$ & $\begin{array}{l}\text { More vs. Less } \\
\text { Practice }\end{array}$ & $\begin{array}{l}\text { Accuracy } \\
\text { Judgment/Problem Solving }\end{array}$ \\
\hline
\end{tabular}


Pleban, Dyer, Salter, and

\section{Brown}

Salter, Eakin, and Knerr

Schlechter, Bessemer, and Kolosh

Reading, Kincaid, Roberts, Hesslink, and Pozos

White, Carson, and

Wilbourn

White, Carson, and

Wilbourn
1998

Virtual Individual Combatant Simulator (VIC)

1999 Virtual Individual Combatant Simulator (VIC)

1992 SIMulation NETworking System (SIMNET)

1994 Noptel Laser Rifle Training System ST-1000PC

$1991 \mathrm{a}$ FATS
Simulation vs. No Simulation Training High vs. Low Fidelity

High vs. Low Fidelity Maneuvering

Simulation vs. No Simulation Training

High vs. Low Fidelity

More vs. Less

Practice

High vs. Low Fidelity

High vs. Low Fidelity

Maneuvering

Accuracy

Accuracy

Accuracy
Judgment/Problem Solving

Judgment/Problem Solving

Communication

1991b FATS 
Table 4

Percentage of studies examining various training factors (i.e., contrasts) of interest in the present meta-analysis.

\begin{tabular}{|c|c|}
\hline Training Factor & $\%$ (Proportion) \\
\hline Simulation training vs. no simulation training & $20(3 / 15)$ \\
\hline \multicolumn{2}{|l|}{ Practice } \\
\hline Amount (more vs. less) & $(3 / 15)$ \\
\hline Distribution (part-to-whole vs. whole task) & $(1 / 15)$ \\
\hline \multicolumn{2}{|l|}{ Feedback } \\
\hline Source (augmented vs. no augmented) & $(3 / 15)$ \\
\hline \multicolumn{2}{|l|}{ Fidelity } \\
\hline Degree (high vs. low) & $67(10 / 15)$ \\
\hline
\end{tabular}

Analysis of Main Effects

Following the fixed effects model (as outlined above), mean un-weighted and weighted effect sizes were examined along with their distributions according to aggregated and unaggregated performance measures. ${ }^{10}$ For the sake of brevity, the results presented within this section are restricted to aggregated performance measures. For the results related to unaggregated measures refer to Appendix E.

Simulation training vs. no simulation training. Studies providing data on simulation training versus no simulation training provided 14 effect sizes from 1401 participants resulting in a mean weighted effect size $\left(d_{w}\right)$ of $.21(S D=.05)$, an associated $95 \%$ confidence interval ( $C D)$ of .10 to .31 , and a $U_{3}$ value of .58 (see Table 5). Thus, incorporating simulation training versus other forms of training into use-of-force contexts produces a significant, but small effect and, on average, individuals receiving simulation 
training perform better than $58 \%$ of those who do not receive simulation training. A similar result is observed when examining the aggregate category of accuracy $\left(d_{w}=.18\right.$, $S D=.05, C I=.07$ to $\left..28, U_{3}=.57\right)$, with even larger effect sizes observed for the judgment/problem solving $\left(d_{w}=.94, S D=.45, C I=.04\right.$ to $\left.1.82, U_{3}=.83\right)$ and maneuvering categories $\left(d_{w}=.94, S D=.45, C I=.05\right.$ to $\left.1.83, U_{3}=.83\right)($ the communication category could not be examined because none of the studies comparing simulation training to other forms of training incorporated performance measures of this type).

\footnotetext{
${ }^{10}$ In some cases, effect sizes for aggregate performance measures are not provided due to the small number of effect sizes. In addition, not all unaggregated performance measures were used in each study and thus they are not available to report.
} 
Table 5

Mean effect of simulation training versus no simulation training on aggregated outcome measures of training effectiveness.

\begin{tabular}{|c|c|c|c|c|c|c|}
\hline Contrast $(k)$ & $N$ & $d_{\text {corr }}(S D)$ & $C I_{d c o r r}$ & $d_{w}(S D)$ & $C I_{d w}$ & $U_{3}$ \\
\hline $\begin{array}{l}\text { Simulation Training vs. No } \\
\text { Simulation Training (14) }\end{array}$ & 1401 & $.90(.06)$ & .80 to 1.00 & $.21(.05)$ & .10 to .31 & .58 \\
\hline Accuracy (8) & 1401 & $.85(.06)$ & .75 to .95 & $.18(.05)$ & .07 to .28 & .57 \\
\hline Judgment/Problem Solving (4) & 24 & $.98(.49)$ & .34 to 1.61 & $.94(.32)$ & .30 to 1.57 & .83 \\
\hline Maneuvering (2) & 24 & $.95(.49)$ & .06 to 1.84 & $.94(.45)$ & .05 to 1.83 & .83 \\
\hline
\end{tabular}


More practice vs. less practice. When examining more versus less practice, 27 effect sizes were obtained from 455 participants resulting in a $d_{w}$ of $.18(S D=.04)$, an associated $95 \%$ CI of .10 to .27 , and a $U_{3}$ value of .57 (see Table 6). Thus, incorporating more versus less practice in use-of-force simulation training contexts produces a significant, but small effect and, on average, individuals receiving more practice perform better than $57 \%$ of those who receive less practice. When examining the aggregate categories, a very small but significant effect was found for accuracy $\left(d_{w}=.11, S D=.05\right.$, $C I=.01$ to $.21, U_{3}=.54$ ), a significant small effect was found for judgment/problem solving $\left(d_{w}=.37, S D=.08, C I=.20\right.$ to $\left..53, U_{3}=.64\right)$, and lastly, a significant moderate effect was found for maneuvering $\left(d_{w}=.75, S D=.52, C I=-.27\right.$ to $1.76, U_{3}=.77$ ) (again, the communication measures were not utilized in these studies).

Part-to-whole-task practice vs. whole-task practice. Only one effect size was obtained from a single study of 16 participants examining the effect of part-to-whole-task vs. whole-task practice (see Table 6). A small $d_{w}$ of $.25(S D=.54)$ was obtained, with a $U_{3}$ of .60 , indicating that participants who receive simulation training incorporating partto-whole-task practice exhibit greater performance than those who do not receive such training. However, given that this effect is based on a single study, it should be interpreted cautiously. 
Table 6

Mean corrected $d$ and mean weighted $d$ for the influence of practice on aggregated outcome measures of training effectiveness.

\begin{tabular}{|c|c|c|c|c|c|c|}
\hline Contrast $(k)$ & $N$ & $d_{\text {corr }}(S D)$ & $C I_{d c o r r}$ & $d_{w}(S D)$ & $C I_{d w}$ & $U_{3}$ \\
\hline More Practice vs. Less Practice (27) & 455 & $.14(.09)$ & .06 to .23 & $.18(.04)$ & .10 to .27 & .57 \\
\hline Accuracy (18) & 455 & $.05(.09)$ & -.05 to .15 & $.11(.05)$ & .01 to .21 & .54 \\
\hline Judgment/Problem Solving (8) & 288 & $.28(.12)$ & .11 to .44 & $.37(.08)$ & -20 to .53 & .64 \\
\hline Maneuvering (1) & 16 & $.75(.52)$ & -.27 to 1.76 & - & - & .77 \\
\hline Part to Whole-task Practice vs. Whole-task Practice (1) & 16 & $.25(.54)$ & -.81 to 1.31 & - & - & .60 \\
\hline Accuracy (1) & 16 & $.25(.54)$ & -.81 to 1.31 & - & - & .60 \\
\hline
\end{tabular}

Note. When only 1 effect size is available it is provided as the average corrected effect size. $k=$ number of effect sizes; $N=$ total sample size; $d_{c o r r}=$ average corrected effect size; $S D=$ standard deviation; $C I_{c o r r}=95 \%$ confidence interval around the average corrected effect size; $d_{w}=$ mean weighted effect size; $C I_{d w}=$ $95 \%$ confidence interval around the mean weighted effect size; $U_{3}=$ Cohen's $U_{3}$ (Cohen, 1988) for effect size interpretation. 
Augmented feedback vs. no augmented feedback. When examining augmented versus no feedback, nine effect sizes were obtained from 270 participants resulting in a $d_{w}$ of $.41(S D=.12)$, an associated $95 \% C I$ of .18 to .64 , and a $U_{3}$ value of .66 (see Table 7). Thus, incorporating augmented feedback in use-of-force simulation training contexts produces a significant moderate effect and, on average, individuals receiving augmented feedback during simulation training perform better than $68 \%$ of those who receive no augmented feedback. When examining the aggregate categories, a small effect was found for accuracy $\left(d_{w}=.07, S D=.15, C I=-.23\right.$ to $\left..38, U_{3}=.53\right)$, but a much larger effect was found for maneuvering $\left(d_{w}=.85, S D=.18, C I=.50\right.$ to $\left.1.19, U_{3}=.80\right)$ (judgment/problem solving and communication measures were not used in these studies). 
Table 7

Mean corrected $d$ and mean weighted $d$ for the influence of feedback on aggregated outcome measures of training effectiveness.

\begin{tabular}{lcccccc} 
Contrast $(k)$ & $N$ & $d_{\text {corr }}(S D)$ & $C I_{d c o r r}$ & $d_{w}(S D)$ & $C I_{d w}$ & $U_{3}$ \\
\hline Augmented Feedback vs. No Augmented Feedback (9) & 270 & $.22(.12)$ & -.01 to .45 & $.41(.12)$ & .18 to .64 & .66 \\
& & & & & & \\
Accuracy (7) & 172 & $.04(.15)$ & -.26 to .35 & $.07(.15)$ & -.23 to .38 & .53 \\
$\quad$ & 98 & $.85(.25)$ & .50 to 1.19 & $.85(.18)$ & .50 to 1.19 & .80 \\
\hline
\end{tabular}

Note. When only 1 effect size is available it is provided as the average corrected effect size. $k=$ number of effect sizes; $N=$ total sample size; $d_{c o r r}=$ average corrected effect size; $S D=$ standard deviation; $C I_{c o r r}=95 \%$ confidence interval around the average corrected effect size; $d_{w}=$ mean weighted effect size; $C I_{d w}=$ $95 \%$ confidence interval around the mean weighted effect size; $U_{3}=$ Cohen's $U_{3}$ (Cohen, 1988) for effect size interpretation. 
High fidelity vs. low fidelity. With respect to high versus low fidelity, 93 effect sizes were obtained from 1398 participants resulting in a $d_{w}$ of $1.00(S D=.02)$, an associated $95 \% \mathrm{Cl}$ of .95 to 1.05 , and a $\mathrm{U}_{3}$ value of .84 (see Table 8). Thus, incorporating high fidelity into use-of-force simulation training contexts produces a large effect and, on average, individuals receiving simulation training with high fidelity perform better than $84 \%$ of those who receive simulation training with low fidelity. When examining the aggregate categories, significant large effects were found for accuracy $\left(d_{w}=.84, S D=\right.$ $.06, C I=.73$ to $\left..96, U_{3}=.80\right)$, judgment/problem solving $\left(d_{w}=1.03, S D=.07, C I=.92\right.$ to $\left.1.58, U_{3}=.85\right)$, maneuvering $\left(d_{w}=.81, S D=.05, C I=.72\right.$ to $\left..90, U_{3}=.79\right)$, and communication $\left(d_{w}=1.27, S D=.04, C I=1.18\right.$ to $\left.1.36, U_{3}=.90\right)$. 
Table 8

Mean corrected $d$ and mean weighted $d$ for the influence of fidelity on aggregated outcome measures of training effectiveness.

\begin{tabular}{lcccccc}
\hline Contrast $(k)$ & $N$ & $d_{\text {corr }}(S D)$ & $C_{d c o r r}$ & $d_{w}(S D)$ & $C I_{d w}$ & $U_{3}$ \\
\hline High Fidelity vs. Low Fidelity (93) & 1398 & $.82(.06)$ & .77 to .87 & $1.03(.02)$ & .95 to 1.05 & .84 \\
Accuracy (25) & 1352 & $.74(.06)$ & .62 to .85 & $.84(.06)$ & .73 to .96 & .80 \\
Judgment/Problem Solving (18) & 492 & $.87(.10)$ & .74 to 1.00 & $1.03(.07)$ & .90 to 1.16 & .85 \\
Maneuvering (28) & 752 & $.53(.08)$ & .44 to .62 & $.81(.05)$ & .72 to .90 & .79 \\
Communication (22) & 560 & $1.26(.10)$ & 1.17 to 1.34 & $1.27(.04)$ & 1.18 to 1.36 & .90 \\
\hline
\end{tabular}

Note. When only 1 effect size is available it is provided as the average corrected effect size. $k=$ number of effect sizes; $N=$ total sample size; $d_{\text {corr }}=$ average corrected effect size; $S D=$ standard deviation; $C I_{c o r r}=95 \%$ confidence interval around the average corrected effect size; $d_{w}=$ mean weighted effect size; $C I_{d w}=$ $95 \%$ confidence interval around the mean weighted effect size; $U_{3}=$ Cohen's $U_{3}$ (Cohen, 1988$)$ for effect size interpretation 
Moderator Analysis

Due to the diversity of studies included in the present analysis, tests for heterogeneity were conducted (see Table 9). The present sample was found to contain a relatively heterogeneous effect size distribution indicating that there are differences among the effect sizes that have some source beyond subject-level sampling error (Lipsey \& Wilson, 2001). More specifically, a significant $Q$ was found for those studies comparing simulation training versus no simulation training $(p<.05)$, more versus less practice $(p<.001)$, and high versus low fidelity $(p<.001) .{ }^{11}$ As a result, an examination of potential moderators will be conducted to determine if they can explain any of the variation in these effect sizes (see Tables 10,11, and 12 below). A significant $Q$ was not found for the effect size distributions of those studies examining the provision of augmented feedback. However, because this comparison was based on only seven to nine effect sizes (which, in turn, were obtained from studies with relatively small samples) the test of heterogeneity suffers from a lack of power (i.e., heterogeneity may not be found even when there is considerable variability among effect sizes) (Lipsey \& Wilson, 2001). Thus, potential moderators were examined for this contrast as well (see Table 11). ${ }^{12}$

\footnotetext{
${ }^{11}$ Since multiple comparisons are conducted in the moderator analyses, a Bonferroni correction was used to determine the significance levels of all moderator variables.

${ }^{12}$ In addition, according to Hall and Rosenthal (1991), an examination of moderator variables is always warranted when based on a theoretical rationale, regardless of the results of the heterogeneity test.
} 
Table 9

$Q$ statistics for the heterogeneity analysis of the training factors (overall and according to the aggregate categories of performance measures).

\begin{tabular}{lcc}
\hline Training Factor & $Q(d f)$ & $p$ \\
\hline Simulation Training vs. No Simulation Training & $26.25(13)$ & $<.05$ \\
Accuracy & $15.99(7)$ & $<.05$ \\
Judgment/Problem Solving & $2.01(3)$ & $\mathrm{ns}$ \\
Maneuvering & $0.21(1)$ & $\mathrm{ns}$ \\
Communication & - & - \\
& & \\
More vs. Less Practice & $57.14(26)$ & $<.001$ \\
Accuracy & $42.88(17)$ & $<.001$ \\
Judgment/Problem Solving & $6.47(7)$ & $\mathrm{ns}$ \\
Maneuvering & - & - \\
Communication & - & - \\
& & \\
Augmented vs. No Augmented Feedback & $14.22(8)$ & $\mathrm{ns}$ \\
Accuracy & $3.23(6)$ & $\mathrm{ns}$ \\
Judgment/Problem Solving & - & - \\
Maneuvering & $0.112(1)$ & $\mathrm{ns}$ \\
Communication & - & - \\
High vs. Low Fidelity & & \\
Accuracy & $1276.89(92)$ & $<.001$ \\
Judgment/Problem Solving & $337.32(24)$ & $<.001$ \\
Maneuvering & $310.03(17)$ & $<.001$ \\
Communication & $308.20(27)$ & $<.001$ \\
& $261.00(21)$ & $<.001$ \\
\hline
\end{tabular}


Simulation training vs. no simulation training. Three moderators were significant concerning the contrast, simulation training versus no simulation training. These include two study characteristics (publication source and selection bias) and one training characteristic (whether participants had previous task-related training) (see Table 10). More specifically, stronger effects were found for unpublished studies $\left(d_{w}=.96\right)$ compared to published studies $\left(d_{w}=.12\right)$. In addition, stronger effects were found for studies with no evidence of a selection bias $\left(d_{w}=.97\right)$ compared to those studies where participants were selected based on certain criteria $\left(d_{w}=.15\right)$. Lastly, stronger effects were observed when studies incorporated participants who had previous task-related training $\left(d_{w}=.97\right)$ compared to those where participants had no such training $\left(d_{w}=.82\right)$. These results also hold for the aggregate category of accuracy-based performance measures. 
Table 10

Mean weighted $d, Q$ statistics, and significance levels of significant moderating variables for simulation vs. no simulation training.

\begin{tabular}{|c|c|c|c|c|c|c|c|}
\hline Moderator Variables & $k$ & $d_{w}(S D)$ & $C I_{d w}$ & $Q_{b}\left(d f_{b}\right)$ & $p$ & $Q_{w}\left(d f_{w}\right)$ & $p$ \\
\hline \multicolumn{8}{|c|}{$\begin{array}{l}\text { Simulation Training vs. No Simulation } \\
\text { Training }\end{array}$} \\
\hline \multicolumn{8}{|l|}{ Publication Source } \\
\hline Published & 1 & $.12(.05)$ & .02 to. 23 & $21.72(1)$ & $<.001$ & $4.53(12)$ & $<.975$ \\
\hline Unpublished & 13 & $.92(.16)$ & .60 to 1.23 & & & & \\
\hline \multicolumn{8}{|l|}{ Selection Bias } \\
\hline No & 10 & $.97(.20)$ & .57 to 1.38 & $15.06(1)$ & $<.001$ & $11.19(12)$ & $<.90$ \\
\hline Yes & 4 & $.15(.05)$ & .05 to .26 & & & & \\
\hline \multicolumn{8}{|l|}{ Previous Training } \\
\hline No & 3 & $.82(.26)$ & .31 to 1.33 & $21.94(1)$ & $<.001$ & $4.31(12)$ & $<.975$ \\
\hline Yes & 10 & $.97(.20)$ & .57 to 1.38 & & & & \\
\hline \multicolumn{8}{|l|}{ Accuracy } \\
\hline \multicolumn{8}{|l|}{ Publication Source } \\
\hline Published & 1 & $.12(.05)$ & .02 to .23 & $13.70(1)$ & $<.001$ & $2.29(6)$ & $<.90$ \\
\hline Unpublished & 7 & $.90(.20)$ & .50 to 1.30 & & & & \\
\hline \multicolumn{8}{|l|}{ Selection Bias } \\
\hline No & 4 & $1.03(.32)$ & .39 to 1.66 & $7.06(1)$ & $<.01$ & $8.93(6)$ & $<.20$ \\
\hline Yes & 4 & $.15(.05)$ & .05 to .26 & & & & \\
\hline \multicolumn{8}{|l|}{ Previous Training } \\
\hline No & 3 & $.82(.26)$ & .31 to 1.33 & $13.94(1)$ & $<.001$ & $2.05(6)$ & $<.95$ \\
\hline Yes & 4 & $1.03(.32)$ & .39 to 1.66 & & & & \\
\hline
\end{tabular}


More vs. less practice. Although the effect size distribution was heterogeneous in relation to the contrast, more versus less practice, no significant moderators were identified in the current analysis. It is possible that the moderators examined in the present study do not include those responsible for the variation in these effect sizes (i.e., the variation is due to other, as yet unidentified variables).

Augmented vs. no augmented feedback. Two moderators were significant concerning the contrast, augmented versus no augmented feedback, including one study characteristic (year of publication) and one training characteristic (experience level) (see Table 11). With respect to year of publication, studies published after 1984 have significantly higher effect sizes $\left(d_{w}=.85\right)$ than studies published before $1984\left(d_{w}=.07\right)$. In addition, stronger effects are found for participants with mixed levels of experience $\left(d_{w}\right.$ $=.11)$ compared to participants with only some experience (i.e., 5-10 years) $\left(d_{w}=-.03\right)$.

In contrast to these findings, when considering accuracy-based performance measures selection bias acts as a moderator. In this case, stronger effects are found for studies with no evidence of a selection bias $\left(d_{w}=.11\right)$ compared to those studies where participants were selected based on certain criteria $\left(d_{w}=-.03\right)$. However, consistent with the previous findings, experience level is also found to be a significant moderator. Again, stronger effects were observed for participants with mixed levels of experience $\left(d_{w}=.11\right)$ compared to those with only some experience $\left(d_{w}=-.03\right)$. 
Table 11

Mean weighted $d, Q$ statistics, and significance levels of significant moderating variables for augmented vs. no augmented feedback.

\begin{tabular}{|c|c|c|c|c|c|c|c|}
\hline Moderator Variables & $k$ & $d_{w}(S D)$ & $C I_{d w}$ & $Q_{b}\left(d f_{b}\right)$ & $p$ & $Q_{w}\left(d f_{w}\right)$ & $p$ \\
\hline \multicolumn{8}{|c|}{ Augmented Feedback vs. No Augmented Feedback } \\
\hline \multicolumn{8}{|l|}{ Year of Publication } \\
\hline Up to and Including 1984 & 7 & $.07(.15)$ & -.23 to .38 & $10.88(1)$ & $<.001$ & $3.34(7)$ & $<.90$ \\
\hline After 1984 & 2 & $.85(.18)$ & .50 to 1.19 & & & & \\
\hline \multicolumn{8}{|l|}{ Experience Level } \\
\hline$<1$ year & 0 & & & & & & \\
\hline $5-10$ years & 3 & $-.03(.32)$ & -.65 to .59 & $11.13(1)$ & $<.001$ & $3.09(7)$ & $<.90$ \\
\hline $10-15$ years & 0 & & & & & & \\
\hline Mixed & 4 & $.11(.18)$ & -.24 to .45 & & & & \\
\hline \multicolumn{8}{|l|}{ Accuracy } \\
\hline \multicolumn{8}{|l|}{ Selection Bias } \\
\hline No & 4 & $.11(.18)$ & -.24 to .45 & $11.13(1)$ & $<.001$ & $3.09(5)$ & $<.90$ \\
\hline Yes & 3 & $-.03(.32)$ & -.65 to .59 & & & & \\
\hline \multicolumn{8}{|l|}{ Experience Level } \\
\hline$<1$ year & 0 & & & & & & \\
\hline $5-10$ years & 3 & $-.03(.32)$ & -.65 to .59 & $11.13(1)$ & $<.001$ & $3.09(5)$ & $<.90$ \\
\hline $10-15$ years & 0 & & & & & & \\
\hline Mixed & 4 & $.11(.18)$ & -.24 to .45 & & & & \\
\hline
\end{tabular}

Note. $k=$ number of effect sizes; $N=$ total sample size; $d_{w}=$ mean weighted effect size; $S D=$ standard deviation; $C I_{d w}=95 \%$ confidence interval around the mean weighted effect size; $Q_{b}=$ the $Q$ statistic indicating the variability between means of the categories of moderating variables; $p=$ significance level; $Q_{w}=$ the $Q$ statistic indicating the variability within the categories of moderating variables. 
High vs. low fidelity. There were several significant moderators found when examining the contrast, high versus low fidelity, including three study characteristics (publication source, selection bias, and participant assignment) and six training characteristics (experience level of participants, previous task-related training, tasks practiced, distribution of practice sessions, source of feedback, and type of feedback) (see Table 12).

When examining publication source, unpublished studies $\left(d_{w}=1.07\right)$ compared to published studies $\left(d_{w}=.11\right)$, studies with evidence of selection bias $\left(d_{w}=1.23\right)$ compared to studies without such a bias $\left(d_{w}=.05\right)$, and studies with participants assigned to conditions in a non-random $\left(d_{w}=1.15\right)$ versus random fashion $\left(d_{w}=0\right)$ had larger effect sizes. In addition, stronger effects are found for participants with advanced levels of experience $\left(d_{w}=1.25\right)$ compared to participants with mixed $\left(d_{w}=.51\right)$, some $\left(d_{w}=-1.40\right)$, or little experience $\left(d_{w}=.15\right)$, participants with previous task-related training $\left(d_{w}=1.18\right)$ compared to those without such training $\left(d_{w}=.15\right)$, when whole tasks $\left(d_{w}=1.08\right)$ were practiced compared to part-tasks $\left(d_{w}=.07\right)$, when practice sessions were spaced $\left(d_{w}=\right.$ 1.07) compared to when they were massed $\left(d_{w}=.11\right)$, when the feedback given came from intrinsic and augmented sources $\left(d_{w}=1.12\right)$ compared to intrinsic alone $\left(d_{w}=.04\right)$, and when that feedback was explanatory in nature $\left(d_{w}=1.12\right)$ compared to not receiving any feedback $\left(d_{w}=.04\right)$.

When considering accuracy-based performance measures, the same moderators were found (see Table 12). In contrast, when examining judgment/problem solving-, maneuvering-, and communication-based performance measures only selection bias, experience level, source of feedback, and type of feedback were found to be significant 
moderators (see Table 12). However, the direction of the results was the same as that observed for accuracy-based measures. 
Table 12

Mean weighted $d, Q$ statistics, and significance levels of significant moderating variables for high vs. low fidelity.

\begin{tabular}{|c|c|c|c|c|c|c|c|}
\hline Moderator Variables & $k$ & $d_{w}(S D)$ & $C I_{d w}$ & $Q_{b}\left(d f_{b}\right)$ & $p$ & $Q_{w}\left(d f_{w}\right)$ & $p$ \\
\hline \multicolumn{8}{|c|}{ High Fidelity vs. Low Fidelity } \\
\hline \multicolumn{8}{|l|}{ Publication Source } \\
\hline Published & 4 & $.11(.09)$ & -.08 to .29 & $97.13(1)$ & $<.001$ & $1179.76(1)$ & $<.001$ \\
\hline Unpublished & 89 & $1.07(.03)$ & 1.02 to 1.12 & & & & \\
\hline \multicolumn{8}{|l|}{ Selection Bias } \\
\hline No & 47 & $.05(.05)$ & -.05 to .16 & $412.33(1)$ & $<.001$ & $864.56(91)$ & $<.001$ \\
\hline Yes & 46 & $1.23(.03)$ & 1.23 to 1.35 & & & & \\
\hline \multicolumn{8}{|c|}{ Participant Assignment } \\
\hline Random & 2 & $0(.18)$ & -.36 to .36 & $632.96(1)$ & $<.001$ & $643.93(91)$ & $<.001$ \\
\hline Non-random & 54 & $1.15(.03)$ & 1.09 to 1.21 & & & & \\
\hline \multicolumn{8}{|l|}{ Experience Level } \\
\hline$<1$ year & 3 & $.15(.29)$ & -.42 to .71 & $225.48(3)$ & $<.001$ & $1051.41(89)$ & $<.001$ \\
\hline $5-10$ years & 2 & $-1.40(.43)$ & -2.24 to -.55 & & & & \\
\hline $10-15$ years & 35 & $1.25(.03)$ & 1.19 to 1.31 & & & & \\
\hline Mixed & 51 & $.51(.05)$ & .42 to .61 & & & & \\
\hline \multicolumn{8}{|l|}{ Previous Training } \\
\hline No & 3 & $.15(.29)$ & -.42 to .71 & $323.15(1)$ & $<.001$ & $953.74(91)$ & $<.001$ \\
\hline Yes & 49 & $1.18(.03)$ & 1.13 to 1.24 & & & & \\
\hline \multicolumn{8}{|c|}{ Type of Tasks Practiced } \\
\hline Part-tasks & 6 & $.07(.09)$ & -.11 to .25 & $110.06(1)$ & $<.001$ & $1166.83(91)$ & $<.001$ \\
\hline Whole-tasks & 87 & $1.08(.03)$ & 1.03 to 1.13 & & & & \\
\hline \multicolumn{8}{|c|}{ Distribution of Practice Sessions } \\
\hline Massed & 3 & $.11(.09)$ & -.08 to 29 & $97.13(1)$ & $<.001$ & $1179.76(91)$ & $<.001$ \\
\hline Spaced & 49 & $1.07(.03)$ & 1.02 to 1.12 & & & & \\
\hline Source of Feedbac & & & & & & & \\
\hline
\end{tabular}


Intrinsic Alone

Both Intrinsic and Augmented

Type of Feedback

Corrective

Explanatory

Both Corrective and Explanatory

None Given

Accuracy

Publication Source

Published

Unpublished

Selection Bias

No

Yes

Participant Assignment

Random

Non-random

Experience Level

$<1$ year

5-10 years

$10-15$ years

Mixed

Previous Training

No

Yes

Type of Tasks Practiced

Part-tasks

Whole-tasks

Distribution of Practice Sessions

Massed

\begin{tabular}{|c|c|c|c|c|c|c|}
\hline 492 & $.04(.08)$ & -.11 to .19 & $179.14(1)$ & $<.001$ & $1097.75(91)$ & $<.001$ \\
\hline 906 & $1.12(.03)$ & 1.07 to 1.18 & & & & \\
\hline - & - & & & & & \\
\hline 906 & $1.12(.03)$ & 1.07 to 1.18 & $179.14(1)$ & $<.001$ & $1097.75(91)$ & $<.001$ \\
\hline $\begin{array}{c}- \\
492\end{array}$ & - & $11+010$ & & & & \\
\hline 492 & & -.11 to .19 & & & & \\
\hline 4 & $.11(.09)$ & -.08 to .29 & $99.22(1)$ & $<.001$ & $238.10(23)$ & $<.001$ \\
\hline 21 & $1.30(.07)$ & 1.16 to 1.45 & & & & \\
\hline 16 & $.19(.08)$ & .03 to .34 & $167.15(1)$ & $<.001$ & $170.17(23)$ & $<.001$ \\
\hline 9 & $1.71(.09)$ & 1.53 to 1.88 & & & & \\
\hline 2 & $0(.18)$ & -.36 to .36 & $260.18(1)$ & $<.001$ & $77.14(23)$ & $<.001$ \\
\hline 8 & $1.38(.11)$ & 1,18 to 1.58 & & & & \\
\hline 3 & $.15(.29)$ & -.42 to .71 & $88.68(2)$ & $<.001$ & $248.64(22)$ & $<.001$ \\
\hline- & - & & & & & \\
\hline 3 & $1.72(.11)$ & 1.49 to 1.94 & & & & \\
\hline 17 & $.59(.07)$ & .45 to .73 & & & & \\
\hline 3 & $.15(.29)$ & -.42 to .71 & $44.57(1)$ & $<.001$ & $292.75(23)$ & $<.001$ \\
\hline 10 & $1.00(.07)$ & .87 to 1.13 & & & & \\
\hline 6 & $.07(.09)$ & -.11 to .25 & $117.30(1)$ & $<.001$ & $220.02(23)$ & $<.001$ \\
\hline 19 & $1.36(.08)$ & 1.21 to 1.51 & & & & \\
\hline 4 & $.11(.09)$ & -.08 to .29 & $99.22(1)$ & $<.001$ & $238.10(23)$ & $<.001$ \\
\hline
\end{tabular}




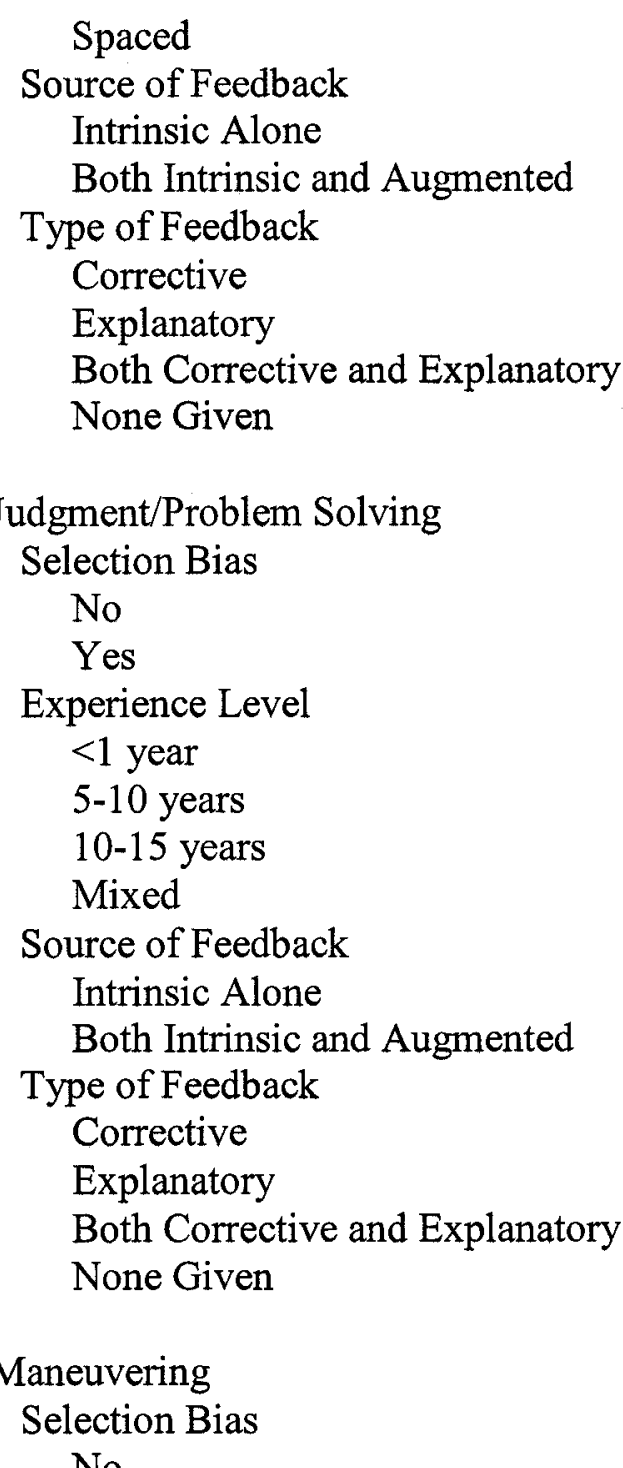

\begin{tabular}{|c|c|c|c|c|c|c|}
\hline 21 & $1.30(.07)$ & 1.16 to 1.45 & & & & \\
\hline 18 & $.07(.09)$ & -.11 to .25 & $117.30(1)$ & $<.001$ & $220.02(23)$ & $<.001$ \\
\hline 71 & $1.36(.08)$ & 1.21 to 1.51 & & & & \\
\hline - & & & & & & \\
\hline 71 & $1.36(.08)$ & 1.21 to 1.51 & $117.30(1)$ & $<.001$ & $220.02(23)$ & $<.001$ \\
\hline 18 & $.07(.09)$ & -.11 to .25 & & & & \\
\hline 11 & $-.17(.12)$ & -.40 to .06 & $152.08(1)$ & $<.001$ & $157.95(16)$ & $<.001$ \\
\hline 7 & $1.60(.08)$ & 1.44 to 1.76 & & & & \\
\hline - & - & & & & & \\
\hline 2 & $-1.40(.43)$ & -2.24 to -.55 & $56.99(2)$ & $<.001$ & $253.04(15)$ & $<.001$ \\
\hline 4 & $1.41(.09)$ & 1.22 to 1.59 & & & & \\
\hline 12 & $.74(.10)$ & .54 to .93 & & & & \\
\hline 3 & $-.04(.07)$ & -.58 to .49 & $16.57(1)$ & $<.001$ & $293.46(16)$ & $<.001$ \\
\hline 15 & $1.10(.27)$ & .96 to 1.24 & & & & \\
\hline - & - & & & & & \\
\hline 15 & $1.10(.27)$ & .96 to 1.24 & $16.57(1)$ & $<.001$ & $293.46(16)$ & $<.001$ \\
\hline$\overline{2}$ & - & & & & & \\
\hline 3 & $-.04(.07)$ & -.58 to .49 & & & & \\
\hline 14 & $-.21(.11)$ & -.44 to .01 & $96.87(1)$ & $<.001$ & $211.33(26)$ & $<.001$ \\
\hline
\end{tabular}


Yes

Experience Level

$<1$ year

$5-10$ years

10-15 years

Mixed

Source of Feedback

Intrinsic Alone

Both Intrinsic and Augmented

Type of Feedback

Corrective

Explanatory

Both Corrective and Explanatory

None Given

\section{Communication \\ Selection Bias \\ No \\ Yes \\ Experience Level \\ $<1$ year \\ 5-10 years \\ $10-15$ years \\ Mixed}

Source of Feedback

Intrinsic Alone

Both Intrinsic and Augmented

Type of Feedback

Corrective

Explanatory
$14 \quad 1.00(.05) \quad .91$ to 1.10

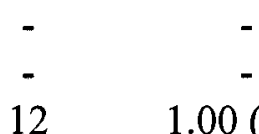

1

$-.21(.11)$

.91 to 1.10

$56.95(1) \quad<.001 \quad 251.25(26)$

$<.001$

$6 \quad-.03(.19) \quad-.40$ to .35

$19.92(1)<.001 \quad 288.28(26)<.001$

$22 \quad .86(.05) \quad .76$ to .95

$-$

0

6

$\begin{array}{lll}6 & -.03(.19) \quad-.40 \text { to } .35\end{array}$

$6 \quad .47(.17) \quad .14$ to .80

$24.38(1) \quad<.001 \quad 236.62(20)$

$<.001$

$16 \quad 1.33(.05) \quad 1.24$ to 1.42

- $\quad-$

$16 \quad 1.33(.05) \quad 1.24$ to 1.42

$24.38(1)<.001 \quad 236.62(20) \quad<.001$

$\begin{array}{lll}6 & .47(.17) \quad .14 \text { to } .80\end{array}$

$3 \quad-.03(.27) \quad-.57$ to .50

$19 \quad 1.31(.05) \quad 1.22$ to 1.40

$23.64(1)<.001 \quad 237.36(20) \quad<.001$

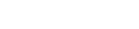

$1.31(.05)$

1.22 to 1.40

$23.64(1)<.001 \quad 237.36(20)$

$<.001$ 
Both Corrective and Explanatory None Given

Note, $k=$ number of effect sizes; $N=$ total sample size; $d_{w}=$ mean weighted effect size; $S D=$ standard deviation; $C I_{d w}=95 \%$ confidence interval around the mean weighted effect size; $Q_{b}=$ the $Q$ statistic indicating the variability between means of the categories of moderating variables; $p=$ significance level; $Q_{w}=$ the $Q$ statistic indicating the variability within the categories of moderating variables. 


\section{Discussion}

The purpose of the present meta-analysis was to determine the relationship, if any, between various training factors and use-of-force simulation training effectiveness. These factors included practice-, feedback-, and fidelity-related issues, which were selected based on the principles of Cognitive Load Theory (CLT). In general, the results of this study suggest that incorporating various training factors into simulation training in a manner consistent with CLT can indeed enhance training effectiveness. However, a number of variables beyond these training factors moderate this relationship. In the section that follows, key research findings emerging from this thesis will be discussed, along with the implications for CLT. Following this, the practical implications of this research will be explored, as well as some potential limitations of the study and directions for future research.

\section{Is Simulation Training Effective?}

The first issue that was examined in this thesis was whether computerized simulation training, compared to other forms of training (e.g., classroom instruction), results in greater training gains. The present findings suggest that, when comparing useof-force training contexts with and without simulation training, those trainees receiving a simulation training component achieve greater training gains (with respect to accuracy, judgment/problem solving, and maneuvering measures). This finding indicates that simulation training is a valuable component of use-of-force training regimes and research into its effectiveness, similar to that conducted here, is warranted. Several exploratory study and sample characteristics were found to moderate the effect of simulation (versus non-simulation) training. In particular, studies that were published, with no evidence of a 
selection bias, which incorporated participants with previous task-related training produced larger effects.

The Significance of Practice, Feedback, and Fidelity in Simulation Training Contexts

Given the superiority of simulation training to non-simulation training for use-offorce instruction in the military, the examination of factors that enhance its effectiveness should greatly interest academics and practitioners alike. As indicated above, the specific factors examined in the present study related broadly to practice, feedback, and fidelity.

Practice. The present findings suggest that greater training gains are observed in use-of-force simulation training contexts that incorporate more versus less practice, thus lending support to the first component of hypothesis 1 (hypothesis 1a). This finding corresponds to current thinking by cognitive load theorists, that sufficient practice time is required for learners to acquire and automate task-relevant schemas (Clark et al., 2006). Having said this, it is not clear from the results reported here exactly how much practice time is needed for adequate schema acquisition and automation to occur. Unfortunately, details of specific practice times were not provided in any of the studies included in the current meta-analysis.

In addition, it was found that greater training gains were observed with the incorporation of part-to-whole-task training (compared to whole-task training alone), lending support to the second component of hypothesis 1 (hypothesis $1 \mathrm{~b}$ ). However, this findings was only based on one study and, therefore, it should be viewed with caution. As was the case in relation to the amount of practice, this result is predicted by CLT. Recall that cognitive load theorists recommend whole-task training because it allows the learner to form stronger relationships between what is being taught during training and what will 
be encountered in the real world (where tasks must be performed simultaneously) (Lim \& Reiser, 2006). However, they also stress that, in order to achieve effective whole-task learning without overloading the learner intrinsic load must be managed. That is to say that complex material may have to initially be simplified in early practice sessions by providing time to practice individual skills (i.e., part-task training) (van Merriënboer et al., 2003).

The third component of hypothesis 1 was related to the distribution of practice sessions (specifically, that spaced practice would be more beneficial than massed practice as distributed practice decreases extraneous cognitive load by frequently freeing up resources in working memory [WM] for schema acquisition). However, none of the studies included in the present sample specifically examined the issue of massed versus spaced practice. Nevertheless, the distribution of practice sessions could be examined as a moderator variable since certain studies presented findings related to massed practice, while others presented findings related to spaced practice. While it was expected that studies examining spaced practice would report greater training effects than those examining massed practice, this training factor was not found to be a significant moderator. Indeed, none of the moderator variables that were examined in relation to practice-related training issues were found to be significant.

Feedback. The results from the present study suggest that greater training gains are observed in use-of-force simulation training contexts that incorporate both augmented and intrinsic feedback versus training that incorporates augmented or intrinsic feedback alone. Thus, the first component of hypothesis 2 (hypothesis 2a) was supported. In fact, all of the studies included in the current sample consisted of training that provided 
intrinsic feedback (i.e., feedback from the simulator itself) and therefore this result highlights the importance of incorporating augmented feedback into use-of-force simulation training. Although the role of augmented feedback is not clearly outlined in the CLT literature, the present findings suggest that such feedback can facilitate meaningful schema acquisition and automation (presumably by encouraging learners to pay attention to relevant cues in the training context) so that performance is maintained after the training ends (e.g., in test sessions) (Clark et al., 2006). Unfortunately, as was the case with practice, the exact amount of augmented feedback required to significantly enhance a learner's performance was unable to be determined due to the fact that these details were not provided in any of the studies included in the present meta-analysis.

The second component of the hypothesis 2 related to the quality of feedback provided in training (e.g., whether the feedback was corrective or explanatory in nature). Unfortunately, none of the studies in the present sample examined the issue of explanatory versus corrective versus no feedback. However, like the distribution of practice, the quality of feedback could be examined as a moderator variable, with the expectation that explanatory feedback (as compared to corrective or no feedback) would be associated with studies reporting larger training effects. Interestingly, the quality of feedback was not found to be a significant moderator in studies incorporating augmented feedback.

Exploratory analyses of several study characteristics were conducted. This analysis revealed that the effectiveness of training incorporating augmented feedback was significantly moderated by the year the study was published. More specifically, larger effects (for unaggregated performance measures) were observed for those studies 
conducted after 1984. While it is not exactly clear from the results of this study why more recent publications resulted in greater training gains from augmented feedback, it may have to do with the significant advances in simulator technology in the 1980s and 90 s and the parallel advances made in the area of use-of-force instruction (FLETC, 1986). For example, since the 1980s, North American use-of-force instructors have been required to go through a certification process before providing training (FATS, 2006), likely improving the quality of the feedback that these instructors provide (e.g., in terms of their ability to facilitate schema acquisition in their trainees). In addition, selection bias was found to moderate the effect of augmented feedback (but only for accuracy-based performance measures) with greater training gains found when no criteria were used to select trainees. It is not clear why this variable would act as a moderator of training where augmented feedback is provided.

Additional analyses of several sample characteristics were also carried out to explore the issue of learner experience. The experience level of the learner was found to moderate the results observed in training contexts incorporating augmented feedback. In particular, participants with mixed levels of experience (i.e., including individuals who had either 10 to 15 years of experience, five to 10 years, one to five years, and/or less than one year) exhibited greater training gains for unaggregated and accuracy-based performance measures when compared to learners with only some experience (i.e., one to five years of experience). This finding seems to indicate that, in general, more experienced learners exhibit greater training gains than those with less experience in training contexts that include augmented feedback (though in some of the studies that were analyzed it was unclear how many inexperienced learners were included in the 
mixed experience groups). Perhaps this is the case because augmented feedback necessarily increases the level of extraneous cognitive load imposed on the learner (due to the fact that the feedback has to be processed in WM) and more experienced learners (who have previously developed task-relevant schemas) may be better equipped to attend to this extra information. In other words, augmented feedback may impose excessive extraneous load on novice learners but germane load on expert learners.

Fidelity. Across the training factors examined in the current study, the greatest training gains were observed for those studies incorporating high degrees of realism compared to those studies incorporating less realism, lending strong support to hypothesis 3. In relation to CLT, the results support the idea that incorporating realism into the training context serves to lessen the degree to which the learner has to use WM capacity to process what they are learning (e.g., by visualizing that they are in the middle of a combat scenario versus being present in a simulated combat scenario) (Clark et al., 2006). Thus, some light is shed on the quandary that currently exists in the research literature regarding the degree of realism necessary within the training context (Boyd 1992; Dobson et al., 2001; Moreno \& Mayer, 2004). Clearly, realism is important. However, as was the case with practice and feedback, the degree of fidelity in the current study could only be described in relative, rather than absolute terms (i.e., more versus less) and, thus, it is not possible to draw conclusions about how realistic training needs to be in order to achieve certain levels of performance.

Additional moderator analyses of training factors supported a number of CLTbased predictions. In particular, within training contexts incorporating a high degree of fidelity, greater training gains were achieved when: (1) whole-task training took place 
(but only for unaggregated and accuracy-based performance measures), (2) practice sessions were spaced over time (again, only for unaggregated and accuracy-based measures), (3) augmented feedback was provided in addition to intrinsic feedback, and (4) augmented feedback was explanatory in nature. Collectively, these findings can be explained by drawing on CLT principles. For example, according to CLT, providing participants with whole-task training, augmented feedback, and explanations of why performance is sub-par will maximize the degree to which a learner will acquire generalized schemas that allow for enhanced performance across a range of settings (Clark et al., 2006). In addition, relying on spaced practice sessions will prevent WM capacity from being exceeded by decreasing extraneous load (because large amounts of information are not presented to the learner in a single session) and this will facilitate the acquisition and schemas and their transfer to LTM (Clark et al., 2006).

Additional exploratory analyses of several study characteristics were conducted and it was found that publication source, selection bias, and participant assignment significantly moderated the gains observed in training environments with high levels of fidelity. More specifically, larger training effects were observed in unpublished studies, studies with a selection bias, and studies where participants were assigned to conditions in a non-random fashion.

As a potential explanation for the publication effect found in this analysis, it is interesting to note that the majority of published studies included in this analysis ( 2 out of 3) were conducted by academics who were not directly affiliated with the simulation training program they were evaluating. In contrast, all of the unpublished studies (12 out of 12) were conducted by such individuals. Thus, large training effects may be 
characterized by the unpublished studies, in part at least, because the authors of these studies had a vested interest in the training program they were evaluating. To understand why studies with a selection bias result in larger training effects, it is perhaps important to highlight the form of bias that typically exists in the sampled studies. More often than not, a selection bias exists in studies where very specialized simulation training is being carried out (e.g., M1 tank simulation training). In these cases, participants are generally selected based on their qualifications on the simulated machinery (e.g., M1 tank-qualified soldiers). Thus, a potential reason for why a selection bias may result in larger training effects (as compared to studies without such a bias) is that relatively experienced trainees are focused on in the biased studies; trainees that already possess schemas that allow them to operate well in high fidelity situations (see above for a more thorough discussion of this issue). The finding related to non-random assignment is more difficult to explain, but may relate in some way to the issue just discussed (i.e., participants are assigned to conditions based on their qualifications).

Another very important finding emerging from the moderator analysis was that, within training contexts incorporating a high degree of fidelity, greater training gains were achieved when the trainees possessed relatively high levels of experience and when participants had previous task-related training. Again, this is predicted from CLT. Recall that, according to cognitive load theorists, a larger training effect would be expected from more experienced learners in training environments with a high degree of realism since learning in these contexts requires more cognitive resources (J. Sweller, personal communication, October 3,2005$)$. Thus, this study provides evidence of the expertise reversal effect, which posits that what works for novice learners may not work for those 
who are more experienced and vice versa (Kalyuga et al., 1998). Clearly, while high fidelity training may be effective for trainees who have already acquired task-relevant schemas, this type of training may be too complicated (causing excessive extraneous load) for novice learners. In these cases, a reduction of realism in training may be required to enable the learner to build up appropriate schemas without exceeding their cognitive capacity (Alessi, 2000; Alluisi, 1978; Winn, 2000).

\section{Recommendations for Improving Use-of-Force Simulation Training}

Based on the findings reported above, there is clear evidence that simulation training can serve as an effective training tool for military personnel in the area of use-offorce decision-making. When use-of-force simulation training is tested under conditions that are compatible with CLT (i.e., longer training times, providing instructor feedback, incorporating high degrees of fidelity, etc.), significant improvements in performance (in terms of accuracy, judgment/problem solving, maneuvering, and communication) are observed. ${ }^{13}$ Based on these findings, a number of preliminary recommendations can now be offered that may enhance the effectiveness use-of-force simulation training in the military domain. These include:

1. Practice time should be maximized within a given training context, based on the resources available (it should be noted that performance gains are likely to plateau with extreme amounts of practice, and due to limited resources in the military domain for training purposes, it seems doubtful that extreme amounts of practice are feasible).

\footnotetext{
${ }^{13}$ In terms of differences between the different aggregate categories of performance measures, at a descriptive level those associated with the greatest training gains were communication, maneuvering, judgment/problem solving, and accuracy, respectively. However, there were rarely any statistical differences between these aggregate categories.
} 
2. If high-fidelity training is being provided, space simulator training sessions (e.g., over a number of days) rather than condense an equal number of training hours on the simulator into a single session.

3. Incorporate part-to-whole task training into the training context to ensure accurate schema acquisition and automation without overloading the learner's limited cognitive resources (whole-task training appears to be particularly important in high fidelity training).

4. Incorporate instructor feedback into training sessions in addition to the intrinsic feedback provided by the training context itself (the provision of augmented feedback seems to be particularly important with more experienced learners).

5. The type of feedback delivered to trainees should be explanatory in nature, at least in high fidelity training situations. That is, trainees should be told whether the decisions they are making are right or wrong (i.e., corrective feedback), and if they are wrong, how they can improve (i.e., explanatory feedback).

6. High fidelity use-of-force simulation training conducted is best suited to learners with reasonably high levels of experience. Under these training conditions, ensure that schema acquisition is facilitated through the use of whole-task training, feedback from augmented as well as intrinsic sources, and explanatory feedback. Also, ensure that the intrinsic load of learners is managed through spaced practice when delivering high fidelity training.

These recommendations, if adopted, could potentially have an immediate and direct impact on the effectiveness of use-of-force simulation training for military 
personnel. Implications of these recommendations include the likelihood that the safety of soldiers will be enhanced as well as the citizens that they serve.

\section{Study Limitations and Suggestions for Future Research}

Given that this is the first study to have examined the influence of various training factors on the effectiveness of use-of-force simulation training, there are a number of limitations that should be mentioned and a variety of suggestions for future research in this area.

Perhaps one of the most serious limitations of the current study was the relatively low level of agreement between the two coders. Recall, this was 65\% (although this level improved substantially with the removal of one particular study). While the majority of the disagreements could be viewed as relatively trivial (e.g., discrepancies between the number of groups tested compared to the training factors examined in the studies), this raises questions about the weight we can put on the findings of the current study. It should be noted, however, that the majority of the articles that were coded exceeded 200 pages, necessarily making the coding quite complicated. In future research the reliability of the coding manual will have to be examined to identify any problematic areas. For example, it may be determined that the variables included in the manual are in fact relatively unambiguous but that additional training is needed for the coder. Alternatively, perhaps clearer definitions are needed, or a shortening of the manual to include only those variables relevant to the current thesis.

Another limitation of the current study is the lack of specificity in the hypotheses that could be tested. As mentioned above, a lack of detail in the sampled studies (in relation to each of the training factors) meant that it was only possible to examine 
hypotheses related to relative amounts of practice, feedback, and fidelity. This necessarily limits the degree to which practically useful conclusions can be drawn from the analysis. It is acknowledged that, while practitioners would be interested in knowing that more practice is better than less practice for achieving a particular training objective, they would be even more interested in knowing exactly how much practice is needed to achieve that objective. Future research is required that examines this issue more specifically across the training factors outlined in this study (e.g., by manipulating practice times and measuring the related performance gains). However, having said this, it is important to stress that the primary purpose of the current study was not to provide recommendations for use-of-force simulation training per se, but rather to examine CLT as a theory for explaining the effectiveness of use-of-force simulation training. By examining the variation in training effects that emerge across training conditions, solely in relative terms, it can be argued that this has been accomplished.

Another limitation is the fact that certain training factors, which are emphasized in CLT, were absent in the sampled studies and, therefore, could not be examined. For example, providing a variety of practice scenarios within the training context is viewed as beneficial by cognitive load theorists (varied practice scenarios are known to facilitate the development of flexible, and therefore, transferable schemas; Clark et al., 2006), as is providing feedback on a thinned versus continuous schedule (using a thinned schedule of feedback is known to reduce the extent to which trainees become dependent on instructor feedback; van Merriënboer et al., 2003). In addition, CLT suggests that self-explanation on the part of the learner (having the learner describe to themselves what they did wrong and right, either during or after training; Renkl, Stark, Gruber, \& Mandl, 1998) can be 
beneficial in terms of aiding in schema acquisition and transfer of training (Clark et al., 2006). However, due to a lack of information in the present study, this issue also could not be examined. Future research is needed that incorporates these variables in order to examine if they have any effect on learning in use-of-force simulation training contexts.

Also of concern is the fact that the theory driving the present study is CLT, however, no measure of cognitive load is actually ever provided in any of the sampled studies, despite the fact that a number of procedures now exist to directly, or indirectly, measure cognitive load (Clark et al., 2006; Paas, Tuovinen, Tabbers, \& Van Gerven, 2003; Tindall-Ford, Chandler, \& Sweller, 1997). In addition, the primary principles of CLT center around issues of schema acquisition and automation, yet none of the studies included in the meta-analysis provide any indication as to the degree to which trainees have acquired or automated schemas. Tools also exist for this purpose (Clark et al., 2006). Furthermore, much of the recent research in the area of CLT has focused on the importance of expertise, which has also been highlighted in the current study. However, while proxy measures of expertise (i.e., years of experience and previous task-related training) were used to examine this issue in the current study, such measures are obviously problematic (i.e., they do not always reflect one's level of expertise in an area) (Ericsson \& Lehman, 1996). New ways of measuring expertise are being developed by cognitive load theorists (e.g., Clark et al., 2006), and future research in the area of use-offorce simulation training will benefit from drawing on these new measures as a way of objectively quantifying learner expertise.

Lastly, while the overall sample size of the present study is sufficient for a meaningful meta-analysis (Cooper and Rosenthal, 1980), the sample sizes of the 
unaggregated and aggregated performance measures (partitioned according to the training factors of interest) are somewhat small. In some cases, it was not possible to examine mean effect sizes for unaggregated performance measures or aggregated categories because they only contained one performance measure (see Table 6 and Tables 13 to 16 in Appendix E). For example, when comparing studies with more versus less practice, only one performance measure (i.e., exposure to opposing forces) was available in the aggregate category of maneuvering. Similarly, the sample sizes available for the moderator analyses were also relatively small. The result of relying on small sample sizes is reduced reliability in the reported effect sizes and, therefore, the results of the present meta-analysis should be interpreted with an appropriate degree of caution. ${ }^{14}$

\section{Conclusion}

The current study is novel in that it represents the first meta-analytic study of the relationship between practice, feedback, and fidelity, as derived from the principles of CLT, and use-of-force simulation training effectiveness. Given the results, support is found for enhanced training effectiveness with the incorporation of CLT-based training factors (e.g., more practice, augmented feedback, high fidelity, etc.). These results provide support that CLT, which has primarily been used to explain how learning occurs in traditional classroom environments, may be a useful theory for understanding how learning occurs in simulated training contexts. These results may also have positive practical benefits for agencies that incorporate use-of-force simulation training into their

\footnotetext{
${ }^{14}$ It should be noted that, although the number of effect sizes are small, the use of a statistical review in this case (in contrast to a traditional narrative review) is warranted. In fact, in a study conducted by Cooper and Rosenthal (1980), faculty members and graduate students were asked to use statistical or traditional methods to draw conclusions about a small set of studies (7). Traditional reviewers tended to report statistically significant results as non-supportive $50 \%$ of the time (versus $16 \%$ of the time for statistical reviewers). Thus, although conclusions based on small sample sizes may have to be interpreted cautiously, they are generally found to be more reliable than those obtained from traditional narrative reviews.
} 
instructional regime (e.g., military, police, security, etc.). Having said this, future research is needed to further delineate the way in which the training factors examined in this study should be incorporated into training (e.g., in terms of the specific amount of practice required) to produce desired training gains. In addition, it will be necessary to incorporate measures of cognitive load, schema development, and learner expertise in future research examining the impact of simulation training if a more in-depth evaluation of CLT is to be conducted. 


\section{References}

References marked with an asterisk (*) indicate studies included in the meta-analysis.

Abelson, R. P. (1981). Psychological status of the script concept. American Psychologist, $36,715-729$.

Alessi, S. M. (2000). Simulation design for training and assessment. In H. F. O'Neil, Jr., \& D. H. Andrews (Eds.), Aircrew training and assessment (pp. 197-222). Mahwah, NJ: Lawrence Erlbaum Associates.

Alessi, S. M. (1988). Fidelity in the design of instructional simulations. Journal of Computer-Based Instruction, 15, 20-47.

Alluisi, E. A. (1978). A discussion of psychological fidelity in simulated work environments. In D. E. Erwin (Ed.), Psychological fidelity in simulated work environments (pp. 57-65). Symposium conducted at the annual meeting of the American Psychological Association, Toronto, Canada.

Andrews, D. H., Carol, L. A., \& Bell, H. H. (1995). The future of selective fidelity in training devices. Educational Technology (November-December), 32-36.

Andrews, D. A., \& Dowden, C. (2005). Managing correctional treatment fro reduced recidivism: A meta-analytic review of programme integrity. Legal and Criminological Psychology, 10, 173-187.

Army Research Institute (1996). Retrieved July 16, 2005 from http://www.rotc.monroe.army.mil/helpdesk/definitions-1/term.htm

Arthur Jr., W., Bennett Jr., W., Edens, P. S., \& Bell, S. T. (2003). Effectiveness of Training in Organizations: A meta-analysis of design and evaluation features. Journal of Applied Psychology, 88, 234-245. 
Baddeley, A. D. (1992). Working memory. Science, 255, 556-559.

Baddeley, A. D., \& Hitch, G. (1974). Working memory. In G. A. Bower (Ed.), The psychology of learning and motivation, Vol. 8 (pp. 47-90). New York: Academic Press.

Baddeley, A. D., \& Longman, D. J. A. (1978). The influence of length and frequency of training session on the rate of learning to type. Ergonomics, 21, 627-635.

Bannert, M. (2002). Managing cognitive load-recent trends in cognitive load theory. Learning and Instruction, 12, 139-146.

Baron, M., \& Kenny, D. A. (1986). The moderator-mediator variable distinction in social psychological research: Conceptual, strategic, and statistical considerations. Journal of Personality and Social Psychology, 51, 1173-1182.

Beilin, H. (1965). Learning and operational convergence in logical thought development. Journal of Experimental Child Psychology, 2, 317-339.

Bennell, C., \& Jones, N. (2004). The effectiveness of use of force simulation training: Final report. Retrieved September 5, 2004 from http://www.cprc.org/tr/tr-200501.pdf

Bernstein, B. R., \& Gonzales, B. K. (1971, February). Learning, retention, and transfer. Navtradevcen Technical Report, 69-C-0215-1,215.

Bjork, R. A. (1994). Memory and meta-memory considerations in the training of human beings. In J. Metcalfe \& A. P. Shimamura (Eds.), Meta-cognition: Knowing about knowing (pp. 185-205). Cambridge, MA: The MIT Press. 
Boyd, S. (1992). Training effectiveness of interactive video systems for the use of lethal force decision making. Unpublished doctoral dissertation, University of San Francisco, California.

Bower, G. H. (1972). Mental imagery and associative learning. In L. Gregg (Ed.), Cognition in learning and memory (pp. 51-88). New York: Wiley.

Brainerd, C. J. (1972). Reinforcement and reversibility in quantity conservation acquisition. Psychonomic Science, 27, 114-116.

Burnside, B. L. (1990). Assessing the capabilities of training simulations: A method and simulation networking (SIMNET) application (Rep. No. 1565). Alexandria, VA: U.S. Army Research Institute for the Behavioral and Social Sciences.

Cahill, A., \& Toppino, T. C. (1993). Young children's recognition as a function of the spacing of repetitions and the type of study and test stimuli. Bulletin of the Psychonomic Society, 31, 481-484.

California Assembly Concurrent Resolution (ACR) 58 Study Committee. (1991, January). California law enforcement training in the 1990s: A vision of excellence. Retrieved May 28, 2004, from http://libcat.post.ca.gov/dbtwwpd/documents/POST/vision.pdf

*Campshure, D. A., Witmer, B. G., \& Drucker, E. H. (1990). The effects of Amount of MI Unit Conduct-of-Fire Trainer (U-COFT) transition training on crew gunnery proficiency (Rep. No. 90-03). Alexandria, VA: Army Research Institute for the Behavioral and Social Sciences.

Canadian Police College (2003). The use of simulators in judgmental training. Ottawa, Ontario: Canadian Police College. 
Chandler, P., \& Sweller, J. (1996). Cognitive load while learning to use a computer program. Applied Cognitive Psychology, 10, 141-170.

Chi, M. T. H., Glaser, R., \& Rees, E. (1982). Expertise in problem solving. In R. S. Sternberg, (Ed.), Advances in the Psychology of Human Intelligence, Vol. 1., (pp. 1-75). Hillsdale, NJ: Erlbaum.

Christina, R. W. (1996). Major determinants of the transfer of training: Implications for enhancing sport performance. In K. W. Kim (Ed.), Human performance determinants in sport (pp. 25-52). Seoul, Korea: Korean Society of Sport Psychology.

Clark, R., Nguyen, F., \& Sweller, J. (2006). Efficiency in learning: Evidence-based guidelines to manage cognitive load. San Francisco, CA: John Wiley \& Sons.

Clements, D. H., \& Merriman, S. (1988). Componential developments in LOGO programming environments. In R. E. Mayer (Ed.), Teaching and learning in computer programming (pp. 13-54). Hillsdale, NJ: Erlbaum.

Cohen, J. (1988). Statistical power analysis for the behavioral sciences $\left(2^{\text {nd }}\right.$ Ed.). New York, NY: Academic Press.

Cooper, G. (1998). Research into cognitive load theory and instructional design at UNSW. Retrieved on June 10, 2005 from http://education.arts.unsw.edu.au/CLT_NET_Aug_97.HTML

Cooper, H. M. \& Rosenthal, R. (1980). Statistical versus traditional procedures for summarizing research findings. Psychological Bulletin, 87, 442-449. 
Corrington, K. A. (1997). Changing cognitive demands in complex skill acquisition.

Dissertation Abstracts International Section A: Humanities and Social Sciences, $58(1-\mathrm{A}), 0080$.

Craig, R. C. (1956). Directed versus independent discovery of established relations. Journal of Educational Psychology, 47, 223-234.

Dalbey, J., \& Linn, M. C. (1985). The demands and requirements of computer programming: A literature review. Journal of Educational Computing Research, $1,253-274$.

Dempster, F. N., \& Farris, R. (1990). The spacing effect: Research and practice. Journal of Research and Development in Education, 23, 97-101.

Dennis, K. A., \& Harris, L. M. (1998). Computer-based simulation as an adjunct to ab initio flight training. The International Journal of Aviation Psychology, 8, 261276.

Detweiler, M. C., \& Lundy, D. H. (1995). Effects of single- and dual-task practice on acquiring dual-task skills. Human Factors, 37, 193-211.

Dobson, M. W., Pengelly, M., Sime, J. A., Albaladejo, S. A., Garcia, E. V., Gonzales, F., et al. (2001). Situated learning with co-operative agent simulations in team training. Computers in Human Behavior, 17, 547-573.

Dochy, F., Segers, M., Van den Bossche, P., \& Gijbels, D. (2003). Effects of problembased learning: A meta-analysis. Learning and Instruction, 13, 533-568.

Dowden, C. (1998). A meta-analytic examination of the risk, need and responsivity principles and their importance within the rehabilitation debate. Unpublished masters thesis. Carleton University, Ottawa, Ontario, Canada. 
Druckman, D., \& Bjork, R. A. (1991). In the mind's eye: Enhancing human performance. Washington, D.C.: National Academy Press.

*DuBois, R. S., \& Smith, P. G. (January, 1991). Simulation-based assessment of automated command, control, and communication capabilities for armor crews and platoons: The Intervehicular Information System (Rep. No. 918). Alexandria, VA: Army Research Institute for the Behavioral and Social Sciences.

Eddowes, E. E. (1978). Flight simulator fidelity and flying training effectiveness. In D. E. Erwin (Ed.), Psychological fidelity in simulated work environments (pp. 45-56). Symposium conducted at the annual meeting of the American Psychological Association, Toronto, Canada.

*Elliott, G. S., Wong, D. T., Dreby, C. A., \& Jarboe, J. E. (1995). A simulation-based evaluation of a force protection system: Soldier performance, training requirements, and soldier-machine interface considerations (Rep. No. 1671). Alexandria, VA: Army Research Institute for the Behavioral and Social Sciences. Endsley, M. R., Holder, L. D., Leibrecht, B. C., Garland, D. J., Wampler, R. L., \& Matthiews, M. D. (2000). Modeling and measuring situation awareness in the infantry operational environment (Rep. No. 1753). Alexandria, VA: Army Research Institute for the Behavioral and Social Sciences.

Ericsson, K. A., \& Lehman, A. C. (1996). Expert and exceptional performance: Evidence of maximal adaptation to task constraints. Annual Review of Psychology, 47, 273305. 
Erwin, D. E. (1978). Engagement simulation training systems: Simulation training in collective, man-ascendant tactical environments. In D. E. Erwin (Ed.), Psychological fidelity in simulated work environments (pp. 29-43). Symposium conducted at the annual meeting of the American Psychological Association, Toronto, Canada.

Fay, A. L. \& Mayer, R. E. (1994). Benefits of teaching design skills before teaching Logo computer programming: Evidence for syntax-independent learning. Journal of Educational Computing Research, 11, 187-210.

Federal Law Enforcement Training Centre. (1986, October). FLETC and judgment pistol shooting technology. The Police Chief, 66-69.

Fink, C. D., \& Shriver, E. L. (1978). Simulators for maintenance training: Some issues, problems, and areas for future research (Rep. No. AFHRL-TR-78-27). Alexandria, VA: HQ Air Force Human Resources Laboratory (AFSC).

Firearms Training Systems (FATS), Inc. (2005a). Law enforcement. Retrieved August 28, 2005 from http://www.fatsinc.com

Firearms Training Systems (FATS), Inc. (2005b). 2005 Annual Report: Firearms Training Systems. Retrieved August 28, 2005 from http://www.fatsinc.com/PDFs/2005_report.pdf

Firearms Training Systems (FATS), Inc. (2006). FATS Virtual Training Solutions Company. Retrieved August 15, 2006 from http://www.fatsinc.com

Frank, M. A. (2002). Feedback, self-efficacy, and the development of motor skills. Retrieved August 2, 2006 from http://www.behavioralconsultants.com/feedback.htm 
Gagné, R. M., \& Brown, L. T. (1961). Some factors in the programming of conceptual learning. Journal of Experimental Psychology, 62, 313-321.

Geber, B. (1990). Simulating reality. The Magazine of Human Resources Development Training, 27, 41-46.

Gelman, R. S. (1969). Conservation acquisition: A problem of learning to attend to relevant attributes. Journal of Experimental Child Psychology, 7, 167-187.

Gendreau, P., Goggin, C., Cullen, F. T., \& Andrews, D. A. (2001). The effects of community sanctions and incarceration on recidivism. In L. L. Motiuk \& R. C. Serin (Eds.) Compendium 2000 on Effective Correctional Programming. Correctional Service Canada.

Glass, G. V., McGaw, B., \& Smith, M. L. (1981). Meta-analysis in social research. Beverly Hills, CA: SAGE Publications.

Goodyear, P., Njoo, M., Hijne, H., \& van Berkum, J. (1991). Learning processes, learner attributes and simulations. Education \& Computing, 6, 263-304.

Gordon, J. A., Wilkerson, W. M., Shaffer, D. W., \& Armstrong, E. G. (2001). Practicing medicine without risk: Students' and educators' responses to high-fidelity patient simulation. Academic Medicine, 76, 469-472.

*Gray, T. H., \& Fuller, R. R. (July, 1977). Effects of simulator training and platform motion on air-to-surface weapons delivery training (Rep. No. AFHRL-TR-7729). Williams Air Force Base, AZ: Air Force Human Resources Laboratory. Groeger, J. A. (1997). Memory and remembering: Everyday memory in context. London, UK: Longmans. 
Hall, J. A. \& Rosenthal, R. (1991). Testing for moderator variables in meta-analysis: Issues and methods. Communication Monographs, 58, 437-448.

Hauptmann, B., \& Karni, A. (2002). From primed to learned: The saturation of repetition priming and the induction of long-term memory. Cognitive Brain Research, 13, 313-322.

Hays, R. T., \& Singer, M. J. (1989). Simulation Fidelity in Training System Design. New York: Springer-Verlag.

Helsen, W. F., \& Starkes, J. L. (1999). A new training approach to complex decision making for police officers in potentially dangerous interventions. Journal of Criminal Justice, 27, 395-410.

Holding, D. H. (1965). Principles of training. Oxford: Pergamon Press.

Honebein, P. C., Duffy, T. M., \& Fishman, B. J. (1993). Constructivism and the design of learning environments: Context and authentic activities for learning. In T. M. Duffy, J. Lowyck, \& D. H. Jonassen (Eds), Designing environments for constructive learning (pp. 87-108). New York, NY: Springer-Verlag.

*Hughes, R. G., Paulsen Jr., J., Brooks, R., \& Jones, W. (1978). Visual cue manipulation in a simulated air-to-surface weapons delivery task. Williams Air Force Base, AZ: Air Force Human Resources Laboratory.

Hurlock, R., \& Montague, W. (1982). Skill retention and its implications for navy tasks: An analytical review (Rep. No. NPRDC SR 82-21). San Diego, CA: Navy Personnel Research and Development Center.

Inhelder, B., Sinclair, H., \& Bovet, M. (1974). Learning and cognitive development. Cambridge, MA: Harvard University Press. 
James, K. H., Humphrey, G. K., Vilis, T., Corrie, B., Baddour, R., \& Goodale, M. A. (2002). "Active" and "passive" learning of three-dimensional object structure within an immersive virtual reality environment. Behavior Research Methods, Instruments, \& Computers, 34, 383-390.

Kalyuga, S., Ayres, P., Chandler, P., \& Sweller, J. (2003). The expertise reversal effect. Educational Psychologist, 38, 23-31.

Kalyuga, S., Chandler, P., \& Sweller, J. (2000). Incorporating learner experience into the design of multimedia instruction. Applied Cognitive Psychology, 13, 351-371.

Kalyuga, S., Chandler, P., \& Sweller, J. (1998). Levels of expertise and instructional design. Human Factors, 40, 1-17.

Kirschner, P. A. (2002). Cognitive load theory: Implications of cognitive load theory on the design of learning. Learning and Instruction, 12, 1-10.

Kirschner, P. A., Sweller, J., \& Clark, R. E. (2006). Why minimal guidance during instruction does not work: An analysis of the failure of constructivist, discovery, problem-based, experiential, and inquiry-based teaching. Educational Psychologist.

Kittel, J. E. (1957). An experimental study of the effect of external direction during learning on transfer and retention of principles. Journal of Educational Psychology, 48, 391-405.

Klahr, D., \& Nigam, M. (2004). The equivalence of learning paths in early science instruction: Effects of direct instruction and discovery learning. American Psychological Society, 15, 661-667. 
Knuth, R. A., \& Cunningham, D. J. (1993). Tools for constructivism. In T. M. Duffy, J. Lowyck, D. H. Jonassen, and T. M. Welsh (Eds.), Designing environments for constructive learning (pp. 163-188). New York, NY: Springer-Verlag.

Krebs, W. K., McCarley, J. S., \& Bryant, E. V. (1999). Effects of mission rehearsal simulation on air-to-ground target acquisition. Human Factors, 41, 553-558.

Kurland, D. M. \& Pea, R. D. (1985). Children's mental modes of recursive logo programs. Journal of Educational Computing Research, 1, 235-243.

*Lampton, D. R., McDonald, D. P., Rodriguez, M. E., Cotton, J. E., Morris, C. S., Parsons, J., et al. (2001). Instructional strategies for training teams in virtual environments (Rep. No. 1110). Alexandria, VA: U.S. Army Research Institute for the Behavioral and Social Sciences.

Lane, D. M., \& Tang, Z. (2000). Effectiveness of a simulation on transfer of statistical concepts. Educational Computing Research, 22, 383-396.

Lavoie, D. R., \& Good, R. (1988). The nature of prediction skills in a biological computer simulation. Journal of Research in Science Teaching, 25, 335-360.

Lee, M., \& Thompson, A. (1997). Guided instruction in LOGO programming and the development of cognitive monitoring strategies among college students. Journal of Educational Computing Research, 16, 125-144.

*Leibrecht, B. C., Meade, G. A., Schmidt, J. H., Doherty, W. J., \& Lickteig, C. W. (June, 1994). Evaluation of the Combat Vehicle Command and Control System: Operational effectiveness of an armor battalion (Rep. No. 998). Alexandria, VA: Army Research Institute for the Behavioral and Social Sciences. 
Lim, J., \& Resier, R. A. (June/July, 2006). Effects of part-task and whole-task instructional approaches and levels of learner expertise on learner acquisition and transfer of a complex cognitive skill. Paper presented at the International Conference of the Learning Sciences, Bloomington, IN.

*Lintern, G., Thomley, K. E., Nelson, B. E., \& Roscoe, S. N. (July, 1984). Content, variety, and augmentation of simulated visual scenes for teaching air-to-ground attack (Rep. No. 81-C-0105-3). Orlando, FL: Naval Training Equipment Center.

Lipsey, M. W., \& Wilson, D. B. (2001). Practical meta-analysis. Thousand Oaks, CA: Sage Publications.

Littlefield, J., Delclos, V. R., Lever, S., Clayton, K. N., Bransford, J. D., \& Franks, J. J. (1988). Learning LOGO: Method of teaching, transfer of general skills, and attitudes toward school and computers. In R. E. Mayer (Ed.), Teaching and learning computer programming (pp. 111-136). Hillsdale, NJ: Erlbaum.

Magee, L. E. (1987). TOW Video interactive Gunnery Simulator (TVIGS) (Rep. No. 1679). Downsview, ON: Department of National Defense - Canada.

Marshall, S. P. (1995). Schemas in problem solving. New York, NY: Cambridge University Press.

Matheny, W. G. (1978). The concept of performance equivalence in training systems. In D. E. Erwin (Ed.), Psychological fidelity in simulated work environments (pp. 316). Symposium conducted at the annual meeting of the American Psychological Association, Toronto, Canada.

May, R. B., \& Tisshaw, S. K. (1975). Variations in learning-set training and quantity conservation. Child Development, 48, 661-667. 
Mayer, R. E. (2004). Should there be a three-strikes rule against pure discovery learning?: The case for guided methods of instruction. The American Psychologist, 59, 14-19.

Mayer, R., \& Moreno, R. (2003). Nine ways to reduce cognitive load in multimedia learning. Educational Psychologist, 38, 43-52.

*McAnulty, D. M. (1992, April). Effectiveness of the AH-1 flight and weapons simulator for sustaining aerial gunnery skills (Rep. No. 1612). Alexandria, VA: Army Research Institute for the Behavioral Sciences.

McNamara, D. S., Kintsch, E., Songer, N. B., \& Kintsch, W. (1996). Are good texts always better? Interactions of text coherence, background knowledge, and levels of understanding in learning from text. Cognition and Instruction, 14, 1-43.

Means, B., Salas, E., Crandall, B., \& Jacobs, T. O. (1993). Training decision makers for the real world. In G. Klein, J. Orasanu, R. Calderwood, \& C. E. Zsambok (Eds.), Decision making in action: Models and methods (pp. 306-326). Norwood, NJ: Ablex.

Moreno, R., \& Mayer, R. E. (2004). Personalized messages that promote science learning in virtual environments. Journal of Educational Psychology, 96, 165-173.

Moreno, R. (2004). Decreasing cognitive load for novice students: Effects of explanatory versus corrective feedback in discovery-based multimedia. Instructional Science, $32,99-113$.

Moss, V.D. (1996). The efficacy of massed versus distributed practice as a function of desired learning outcomes and grade level of the student. Dissertation Abstracts International: Section B: The Sciences \& Engineering, 56(9-B), 5204. 
Narayanan, K. (2005). The neurological scratchpad: Looking into working memory. Retrieved on September 9, 2005 from http://www.brainconnection.com/topics/?main=fa/working-memory

Nullmeyer, R. T., \& Spiker, V. A. (2000). Simulation-based mission rehearsal and human performance. In H. F. O’Neil, Jr. \& D. H. Andrews (Eds.), Aircrew training and assessment (pp. 131-152). Mahwah, NJ: Lawrence Erlbaum Associates.

Paas, F., Renkl, A., \& Sweller, J. (2003). Cognitive load theory and instructional design: Recent developments. Educational Psychologist, 38, 1-4.

Paas, F., Tuovinen, J. E., Tabbers, H., \& Van Gerven, P. W. M. (2003). Cognitive load measurement as a means to advance cognitive load theory. Educational Psychologist, 38, 63-71.

*Pleban, R. J., Dyer, J. L., Salter, M. S., \& Brown, J. B. (1998). Functional capabilities of four Virtual Individual Combat (VIC) simulator technologies: An independent assessment (Rep. No. 1078). Alexandria, VA: U.S. Army Research Institute for the Behavioral and Social Sciences.

Pleban, R. J., Matthews, M. D., Salter, M. S., \& Eakin, D. E. (2002). Training and assessing complex decision-making in a virtual environment. Perceptual and Motor Skills, 94, 871-882.

Pleban, R. J., \& Salvetti, J. (2003). Using virtual environments for conducting small unit dismounted mission rehearsals (Rep. No. 1806). Alexandria, VA: U.S. Army Research Institute for the Behavioral and Social Sciences.

Pollock, E., Chandler, P., \& Sweller, J. (2001). Assimilating complex information. Learning and Instruction, 12, 61-86. 
*Reading, J. E., Kincaid, P. S., Roberts, D. E., Hesslink, R. L., Pozos, R. S. (1994). Effects of shivering on rifle shooting performance in U.S. Marines (Rep. No. 945). San Diego, CA: Naval Health Research Center.

Renkl, A., Stark, R., Gruber, H., \& Mandl, H. (1998). Learning from worked-out examples: The effects of example variability and elicited self-explanations. Contemporary Educational Psychology, 23, 90-98.

Roblyer, M. D. (1996). The constructivist/objectivist debate: Implications for instructional technology research. Learning and Leading with Technology 24, $12-$ 16.

Rosenthal, R. (1984). Meta-analytic procedures for social research. Beverly Hills, CA: Sage Publications.

Rosenthal, R. (1995). Writing meta-analytical reviews. Psychological Bulletin, 118, 183192.

Rushall, B. S., \& Siedentop, D. (1972). The development and control of behavior in sport and physical education. Philadelphia, PA: Lea \& Febiger.

*Salter, M. S., Eakin, D. E., \& Knerr, B. W. (1999). Dismounted Warrior Network Enhanced Restricted Terrain (DWN ERT): An independent assessment (Rep. No. 1742). Alexandria, VA: U.S. Army Research Institute for the Behavioral and Social Sciences.

Schroth, M. L. (1995). Variable delay of feedback procedures and subsequent concept formation transfer. Journal of General Psychology, 122, 393-399.

Sharpe, D., \& Rossiter, L. (2002). Siblings of children with a chronic illness: A metaanalysis. Journal of Pediatric Psychology, 27, 699-710. 
*Shlechter, T. M., Bessemer, D. W., \& Kolosh, K. P. (1992). Computer-based simulation systems and role-playing: An effective combination for fostering conditional knowledge. Journal of Computer-Based Instruction, 19, 110-114.

Shlechter, T. M., Bessemer, D. W., Nesselroade, Jr., P., \& Anthony, J. (1995). An initial evaluation of a simulation-based training program for army National Guard units (Rep. No. 1679). Alexandria, VA: U.S. Army Research Institute for the Behavioral and Social Sciences.

Shulman, L. S., \& Keisler, E. R. (1966). Learning by discovery. Chicago: Rand McNally. Sinclair \& Bovet (1974).

Sterling, B. S. (1996). Relationship between platoon gunnery training and live-fire performance (Rep. No. 1701). Alexandria, VA: U.S. Army Research Institute for the Behavioral and Social Sciences.

Stock, H. V., Borum, R., \& Baltzley, D. (1998). Police use of deadly force. Retrieved May 28, 2004, from http://www.violenceprediction.com/pdf/chap13.pdf

Sweller, J. (1988). Cognitive load during problem solving: Effects on learning. Cognitive Science, 12, 257-285.

Sweller, J. (1994). Cognitive load theory, learning difficulty and instructional design. Learning and Instruction, 4, 295-312.

Sweller, J. (1999). Instructional Design in Technical Areas. Victoria, Australia: Australian Council for Educational Research.

Sweller, J., \& van Merriënboer, J. J. G., \& Paas, F. (1998). Cognitive architecture and instructional design. Educational Psychology Review, 10, 251-296. 
Tailby, R., \& Haslam, C. (2003). An investigation of errorless learning in memoryimpaired patients: Improving the technique and clarifying theory. Neuropsychologia, 41, 1230-1240.

Tennyson, R. D. \& Elmore, R. (1997). Learning theory foundations for instructional design. In R. D. Tennyson, F. Schott, N. M. Seel, \& S. Dijkstra, (Eds.), Instructional design: International perspectives. Vol. 1 (pp. 55-78). New Jersey: Lawrence Erlbaum.

Tennyson, R., \& Schott, F. (1997). Instructional design theory, research and models. In R. Tennyson, F. Schott, N. M. Seel, \& S. Dijkstra (Eds.), Instructional design: International perspectives. Vol. 1 (pp. 1-16). Mahwah, NJ: Erlbaum.

Tindall-Ford, S., Chandler, P., \& Sweller, J. (1997). When two sensory modes are better than one. Journal of Experimental Psychology: Applied, 3, 257-287.

Tremblay, L., Welsh, T.N., \& Elliott, D. (2001). Specificity versus variability: Effects of practice conditions on the use of afferent information for manual aiming. Motor Control, 5, 347-360.

US Army Field Manual. (1992). FM 22-100 Army Leadership, Be, Know, Do. Retrieved on August 6, 2006 from https://atiam.train.army.mil/soldierPortal/atia/adlsc/view /public/9502-1/fm/22-100/toc.htm

van Berkum, J. J. A., \& de Jong, T. (1991). Instructional environments for simulations. Education \& Computing, 6, 305-358.

van Merriënboer, J. J. G., Kirschner, P. A., \& Kester, L. (2003). Taking the load of a learners' mind: Instructional design for complex learning. Educational Psychologist, 38, 5-13. 
Wallach, L., \& Sprott, R. L. (1964). Inducing conservation in children. Child Development, 35, 71-84.

Webster, M. (2005). Merriam-Webster Online Dictionary. Retrieved on October 15, 2005 from http://www.m-w.com/cgi-bin/dictionary

Wehrenberg, S. B. (1986, April). Simulations: Capturing the experience of the real thing. Personnel Journal, 65, 101-103.

*White, C. R., Carson, J. L., \& Wilbourn, J. M. (1991a). Training effectiveness of an M16 rifle simulator. Military Psychology, 3, 177-184.

*White, C. R., Carson, J. L., \& Wilbourn, J. M. (1991b). Handgun marksmanship training: Evaluation of an advanced marksmanship trainer. Performance Improvement Quarterly, 4, 63-73.

Wickens, C. D. (1992). Engineering Psychology and Human Performance (2nd ed.). New York, NY: Harper Collins Publishers Inc.

Winn, W. (2002). Current trends in educational technology research: The study of learning environments. Educational Psychology Review, 14, 331-351.

Wolf, F. 1986. Meta-Analysis. Thousand Oaks, CA: Sage Publications. 
Appendix A

List of Researchers Contacted for Studies or Data for Inclusion in the Present MetaAnalysis

\begin{tabular}{ll}
\hline \multicolumn{1}{c}{ Researcher } & \multicolumn{1}{c}{ Affiliation } \\
\hline Art Cortes & $\begin{array}{l}\text { University of Central Florida Institute for Simulation and } \\
\text { Training }\end{array}$ \\
Eduardo Salas, Ph.D. & $\begin{array}{l}\text { University of Central Florida Institute for Simulation and } \\
\text { Training }\end{array}$ \\
Craig Wright & Naval Air Warfare Center, Training Systems Division \\
Simon Goerger, Ph.D. & Operations Research Center of Excellence (ORCEN) \\
Steve Goldberg & Army Research Institute \\
Louis Birta, Ph.D. & The McLeod Institute of Simulation Sciences \\
Gabriel Wainer, Ph.D. & The McLeod Institute of Simulation Sciences \\
Kenneth Christensen & NASA SimLabs \\
Liz Wright & Defence Science and Technology Organisation \\
Katharine Golas & Training, Simulation and Performance Improvement Division, \\
& Southwest Research Institute \\
Mike Meehan & Defense Modeling and Simulation Office, Department of Defense \\
Barb Kiliz & Advanced Interactive Systems, Inc. \\
Gaye Daniels & National Center for Applied Learning Technologies \\
Jacqueline Gaines & Peter M. Winter Institute for Simulation Education Research \\
Mark D. White, Ph.D. & Flight Simulation Laboratory, The University of Liverpool \\
Gareth Padfield & Flight Simulation Laboratory, The University of Liverpool \\
\hline
\end{tabular}


Appendix B

Coding Manual

\section{CODING MANUAL}

Instructions: Please answer the following questions/statements regarding each study. The information provided in the study must be explicitly stated or very clear in order for you to record it, if it is not clear or there is no indication of what the question asks then please circle (when it is given as an option) or write NOT STATED after the numbered item. If the question is not applicable just leave it blank. Please provide any information that you think is necessary, important, or applicable. If more space is needed for a particular question please use the back of the subsequent page and label it using the question number. Please ignore any highlighted questions.

1. Study ID\# (found in right hand corner of title page)?

2. Authors (list first name, initials, and last name of all authors)?

\section{PUBLICATION INFORMATION:}

*3. Year of publication?

*4. Source of results/study (or publication form):

0 published peer reviewed journal article

1 published non-peer reviewed journal article

2 Ph.D. dissertation

$3 \quad$ M.A. thesis

4 technical report (governmental)

5 book

6 paper presented at convention/conference

7 unpublished manuscript

8 other (please specify):

5. Country of origin of the study? 
6. Affiliation of authors ( $>75 \%$ of the authors must be of the same affiliation or code them as multi-disciplinary, if $>75 \%$ of the authors are of a particular affiliation not listed choose other and specify):

$0 \quad$ academic (e.g., college, university, etc.) (specify institution if possible):

1 research firm/consultant (specify name if possible):

2 government unit or agency, (e.g., Department of Defense, Army, Navy, etc.) (specify agency if possible):

3 multi-disciplinary

4 other (please specify):

7. Has the researcher published other studies in this subject area (i.e., simulation training) (use the internet to search and see if they have other publications to do with simulation training):

0 no, this is the first

1 yes

\section{SAMPLE CHARACTERISTICS:}

*8. Final sample size $(N)$ (please take into account any attrition or growth of any participants throughout the study). In some studies the number of crews is given, if this is the case record that here but specify that it is a crew and please specify the number of individuals within a crew if that information is given:

*9. Provide the sample size of the control group (i.e., those not receiving any type of simulation training) and all experimental groups (i.e., those receiving any type of simulation training). If the n's are not given but \%'s are record those here). In some studies the number of crews is given, if this is the case record that here but specify that it is a crew:
control $n$ :
expt'l group $4 n$ :
expt'1 group $1 n$ :
expt'1 group $5 n$ :
$\operatorname{expt'1~group~} 2 n$ :
expt'1 group $6 n$ :
$\operatorname{expt'1~group~} 3 n$ :
expt'l group $7 n$ :

List any others: 
10. Type of population (Note: if more than one of the following groups is included in the study please circle all of them. If one of the groups is listed but one or more is not, circle the one present and list the others after circling the other option).

0 Army (specify specific job title, unit, or battalion, e.g., Platoon Officer):

1 Navy (specify specific job title, e.g., Navy Seal):

2 Air Force (specify specific job title, e.g., Pilot):

3 Marines (specify specific job title, e.g., Active Marine):

4 other (please specify):

11. Gender of sample:

$0 \quad$ all male

1 all female

2 mixed, please indicate the $n$ for each if stated, Females $n$ , Males

3 not stated

12. What is the age of the subjects? (If the age is provided in another form, please specify below)

total sample:

M(SD) RANGE MEDIAN MODE

control:

experimental group 1:

experimental group 2:

any additional groups:

13. How were the subjects recruited:

$0 \quad$ volunteer

1 required (as part of training, etc.)

2 other (please specify):

3 not stated

*14. Assignment of participants to conditions (circle all that apply):

0 random

1 non-random

2 matched (participants assigned to each group are matched on one or more participant characteristics, e.g., shooting accuracy on a pretest, rank, etc. if so, specify the criteria they are matched on):

3 un-matched (assignment to groups is not based on the matching of participant characteristics)

4 not stated/unclear

5 other (please specify): 
*15. Is there evidence of selection bias (i.e., were participants selected to participate in the study based on a certain criteria):

0 no

1 yes (please specify the criteria):

*16. Please specify how the groups differed in terms of the training received (e.g., control - no simulation training, live-fire training only, experimental group 1 - no feedback during simulation training, experimental group 2 - feedback during simulation training, etc.).

*17. List any training received by the subjects in the control group before they took part in the study, specifically pertaining to use-of-force procedures (e.g., firearms training, etc.), if it is available (please specify if any of this training was on a simulator). In addition, please place an asterisk by any task relevant items specifically related to this study (i.e., specific to the task or training requirements - weapons, machinery, context, etc.).

*18. List any training received by the subjects in all of the experimental groups before they took part in the study, specifically pertaining to use-of-force procedures (e.g., firearms training, etc.), if it is available (please specify if any of this training was on a simulator). In addition, please place an asterisk by any task relevant items specifically related to this study (i.e., specific to the task or training requirements - weapons, machinery, context, etc.). 
*19. Indicate what the experience level of the control group was (please specify below any experience indicated in the study):

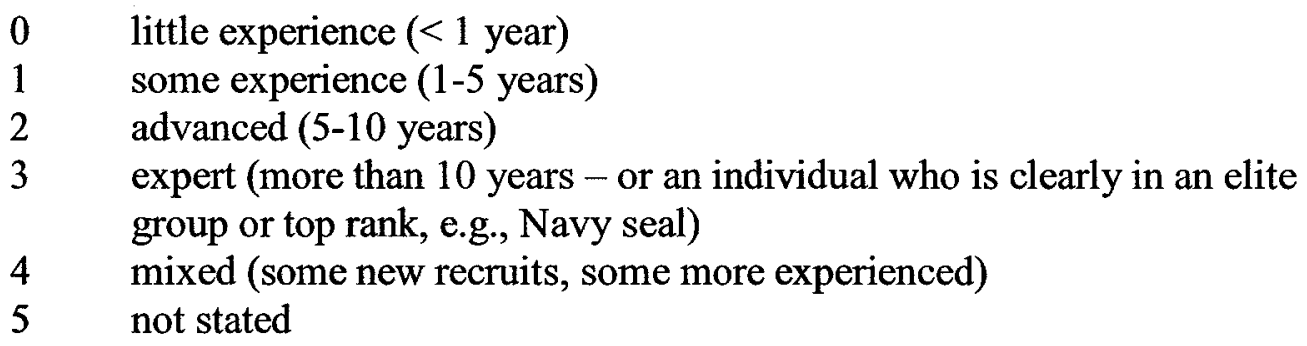

*20. Indicate what the experience level of the experimental group was (please specify below any experience indicated in the study):

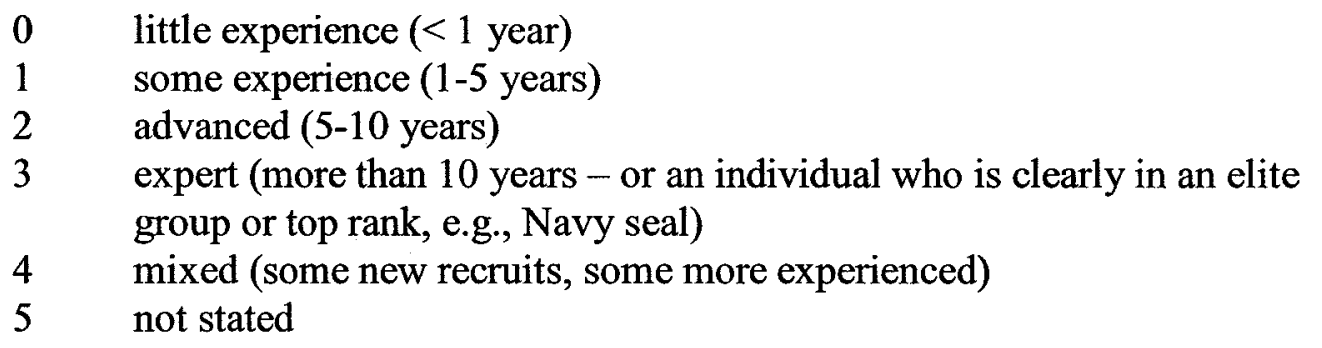

List the number for any other experimental groups here:

21. Based on all the evidence available, how diverse or heterogeneous is the control group with regard to simulator experience, demographics, training setting, etc.:

$0 \quad$ very homogenous (subjects quite similar to each other)

1 very heterogeneous (subjects quite different from each other)

2 not stated (i.e., not enough information is given) 
22. Based on all the evidence available, how diverse or heterogeneous is the experimental group with regard to simulator experience, demographics, training setting, etc.:

$0 \quad$ very homogenous (subjects quite similar to each other)

1 very heterogeneous (subjects quite different from each other)

2 not stated (i.e., not enough information is given)

List the number for any other experimental groups here:

\section{TRAINING:}

23. Was there any form of pre-training (i.e., theory class, briefing session, pre-test, etc.) given to the participants before training (ignore familiarization with the simulator):

$\begin{array}{ll}0 & \text { no } \\ 1 & \text { yes } \\ 2 & \text { not stated }\end{array}$

24. If so, what did it entail and how long did it last (be as detailed as possible and specify per group if they differed in what they received)? For example, $30 \mathrm{~min}$. of classroom lessons on tactical operation, etc.

25. If so, did all participants receive it:

0 no

1 yes

2 not stated 
26. If not all participants received it, was the decision based on some other criteria (e.g., experience level, etc.):

$$
\begin{array}{ll}
0 & \text { no } \\
1 & \text { yes (please specify): } \\
2 & \text { not stated }
\end{array}
$$

27. Was the simulation training in this particular study (If there are multiple groups and the answer varies across groups choose 2 and please specify how):

0 supplemented with other training (e.g., target practice, classroom learning, etc.)

1 constituted entire training (e.g., the only training they received)

2 other (please specify):

3 not stated

28. Was the training monitored to ensure proper delivery (i.e., was an experimenter/instructor always present):

$\begin{array}{ll}0 & \text { no } \\ 1 & \text { yes } \\ 2 & \text { not stated }\end{array}$

*29. Name of simulator(s) used?

30. What type of force was the focus of the simulation training (check all that apply):

$0 \quad$ light artillery (firearms, etc.)

1 heavy artillery (missile launchers, etc.)

2 engaging in battle/combat

3 other (please specify):

31. What type of machinery was simulated:

0 aircraft

1 tank

2 combat environment (i.e., many types of machinery, people, etc.) (e.g., SIMNET)

3 one, participants were on foot

4 other (please specify):

32. Please specify the weapon(s) used during the simulation (e.g., M-16, etc.): 
*33. How long was the training overall for each participant or group (Including all aspects of the training, simulation, classroom, live-fire, etc.)?

*34. What was the total time on the simulator per participant or group (min, hours, days, etc.)?

35. Out of the total time on the simulator how many training sessions were there?

36. Within each session (or the total time) on the simulator how many scenarios were presented? If stated, please specify their duration.

37. What types of scenarios are used (please be as detailed as possible) (specify by group if applicable) (e.g., domestic violence, full size silhouette targets displayed at varying distances, etc.)?

38. How were these scenarios selected:

$0 \quad$ randomly

1 by the instructor

2 by the participants

3 other (please specify):

4 not stated

39. Does each participant get exposed to the same scenarios:
0 no
1 yes
2 not stated 
40. Amount of simulator training received by the subjects was determined by:

0 proficiency based criterion (i.e., experience or skill level)

1 blocked design (all subjects received the same amount of training time)

2 mixed design (subjects randomly received differing amounts of training time)

3 other (please specify):

4 not stated

41. What was the purpose of the training (circle all that apply):

$0 \quad$ initial training

1 retraining (refresher)

2 advanced training

3 not stated

4 other (please specify):

42. What type of training was it:

$0 \quad$ skill training (please specify, e.g., shooting skill only, etc.):

1 tactical decision making (e.g., platoon leader making decisions in a combat scenario)

2 other (please specify):

3 not stated

43. Primary format of training sessions:

$0 \quad$ subject alone (self-administered training)

1 subject and instructor, one on one

2 subject and 2 or more instructors

32 or more subjects and one instructor

42 or more subjects and 2 or more instructors

5 mixed, no single format predominates

6 other (please specify):

7 not stated

44. Do the participants get to observe the other participants undergoing simulation

training:

0 no

1 yes (please specify how long):

2 not stated 
45. Did the training take place in a variety of settings (e.g., in a classroom, outdoors, in various institutions, etc.):

$\begin{array}{ll}0 & \text { no } \\ 1 & \text { yes (please specify all): } \\ 2 & \text { not stated }\end{array}$

\section{FACTORS RELATED TO SIMULATION TRAINING:}

\section{Practice}

46. Were certain aspects of the task practiced more than others, if so, which parts:

$\begin{array}{ll}0 & \text { no } \\ 1 & \text { yes (please specify): }\end{array}$

*47. Was the practice session:

0 a single massed session

1 spaced periodic practice sessions

2 other (if another schedule was used, please describe):

48. If the practice sessions were spaced, how many sessions were there and how much time was given in between the sessions?

*49. What type of tasks did the practice involve:

$0 \quad$ part-task - practice of individual skills only

1 whole-task - practice of multiple skills concurrently

2 not stated

50. If the practice involved part-tasks, specify the tasks practiced?

51. If the practice involved whole-tasks specify the multiple tasks practiced? 
*52. Were varied scenarios practiced by the learner (this can include variations of the same theme, e.g., room setup changed and opposing forces located in different places, etc.):

$\begin{array}{ll}0 & \text { no } \\ 1 & \text { yes } \\ 2 & \text { not stated }\end{array}$

\section{Feedback}

*53. Was feedback given to the participant during the training session:

$\begin{array}{ll}0 & \text { no } \\ 1 & \text { yes } \\ 2 & \text { not stated }\end{array}$

54. Was feedback given to participants when they were interacting with the simulator:

0 no

1 yes (please specify the source):

2 not stated

55. Was the feedback given immediately following the training or was there a delay:
$0 \quad$ immediate
1 delayed
2 not stated
3 other (please specify):

56. If the feedback was delayed, how long was the delay?

57. Was intrinsic feedback provided by:
0 the simulator itself
1 other participants/role players/crew, etc.
2 both 0 and 1
3 other (i.e., instructor) (please specify):

*58. Was augmented feedback provided (i.e., feedback from the instructor, other participants, the simulator, etc.):
0 no
1 yes (please specify all sources):
2 not stated 
*59. What type of feedback did the trainees receive:

0 corrective (how well they did only, right or wrong, i.e., accuracy of shooting)

1 explanatory (how well they did and how they can improve, etc.)

2 other (please specify):

3 not stated

*60. When is this feedback provided:

0 continuously (i.e., after every scenario or task)

1 thinned (i.e., continuously at the beginning but then only after every nth scenario or task)

2 sporadically (i.e., in a random order)

3 never

4 other (please specify):

5 not stated

*61. Does the instructor and the participant discuss the performance together:

$\begin{array}{ll}0 & \text { no } \\ 1 & \text { yes } \\ 2 & \text { not stated }\end{array}$

62. If so, when does this take place?

63. Is there any other type of feedback provided:
0 classroom discussion
1 debriefing
2 other (please specify):
3 not stated

64. If so, what did it incorporate?

*65. Were the participants asked to self-assess their performance:

$\begin{array}{ll}0 & \text { no } \\ 1 & \text { yes } \\ 2 & \text { not stated }\end{array}$




\section{Fidelity}

*66. Did the training context involve physical fidelity (e.g., props used, weapon recoil, shoot-back cannons, etc.)? If you circle 1 than indicate the degree of fidelity (high, selective, low):
0 no
1 yes (please specify):
2 not stated

*67. Did the training context involve psychological fidelity (i.e., the perception of realism by the participant):
0 no
1 yes (please specify):
2 not stated

*68. Did the training context involve physiological fidelity (i.e., production of somatic responses in the participant, such as stress, etc.). This would have to be measured in some way and then reported in the study.

$$
\begin{array}{ll}
0 & \text { no } \\
1 & \text { yes (please specify): } \\
2 & \text { not stated }
\end{array}
$$

69. Was there any sound simulation:

$$
\begin{array}{ll}
0 & \text { no } \\
1 & \text { yes (please specify): } \\
2 & \text { not stated }
\end{array}
$$

70. Was there any visual simulation:

$\begin{array}{ll}0 & \text { no } \\ 1 & \text { yes (please specify): } \\ 2 & \text { not stated }\end{array}$

71. Were any types of fidelity decreased at the beginning of training and then increased afterwards:

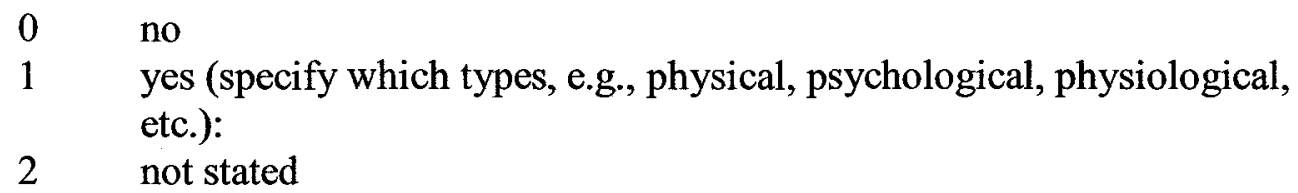


72. Were the scenarios set up in such a way that the difficulty increased as the training progressed?

$\begin{array}{ll}0 & \text { no } \\ 1 & \text { yes } \\ 2 & \text { not stated }\end{array}$

\section{DESIGN:}

73. Was the study:

0 a between-subjects design (a different group of participants is randomly selected

for each level of an independent variable)

1 a repeated measures design (repeatedly measure the same participants under all

conditions of an independent variable)

2 a mixed between and within subjects design

74. Was the study sample representative of the client population (i.e., did the study include individuals who would typically be trained using military use-of-force simulators):

0 no (please specify the sample):

1 yes

75. Was blinding used in data collection:

$0 \quad$ single-blind (i.e., the participants are unaware of the purpose of the study)

1 double-blind (i.e., the participants and the experimenter(s) are unaware of the purpose of the study)

2 un-blinded (i.e., the participants and the experimenter(s) may be or are aware of the purposes of the study)

3 unclear (please specify any information that is given):

4 not stated

76. How many instructors delivered the training?

77. What was the instructor/participant ratio (please specify overall and in experimental groups if applicable)? 
78. Is there any indication of the experience level of the instructor (i.e., a statement saying he or she has extensive experience in urban operations, etc.)? If so, please record it, or the areas the instructor has experience, and be as specific as possible.

79. Were baseline measures taken of each of the groups before the study/manipulations commenced:

$$
\begin{array}{ll}
0 & \text { no } \\
1 & \text { yes } \\
2 & \text { not stated }
\end{array}
$$

\section{OUTCOME VARIABLES:}

80. The measure of training effectiveness was assessed/recorded by:

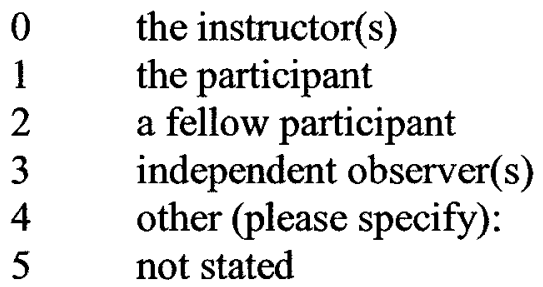

81. If you chose number 2,3 , or 4 on question \#80, was the individual blind to the purpose of the study:

$\begin{array}{ll}0 & \text { no } \\ 1 & \text { yes } \\ 2 & \text { not stated }\end{array}$

82. Was the outcome variable:

$0 \quad$ subjective (i.e., measure of participants feelings/perceptions about training effectiveness)

1 objective (i.e., actual quantitative measurements)

2 both

*83. Type of outcome variable (i.e., what was the outcome variable used to measure training effectiveness in this particular study) (e.g., shooting accuracy, number of instances where the participant did not correctly perform a specific task, etc.)? If there is more than one, list them all. 
84. What type of instrument was used to measure training outcomes?

0 subjective (e.g., interviews, discussions, questionnaires, etc.)

1 objective (e.g., rating scale, validated self-report questionnaire, recording numbers such as hits on target, etc.)

2 both

*85. Are effect sizes given for the outcome or dependent measures? If not, calculate $(d)$ with two decimals and include an algebraic sign in front. Note: the sign should be a plus if the experimental group is favoured (i.e., more "success" for experimental group than control), and a minus if the control group is favoured. Or provide the information that could be used to calculate the effect sizes (e.g., $M, S D, n, t, F, p, z, X^{2}$, etc.). Also, make sure to indicate whether the difference/association was significant. (Please attach as a separate page)

86. Were there pre-and post-test measures of training effectiveness (specify for each outcome measure listed in question \#83 above)?

$\begin{array}{ll}0 & \text { no } \\ 1 & \text { yes (please specify): }\end{array}$

87. Was there an examination of retention (post-training) or transfer of training (to new settings):

$$
\begin{array}{ll}
0 & \text { no } \\
1 & \text { yes }
\end{array}
$$

88. If so, how was this done?

89. If so, when was the re-testing done?

\section{ANALYSIS:}

90. Please provide the level of statistical analysis used in the study:

$0 \quad$ No statistical analysis

1 Descriptive statistics only (M, SD, Correlations)

2 Advanced statistics (t-tests, ANOVA, Regression, etc.) 
91. Were any initial differences between groups corrected by analysis of covariance:

0 no

1 yes (please specify the covariate):

92. Was the reliability, validity, or sensitivity of outcome measures given:

0 no

1 yes (please specify):

93. Was the inter-rater reliability given:

0 no

1 yes (please specify what these reliabilities refer to):

94. If so, what is the inter-rater reliability?

95. Were comparisons of experimental and control groups conducted to check for equivalence on characteristics (e.g., age, ethnicity, gender, experience, etc.)? List all and specify if there were negligible or non-significant differences, some differences, judged of uncertain importance, or significant differences.

96. Authors overall (qualitative) interpretation of research results regarding simulation training effectiveness. If there are two experimental groups then please specify the conditions as to why one or the other was or was not superior (e.g., circle 0 and then state that both groups received simulation training but the one with high fidelity was better, etc.).

$0 \quad$ judged a success

1 judged a mixed success and failure

2 judged a failure

3 no conclusion drawn (e.g. evidence insufficient or simply not discussed) 
Appendix C

List of Individual Performance Measures by Aggregate Categories

\begin{tabular}{|c|c|c|}
\hline $\begin{array}{l}\text { Aggregate } \\
\text { Category }\end{array}$ & Performance Measure & Description \\
\hline \multirow[t]{14}{*}{ Accuracy } & Field exercise score & $\begin{array}{l}\text { Score received upon } \\
\text { completing a field exercise } \\
\text { following the simulation } \\
\text { training. }\end{array}$ \\
\hline & Distance of shot from target & $\begin{array}{l}\text { The error or miss distance from } \\
\text { where shot landed and where } \\
\text { the target was located. }\end{array}$ \\
\hline & Target hit rate & $\begin{array}{l}\text { The speed with which the } \\
\text { enemy targets were hit. }\end{array}$ \\
\hline & Target hit proportion & $\begin{array}{l}\text { Proportion of hits on target, } \\
\text { made by the defending team, to } \\
\text { the number of misses. }\end{array}$ \\
\hline & Target acquisition errors & $\begin{array}{l}\text { Number of times failed to } \\
\text { find/see enemy targets. }\end{array}$ \\
\hline & Simulator navigational errors & $\begin{array}{l}\text { Number of errors made when } \\
\text { using the simulator }\end{array}$ \\
\hline & $\begin{array}{l}\text { Number of bombs impacting } \\
\text { enemy } \\
\quad \text { targets }\end{array}$ & $\begin{array}{l}\text { Number of bombs causing } \\
\text { damage or destruction to } \\
\text { enemy targets. }\end{array}$ \\
\hline & Number of enemy targets killed & $\begin{array}{l}\text { Number of enemy targets (i.e., } \\
\text { enemy soldiers, vehicles, etc.) } \\
\text { killed during the scenario. }\end{array}$ \\
\hline & Losses/kill ratio & $\begin{array}{l}\text { Proportion of the number of } \\
\text { losses of defending soldiers to } \\
\text { the number of enemy targets } \\
\text { killed. }\end{array}$ \\
\hline & Position Accuracy & $\begin{array}{l}\text { Ability to navigate battle } \\
\text { positions accurately throughout } \\
\text { the scenario. }\end{array}$ \\
\hline & Hits on target & $\begin{array}{l}\text { Number of hits on target during } \\
\text { the scenario. }\end{array}$ \\
\hline & Sustained hits & $\begin{array}{l}\text { Number of hits received by } \\
\text { defending soldiers by enemy } \\
\text { targets. }\end{array}$ \\
\hline & Sustained kills & $\begin{array}{l}\text { Number of defending soldiers } \\
\text { killed by enemy targets. }\end{array}$ \\
\hline & Ratings of flying performance & $\begin{array}{l}\text { Instructor ratings of defending } \\
\text { soldiers flying performance. }\end{array}$ \\
\hline Judgment/ & Number of target engagements & Number of times enemy targets \\
\hline
\end{tabular}


Problem Solving

Target engagement time

Overall fire rate

Average time until target engagement

Time to acquire targets

Time taken to avoid enemy fire

Time Until First Hit

Time to plan task/mission

Quickness rating of reaction to target contact/engagement

Performance rating of reaction to target contact/engagement

Difficulty rating of reaction to target contact/engagement

Quickness of engaging/recognizing targets, objects \& people

Maneuvering
Exiting the building within the time limit

Attempting to exit the building were confronted during the scenario.

The total time during which the defending soldier was engaged with/confronting enemy targets.

The overall number of times the defending soldier fired his/her weapon during the scenario.

How long it takes before the defending soldier engaged enemy targets.

Time it takes to find/see enemy targets.

Total time it took to successfully avoid enemy fire when desirable.

Average time until first enemy target was hit.

Total time taken to plan the execution of the task or mission required in the scenario.

Rating of how quickly defending soldiers react to target contact/engagement during the scenario.

Rating of how well defending soldiers performed when contacting/engaging enemy targets during the scenario. Rating of how difficult it was to contact/engage enemy targets during the scenario. How quickly defending soldiers confronted/dealt with targets, objects and civilians during the scenario.

Defending soldiers making it out of the building during the scenario within a given time limit.

Any attempt by defending soldiers to exit the building during the scenario. 
Distance from enemy targets

Exposure to enemy targets

Time to reach task/mission objective

Distance traveled

Fuel used

Quickness rating of tactical movement

Performance rating of tactical movement

Difficulty rating of tactical movement

Quickness rating of room clearing

Performance rating of room clearing

Difficulty rating of room clearing
Transmission time of battle orders

Requests for clarification of battle orders

Number of successful battle orders

Time to plan battle orders

Time to report location
Average distance between defending soldier and enemy targets during scenario.

Defending soldiers use of appropriate cover, degree of exposure to enemy targets during scenario.

Total time taken by defending soldiers to reach the objective of the training scenario.

Total distance traveled during scenario.

The total fuel used during the scenario.

Rating of how quickly defending soldiers move tactically during the scenario. Rating of how well defending soldiers performed when moving tactically during the scenario.

Rating of how difficult it was to move tactically during the scenario.

Rating of how quickly defending soldiers cleared rooms during the scenario. Rating of how well defending soldiers cleared rooms during the scenario.

Rating of how difficult it was to clear rooms during the scenario.

Length of time spent communicating battle orders to base command.

Number of times base requested clarification of battle orders.

Total number of successfully communicated battle orders. Time taken to plan the battle orders sent to base. Time taken to report battle location to base. 
Number of reports sent

Number of reports sent with correct information

Quickness ratings of communication

Performance ratings of communication

Difficulty ratings of communication
Total number of battle location reports sent to base.

Total number of battle location reports sent to base with the correct information.

Rating of how quickly defending soldiers communicated during the scenario.

Rating of how well defending soldiers communicated during the scenario.

Rating of how difficult it was to communicate during the scenario. 
Appendix D

Statistical Conversions to $d$

\begin{tabular}{cl}
\hline Statistic to be converted & Formula for conversion to $d$ \\
\hline$t$ & $d=2 t / \sqrt{\mathrm{df}}$ \\
$F$ & $d=2 \sqrt{ } F / \sqrt{\mathrm{df}}$ error \\
$r$ & $d=2 r / \sqrt{1}-r^{2}$ \\
\hline
\end{tabular}




\section{Appendix E}

Complete Tables of Effect Sizes for the Training Effectiveness of each Training Factor

Table 13

Mean effect of simulation training versus no simulation training on unaggregated and aggregated outcome measures of training effectiveness.

\begin{tabular}{|c|c|c|c|c|c|c|}
\hline Contrast $(k)$ & $N$ & $d_{\text {corr }}(S D)$ & $C I_{d c o r r}$ & $d_{w}(S D)$ & $C I_{d w}$ & $U_{3}$ \\
\hline $\begin{array}{l}\text { Simulation Training vs. No } \\
\text { Simulation Training (14) }\end{array}$ & 1401 & $.90(.06)$ & .80 to 1.00 & $(.05)$ & .10 to .31 & .58 \\
\hline $\begin{array}{l}\text { Accuracy (8) } \\
\text { Field Exercise Score (3) }\end{array}$ & $\begin{array}{l}1401 \\
1377\end{array}$ & $\begin{array}{l}.85(.06) \\
.80(.06)\end{array}$ & $\begin{array}{l}.75 \text { to } .95 \\
.69 \text { to } .91\end{array}$ & $\begin{array}{l}.18(.05) \\
.14(.05)\end{array}$ & $\begin{array}{l}.07 \text { to } .28 \\
.03 \text { to } .24\end{array}$ & $\begin{array}{l}.57 \\
.56\end{array}$ \\
\hline $\begin{array}{l}\text { Distance of Shot From Target (1) } \\
\text { Number of Bombs Impacting }\end{array}$ & 24 & $.62(.44)$ & -.24 to 1.49 & - & - & .73 \\
\hline Enemy Targets (1) & 24 & $1.29(.47)$ & .37 to 2.21 & - & - & .90 \\
\hline Hits on Target (3) & 24 & $.94(.46)$ & .05 to 1.83 & $.93(.45)$ & .04 to 1.82 & .82 \\
\hline Flying Performance Ratings (1) & 24 & $.61(.44)$ & -.26 to 1.47 & - & - & .73 \\
\hline Judgment/Problem Solving (4) & 24 & $.98(.49)$ & .34 to 1.61 & $.94(.32)$ & .30 to 1.57 & .83 \\
\hline $\begin{array}{l}\text { Number of Target Engagements (2) } \\
\text { Target Engagement Time (2) }\end{array}$ & $\begin{array}{l}24 \\
24\end{array}$ & $\begin{array}{r}.59(.45) \\
1.37(.46)\end{array}$ & $\begin{array}{r}-.28 \text { to } 1.46 \\
.43 \text { to } 2.30\end{array}$ & $\begin{array}{r}.58(.44) \\
1.36(.48)\end{array}$ & $\begin{array}{r}-.29 \text { to } 1.45 \\
.42 \text { to } 2.29\end{array}$ & $\begin{array}{l}.72 \\
.91\end{array}$ \\
\hline Maneuvering (2) & 24 & $.95(.49)$ & .06 to 1.84 & $.94(.45)$ & .05 to 1.83 & .83 \\
\hline Exposure to Enemy Targets (2) & 24 & $.95(.49)$ & .06 to 1.84 & $.94(.45)$ & .05 to 1.83 & .83 \\
\hline
\end{tabular}

Note. When only 1 effect size is available it is provided as the average corrected effect size. $k=$ number of effect sizes; $N=$ total sample size; $d_{c o r r}=$ average corrected effect size; $S D=$ standard deviation; $C I_{\text {corr }}=95 \%$ confidence interval around the average corrected effect size; $d_{w}=$ mean weighted effect size; $C I_{d w}=$ $95 \%$ confidence interval around the mean weighted effect size; $U_{3}=$ Cohen's $U_{3}$ (Cohen, 1988) for effect size interpretation. 
Table 14

Mean corrected $d$ and mean weighted $d$ for the influence of practice on unaggregated and aggregated outcome measures of training effectiveness.

\begin{tabular}{|c|c|c|c|c|c|c|}
\hline Contrast $(k)$ & $N$ & $d_{\text {corr }}(S D)$ & $C I_{d c o r r}$ & $d_{w}(S D)$ & $C I_{d w}$ & $U_{3}$ \\
\hline More Practice vs. Less Practice (27) & 455 & $.14(.09)$ & .06 to .23 & $.18(.04)$ & .10 to .27 & .57 \\
\hline Accuracy (18) & 455 & $.05(.09)$ & -.05 to .15 & $.11(.05)$ & .01 to .21 & .54 \\
\hline Field Exercise Score (1) & 16 & $-.50(.51)$ & -.50 to 1.50 & - & - & .31 \\
\hline Distance of Shot From Target (3) & 272 & $.52(.13)$ & .28 to .77 & $.52(.12)$ & .28 to .77 & .70 \\
\hline Target Hit Rate (3) & 272 & $.22(.12)$ & -.02 to .46 & $.21(.12)$ & -.03 to .46 & .58 \\
\hline Target Hit Proportion (3) & 272 & $.03(.12)$ & -.21 to .26 & $.03(.12)$ & -.21 to .26 & .51 \\
\hline Target Acquisition Errors(3) & 272 & $.31(.12)$ & .07 to .55 & $.30(.12)$ & .06 to .54 & .62 \\
\hline Simulator Navigational Errors (3) & 272 & $-.46(.12)$ & .22 to .70 & $-.45(.12)$ & .21 to .69 & .33 \\
\hline Hits on Target (2) & 183 & $-.21(.15)$ & -.09 to .50 & $.09(.15)$ & -.20 to .38 & .54 \\
\hline Judgment/Problem Solving (8) & 288 & $.28(.12)$ & .11 to .44 & $.37(.08)$ & -20 to .53 & .64 \\
\hline Number of Target Engagements (1) & 16 & $-.53(.51)$ & -.47 to 1.52 & - & - & .30 \\
\hline Target Engagement Time (1) & 16 & $.36(.50)$ & -.61 to 1.35 & - & - & .64 \\
\hline Overall Fire Rate (3) & 272 & $.33(.12)$ & .09 to .57 & $.33(.12)$ & .09 to .57 & .63 \\
\hline Average Time Until Target Engagement (3) & 272 & $.47(.13)$ & .22 to .71 & $.46(.12)$ & .22 to .70 & .68 \\
\hline Maneuvering (1) & 16 & $.75(.52)$ & -.27 to 1.76 & - & - & .77 \\
\hline Exposure to Enemy Targets (1) & 16 & $.75(.52)$ & -.27 to 1.76 & - & - & .77 \\
\hline
\end{tabular}




$-$

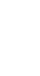

-

Note. When only 1 effect size is available it is provided as the average corrected effect size. $k=$ number of effect sizes; $N=$ total sample size; $d_{c o r r}=$ average corrected effect size; $S D=$ standard deviation; $C I_{c o r r}=95 \%$ confidence interval around the average corrected effect size; $d_{w}=$ mean weighted effect size; $C I_{d w}=$ $95 \%$ confidence interval around the mean weighted effect size; $U_{3}=$ Cohen's $U_{3}$ (Cohen, 1988) for effect size interpretation. 
Table 15

Mean corrected $d$ and mean weighted $d$ for the influence of feedback on unaggregated and aggregated outcome measures of training effectiveness.

\begin{tabular}{|c|c|c|c|c|c|c|}
\hline Contrast $(k)$ & $N$ & $d_{\text {corr }}(S D)$ & $C I_{d c o r r}$ & $d_{w}(S D)$ & $C I_{d w}$ & $U_{3}$ \\
\hline Augmented Feedback vs. No Augmented Feedback (9) & 270 & $.22(.12)$ & -.01 to .45 & $.41(.12)$ & .18 to .64 & .66 \\
\hline $\begin{array}{l}\text { Accuracy (7) } \\
\quad \text { Distance of Shot From Target (7) }\end{array}$ & $\begin{array}{l}172 \\
172\end{array}$ & $\begin{array}{l}.04(.15) \\
.04(.15)\end{array}$ & $\begin{array}{l}-.26 \text { to } .35 \\
-.26 \text { to } .35\end{array}$ & $\begin{array}{l}.07(.15) \\
.07(.15)\end{array}$ & $\begin{array}{l}-.23 \text { to } .38 \\
-.23 \text { to } .38\end{array}$ & $\begin{array}{l}.53 \\
.53\end{array}$ \\
\hline Maneuvering (2) & 98 & $.85(.25)$ & .50 to 1.19 & $.85(.18)$ & .50 to 1.19 & .80 \\
\hline Exiting the Building Within the Time Limit (1) & 98 & $.79(.25)$ & .30 to 1.28 & - & - & .79 \\
\hline Attempting to Exit the Building (1) & 98 & $.91(.25)$ & .42 to 1.40 & - & - & .82 \\
\hline
\end{tabular}

Note. When only 1 effect size is available it is provided as the average corrected effect size. $k=$ number of effect sizes; $N=$ total sample size; $d_{c o r r}=$ average corrected effect size; $S D=$ standard deviation; $C I_{\text {corr }}=95 \%$ confidence interval around the average corrected effect size; $d_{w}=$ mean weighted effect size; $C I_{d w}=$ $95 \%$ confidence interval around the mean weighted effect size; $U_{3}=$ Cohen's $U_{3}$ (Cohen, 1988) for effect size interpretation. 
Table 16

Mean corrected $d$ and mean weighted $d$ for the influence of fidelity on unaggregated and aggregated outcome measures of training effectiveness.

\begin{tabular}{|c|c|c|c|c|c|c|}
\hline Contrast $(k)$ & $N$ & $d_{\text {corr }}(S D)$ & $C I_{d c o r r}$ & $d_{w}(S D)$ & $C I_{d w}$ & $U_{3}$ \\
\hline High Fidelity vs. Low Fidelity (93) & 1398 & $.82(.06)$ & .77 to .87 & $1.03(.02)$ & .95 to 1.05 & .84 \\
\hline Accuracy (25) & 1352 & $.74(.06)$ & .62 to .85 & $.84(.06)$ & .73 to .96 & .80 \\
\hline Distance of Shot From Target (6) & 156 & $.30(.18)$ & -.06 to .66 & $.42(.18)$ & .06 to .78 & .66 \\
\hline Target Hit Proportion (2) & 110 & $.16(.25)$ & -.33 to .66 & $.25(.25)$ & -.25 to .74 & .60 \\
\hline Number of Bombs Impacting Enemy Target (1) & 16 & $.28(.50)$ & -.71 to 1.26 & - & - & .61 \\
\hline Number of Enemy Targets Killed (1) & 18 & $-.43(.68)$ & -.90 to 1.76 & - & - & .33 \\
\hline Loss/Kill Ratio (1) & 18 & $-.74(.69)$ & -.62 to 2.10 & - & - & .23 \\
\hline Position Accuracy (4) & 450 & $1.78(.10)$ & 1.56 to 2.00 & $1.71(.11)$ & 1.50 to 1.93 & .96 \\
\hline Hits on Target (5) & 474 & $.01(.09)$ & -.18 to .19 & $.10(.09)$ & -.09 to .28 & .54 \\
\hline Sustained Hits (2) & 192 & $3.97(.18)$ & 3.56 to 4.38 & $2.30(.21)$ & 1.89 to 2.71 & .99 \\
\hline Sustained Kills (2) & 114 & $1.00(.20)$ & .54 to 1.46 & $1.73(.23)$ & 1.28 to 2.19 & .96 \\
\hline Flying Performance Ratings (1) & 16 & $.07(.50)$ & -.91 to 1.05 & - & - & .53 \\
\hline Judgment/Problem Solving (18) & 492 & $.87(.10)$ & .74 to 1.00 & $1.03(.07)$ & .90 to 1.16 & .85 \\
\hline Overall Fire Rate (4) & 302 & $2.92(.14)$ & 2.59 to 3.24 & $1.25(.17)$ & .92 to 1.58 & .89 \\
\hline Average Time Until Target Engagement (2) & 110 & $-.59(.25)$ & .11 to 1.08 & $-.36(.25)$ & -.12 to .85 & .36 \\
\hline Time to Acquire Targets (3) & 110 & $.71(.14)$ & .43 to 1.00 & $.95(.14)$ & .67 to 1.24 & .83 \\
\hline Time Taken to Avoid Enemy Fire (1) & 144 & $1.82(.20)$ & 1.43 to 2.21 & - & - & .97 \\
\hline Time to Plan Task/ Mission (1) & 144 & $1.48(.19)$ & 1.11 to 1.85 & - & - & .93 \\
\hline Time Until First Hit (1) & 96 & $1.77(.24)$ & 1.30 to 2.25 & - & - & .96 \\
\hline $\begin{array}{l}\text { Quickness Rating of Reaction to Target Contact } \\
\text { Engagement (1) }\end{array}$ & 18 & $-.14(.47)$ & -.78 to 1.07 & - & - & .44 \\
\hline Performance Ratings of Reaction to Target & 18 & $-.03(.47)$ & -.89 to .96 & - & - & .49 \\
\hline
\end{tabular}


Contact/Engagement (1)

Difficulty Rating of Reaction to Target

Contact/Engagement (1)

Quickness Ratings of Engaging and

Recognizing People, Objects, \& Targets (2)

\section{Maneuvering (28)}

Distance from Opposing Force (4)

Exposure to Opposing Force (4)

Time to Reach Task/ Mission Objective (4)

Distance Traveled (5)

Fuel Used (5)

Quickness Rating of Tactical Movement (1)

Performance Rating of Tactical Movement (1)

Difficulty Rating of Tactical Movement (1)

Quickness Rating for Room Clearing (1)

Performance Rating for Room Clearing (1)

Difficulty Rating for Room Clearing (1)

Communication (22)

Transmission Time of Battle Orders (4)

Requests for Clarification of Battle

Orders (1)

Number of Successful Battle Orders (3)

Time to Plan Battle Orders (3)

Time to Report Location (3)

Number of Reports Sent (3)

Number of Reports Sent With Correct

Information (2)

Quickness Ratings of Communication (1)

Performance Ratings of Communication (1)

\begin{tabular}{|c|c|c|c|c|c|}
\hline 18 & $.04(.47)$ & -.88 to .97 & - & - & .52 \\
\hline 28 & $-1.45(.41)$ & -.61 to 2.29 & $-1.40(.43)$ & .56 to 2.24 & .07 \\
\hline 752 & $.53(.08)$ & .44 to .62 & $.81(.05)$ & .72 to .90 & .79 \\
\hline 450 & $.16(.10)$ & -.03 to .34 & $.12(.10)$ & -.07 to .31 & .55 \\
\hline 302 & $.66(.13)$ & .39 to .92 & $.77(.14)$ & .50 to 1.03 & .78 \\
\hline 450 & $1.76(.10)$ & 1.53 to 1.98 & $1.88(.11)$ & 1.65 to 2.10 & .97 \\
\hline 542 & $.36(.09)$ & .18 to .54 & $.74(.09)$ & .55 to .92 & .77 \\
\hline 542 & $.57(.09)$ & .38 to .76 & $1.05(.09)$ & .82 to 1.25 & .85 \\
\hline 18 & $-.17(.47)$ & -.76 to 1.09 & - & - & .43 \\
\hline 18 & $.02(.47)$ & -.90 to .95 & - & - & .51 \\
\hline 18 & $.04(.47)$ & -.88 to .96 & - & - & .52 \\
\hline 18 & $-.02(.47)$ & -.90 to .95 & & & .49 \\
\hline 18 & $-.004(.22)$ & -.92 to .93 & - & - & .49 \\
\hline 18 & $-.03(.47)$ & -.89 to .96 & - & - & .49 \\
\hline 560 & $1.26(.10)$ & 1.17 to 1.34 & $1.27(.04)$ & 1.18 to 1.36 & .90 \\
\hline 450 & $1.40(.10)$ & 1.20 to 1.60 & $1.05(.10)$ & .84 to 1.25 & .85 \\
\hline 18 & $.62(.25)$ & .13 to 1.12 & - & - & .73 \\
\hline 432 & $1.65(.11)$ & 1.43 to 1.87 & $1.64(.11)$ & 1.42 to 1.85 & .95 \\
\hline 432 & $2.81(.11)$ & 2.54 to 3.10 & $2.72(.13)$ & 2.46 to 2.99 & 1.00 \\
\hline 432 & $.96(.10)$ & .76 to 1.16 & $.92(.10)$ & .72 to 1.12 & .82 \\
\hline 432 & $1.16(.10)$ & .96 to 1.37 & $1.09(.10)$ & .89 to 1.30 & .86 \\
\hline 162 & $.87(.17)$ & .55 to 1.19 & $.95(.17)$ & .63 to 1.28 & .83 \\
\hline 18 & $-.05(.47)$ & -.87 to .97 & - & - & .48 \\
\hline 18 & $-.07(.47)$ & -.86 to .99 & - & - & .47 \\
\hline
\end{tabular}




\section{Difficulty Ratings of Communication (1)}

Note. When only 1 effect size is available it is provided as the average corrected effect size. $k=$ number of effect sizes; $N=$ total sample size; $d_{c o r r}=$ average corrected effect size; $S D=$ standard deviation; $C I_{c o r r}=95 \%$ confidence interval around the average corrected effect size; $d_{w}=$ mean weighted effect size; $C I_{d w}=$ $95 \%$ confidence interval around the mean weighted effect size; $U_{3}=$ Cohen's $U_{3}$ (Cohen, 1988) for effect size interpretation. 